\title{
Synthesis of DNA Strands Site-Specifically Damaged by C8-Arylamine Purine Adducts and Effects on Various DNA Polymerases
}

\author{
Nicolas Böge ${ }^{[a]}$ Maike I. Jacobsen, ${ }^{[a]}$ Zita Szombati, ${ }^{[a]}$ Sabrina Baerns, ${ }^{[b]}$ \\ Francesca Di Pasquale, ${ }^{[b]}$ Andreas Marx ${ }^{[b]}$ and Chris Meier*[a]
}

\begin{abstract}
C8 Arylamine dG and C8 arylamine dA adducts have been prepared using palladium cross coupling chemistry. These adducts were subsequently con verted into the corresponding 5' $O$ DMTr $\mathrm{C} 8$ arylamine $3^{\prime} O$ phosphoramidites and then used for the automated synthesis of different site specifically modified oligonucleotides. These "damaged" oligonucleotides have been characterized by ESI MS, UV thermal stability assays, and circular dichroism, and they have been used in EcoRI assays as well as in primer extension studies using various DNA polymerases.
\end{abstract}

Keywords: aromatic amines cross coupling $\cdot$ DNA adducts DNA damage $\cdot$ palladium

\section{Introduction}

Exposure to carcinogens can occur through environmental or work conditions, diet, smoking, and/or endogenous pro cesses. Poly and monocyclic aromatic amines, such as ani line (1), $p$ toluidine (2), 4 aminobiphenyl (4), and 2 amino fluorene (6) (Figure 1), belong to the class of chemical carci nogens that form covalently bonded adducts with the DNA double helix. Covalent damage of DNA (by electrophiles) may be the reason for the induction of chemical carcinogen esis. ${ }^{[1]}$ If such DNA damage is not repaired, it might com promise the fidelity of DNA replication, eventually leading to mutations and possibly cancer. ${ }^{[2,3]}$

Arylamines belong to the group of indirect carcinogens because they require metabolic activation in order to gener

[a] Dipl. Chem. N. Böge, Dipl. Chem. M. I. Jacobsen,

Dipl. Chem. Z. Szombati, Prof. Dr. C. Meier

Organic Chemistry, Department of Chemistry, Faculty of Science

University of Hamburg

Martin Luther King Platz 6, 20146 Hamburg (Germany)

Fax: (+49) 40428385592

E mail: chris.meier@chemie.uni hamburg.de

[b] Dipl. Chem. S. Baerns, Dipl. Pharm. Chem. F. Di Pasquale,

Prof. Dr. A. Marx

Department of Chemistry and

Konstanz Research School Chemical Biology

University of Konstanz

Universitätsstrasse 10, 78457 Konstanz (Germany)

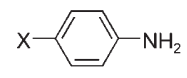

1: $\mathrm{X}=\mathrm{H}$ (aniline) 2. $X=H$ (aniline) 3: $X=O-M e$ - $(p$-anisidine $)$

3: $X=O-M e(p$-anisidine $)$
4: $=\operatorname{Ph}(4$-aminobipheny $)$

Figure 1. Carcinogenic arylamines.

ate the so called ultimate carcinogen (Scheme 1). The initial step is a cytochrome $\mathrm{P} 450$ catalyzed oxidation of the aryl amine to the corresponding $N$ hydroxylamine. ${ }^{[4]}$ The $N$ hy droxylamine is then esterified to an $N$ acetoxy derivative by $N$ acetyltransferase (NAT) or to a sulfate by a sulfotransfer ase (ST) to give the ultimate carcinogens. Solvolysis of these compounds generates the highly reactive arylnitrenium ion 8.

The predominant reaction of the arylnitrenium ion occurs at the $\mathrm{C} 8$ position of $2^{\prime}$ deoxyguanosine $(\mathrm{dG})$ and $2^{\prime}$ deoxy adenosine (dA), leading to the corresponding adducts 9a and $\mathbf{9 b}$ as major products. Moreover, $N^{2}$ adducts of dG (10) and $N^{6}$ ortho arylamine adducts of dA have been identified as minor products. ${ }^{[5,6]}$

So far, the most extensively studied arylamine adducts have been those derived from 2 aminofluorene (AF) and $N$ acetyl 2 aminofluorene (AAF) ${ }^{[7]}$ Zhou and Romano report ed on the synthesis of C8 deoxyguanosine phosphoramidite reagents of 2 aminofluorene and its $N$ acetyl counterpart for the site specific synthesis of oligonucleotide strands contain ing these $\mathrm{C} 8$ adducts. As protecting group for the exocyclic amino function of $\mathrm{dG}$, the Fmoc group was used. ${ }^{[8,9]}$ 

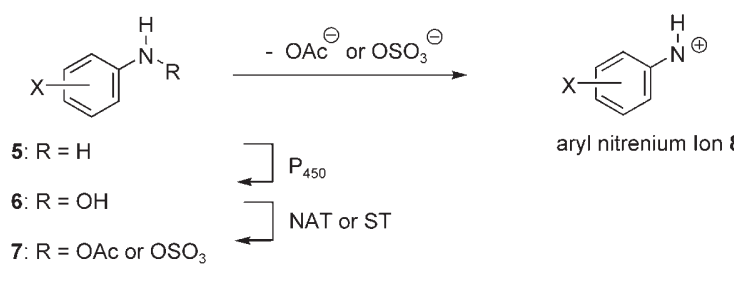

aryl nitrenium Ion 8

$\mathrm{Ac}$ or $\mathrm{OSO}_{3}$
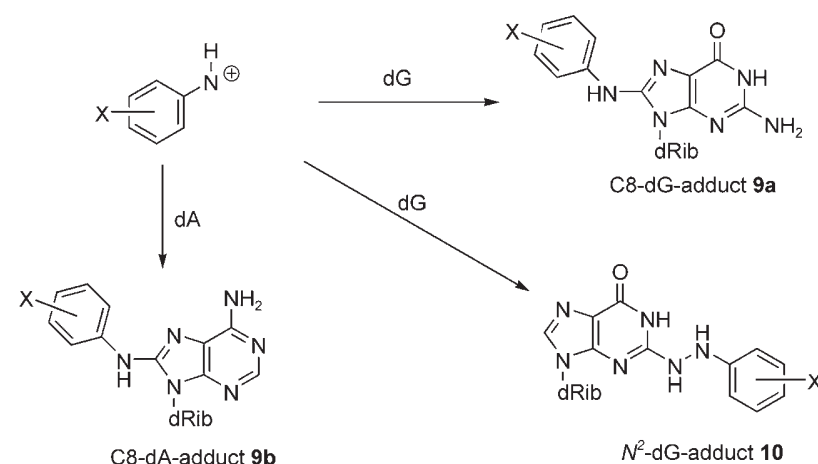

Scheme 1. Metabolism of arylamines and the adducts formed.

A strategy for obtaining the $N$ acetyl adducts was intro duced by Schärer and Gillet, ${ }^{[10]}$ which involves transient di methoxytrityl (DMTr) protection of the $N^{2}$ position of an 8 $\mathrm{BrdG}$ derivative. After a palladium catalyzed cross cou pling reaction of $8 \mathrm{BrdG}$ with the arylamine, the products are subsequently acetylated at the $N^{8}$ position. In 2005, these authors reported the successful conversion of the $N$ acetylated adducts into the corresponding phosphoramidites (12 steps overall) and their site specific incorporation into oligonucleotides. It was proven that the $N^{8}$ acetyl group was not cleaved during the final deprotection. ${ }^{[11]}$

Recently, Rizzo reported the synthesis of oligonucleotides containing $\mathrm{C} 8$ adducts of a heterocyclic amine, the dietary mutagen 2 amino 3 methylimidazo[4,5 f]quinoline (IQ). ${ }^{[12]}$

In contrast, our interest is related to DNA adducts of monocyclic aromatic amines that act as so called borderline carcinogens, such as toluidine, dimethylaniline, and anisi dine.$^{[13,14]}$ In contrast to arylamines such as 4 aminobiphenyl (4), these are often used, for example, as pharmacophores. In 2002, we reported on an efficient synthesis of a phosphor amidite building block for the $\mathrm{C} 8 \mathrm{dG}$ adduct of toluidine. ${ }^{[15]}$ In 2006, we published the synthesis and the site specific in corporation of these $\mathrm{C} 8$ arylamine modified $\mathrm{dG}$ phosphor amidites into oligonucleotides. ${ }^{[16]}$ Also in 2006, we reported on the first synthesis of $\mathrm{C} 8 \mathrm{dA}$ adducts and their successful conversion into the corresponding phosphoramidites as well as their site specific incorporation into an oligonucleotide. ${ }^{[17]}$ In 2007, we published a simple and efficient route for the synthesis of the $\mathrm{C} 8 \mathrm{~N} \mathrm{Ac} \mathrm{dG}$ adducts and their phosphor amidites, and recently we have developed a synthetic route for the $N^{2}$ hydrazinoaryl and $N^{2}$ azoaryl dG adducts. ${ }^{[18,19]}$ Here, we report on a highly efficient synthesis of these C8 adducts using palladium catalyzed cross coupling chemistry, an improved synthesis of the $3^{\prime}$ phosphoramidites, and their use in solid phase DNA synthesis to give site specifically modified oligonucleotides of mixed sequences containing several dGs or dAs. The effect of these modifications in re lation to the restriction of a damaged DNA duplex by EcoRI is investigated. Moreover, the site specific incorpora tion of $\mathrm{C} 8$ arylamine damaged phosphoramidites into 30 mer oligonucleotides for DNA polymerase studies is re ported for the first time.

\section{Results and Discussion}

Synthesis of the $\mathbf{C 8}$ adducts of monocyclic arylamines: The synthesis of $\mathrm{C} 8$ arylamine $\mathrm{dG}$ adducts by simple electrophil ic amination has been reported to give only low yields. ${ }^{[20,21]}$ Thus, this approach is not suitable as the key reaction for the synthesis of phosphoramidites. ${ }^{[8,9]}$ Attempts to optimize the electrophilic amination used in these biomimetic reac tions failed in our hands (unpublished data). Also, the use of nucleophilic substitution as reported for $\mathrm{C} 8 \mathrm{Br}$ (ribo)gua nosine was unsuccessful because extensive depurination was observed when fully protected $8 \mathrm{Br} 2^{\prime}$ deoxyguanosine was treated with arylamines. ${ }^{[22]} \mathrm{C} 8 \mathrm{~N}$ bond formation was first reported by Lakshman ${ }^{[23]}$ and Johnson ${ }^{[24]}$ in the synthesis of $N^{6}$ aryl adducts of adenosine and $N^{2}$ aryl $\mathrm{dG}$ adducts of gua nosine using palladium catalysts (Buchwald Hartwig reac tion). ${ }^{[25]}$ Schoffers prepared C8 arylamine adducts of tris $O$ TBDMS (ribo)adenosine using the same reaction. ${ }^{[26]}$ How ever, these compounds were never converted into their phosphoramidites. In 2004, Rizzo et al. published the synthe sis of $2^{\prime} \mathrm{dG}$ phosphoramidites containing a heterocyclic food mutagen (IQ) in the $\mathrm{C} 8$ position. ${ }^{[12]}$ Their approach required the use of strong bases such as LiHMDS or $\mathrm{NaO} t \mathrm{Bu}$ and/or their protecting group chemistry was incompatible with the conditions of automated oligonucleotide synthesis. In 2006, we published the synthesis and site specific incorporation of C8 arylamine modified 2 ' deoxyguanosine phosphoramidites into oligonucleotides. ${ }^{[16]}$ In that work, the exocyclic amino function of $\mathrm{dG}$ was protected using the isobutyryl group, which is a standard protecting group in oligonucleotide syn thesis. A drawback of this group is the long reaction time needed for the deprotection after the synthesis using ammo nia solution $\left(8 \mathrm{~h}\right.$ at $\left.55^{\circ} \mathrm{C}\right)$. Nevertheless, oligonucleotides in corporating the adducts were successfully isolated. Also, the first primer template extensions using standing start as well as standing start +1 conditions were accomplished. Howev er, in these studies, no difference in primer extension was observed between borderline and strong carcinogens. ${ }^{[27]}$

Due to the fact that $\mathrm{C} 8$ arylamine damaged oligonucleo tides are base labile, there was a pressing need to reduce the time required for $N^{2}$ deprotection. In this context, we re ported on the synthesis and incorporation of C8 arylamine modified $2^{\prime} \mathrm{dG}$ phosphoramidites using formamidine as the protecting group for the exocyclic amino function. ${ }^{[28]}$ Using this strategy, which allows for milder deprotection, the de protection was completed after $4 \mathrm{~h}$ at $40{ }^{\circ} \mathrm{C}$ instead of $8 \mathrm{~h}$ at 
$55^{\circ} \mathrm{C}$, and the yield of modified oligonucleotides was four to fivefold higher as compared to that with the isobutyryl strategy.

For the synthesis of the formamidine protected C8 aryl amine $2^{\prime} \mathrm{dG}$ phosphoramidites 16, palladium catalyzed cross coupling was again used as the key step. The $O^{6}$ posi tion of guanine as well as the hydroxyl groups of the glycon need to be blocked during the reaction. The fully protected $\mathrm{dG}$ derivative was synthesized as described previously. ${ }^{[16]}$ However, protection of the exocyclic amino group of $\mathrm{dG}$ was not necessary for the Buchwald Hartwig reaction, which was carried out starting from intermediate $\mathbf{1 1}$ under previously published conditions (Scheme 2). ${ }^{[15]}$ The coupling proceeded smoothly to give the C8 arylamine adducts 12 a f in yields of $6592 \%$. The C8 arylamine adducts 12a f were converted into the corresponding phosphoramidites as sum marized in Scheme 2. The $O^{6}$ position was deblocked using $\mathrm{Pd} / \mathrm{H}_{2}$ and the hydroxyl groups were desilylated using tri ethylamine trihydrofluoride to give the unprotected inter mediates. The formamidine group was introduced using di methylformamide diethyl acetal to give 14a f. These com pounds were $5^{\prime} O$ dimethoxytritylated in yields of $7884 \%$ and further converted into the 5' $O$ DMTr $3^{\prime} O$ phosphor amidites 16a f (57 $88 \%$ yields). No side reaction at the $N^{8}$ atom took place, neither during the introduction of the DMTr group nor in the course of the phosphoramidite reac tion.

In the case of $2^{\prime}$ deoxyadenosine, nothing was known about the synthesis of $\mathrm{C} 8$ adducts with aromatic amines prior to our recent report on the synthesis of $\mathrm{C} 8$ arylamine modified 2' dA adducts. Moreover, we proved that the ad ducts could be converted into the phosphoramidites and they were successfully site specifically incorporated into a DNA sequence. ${ }^{[17]}$ In contrast to the preparation of the $\mathrm{dG}$ C8 adducts, we selected the Markiewicz (TIPDS) protecting group instead of the tert butyldimethylsilyl group for the protection of the $3^{\prime}$ and $5^{\prime}$ hydroxyl moieties of $2^{\prime} \mathrm{dA}$. This was necessary because of incomplete cleavage of the tert bu tyldimethylsilyl ethers from the $N^{6}$ benzoyl protected C8 substituted $2^{\prime}$ dA adducts. Neither with tetrabutylammoni um fluoride nor with triethylamine trihydrofluoride as de protecting reagent could a satisfactory deprotection be real ized. Interestingly, the desilylation proceeded in nearly quantitative yield after the Buchwald Hartwig coupling when the exocyclic $N^{6}$ amino function was still unprotected. Since this first report in 2006, improvements have been ach ieved using morpholine for the selective debenzoylation of the $N^{6}$ amino position instead of a mixture of aqueous am monia, water, and pyridine. ${ }^{[29]}$ The commonly used tech nique with sodium methanolate failed in our hands. A modi fication of the reaction conditions was also necessary for the 5 ' dimethoxytritylation because the originally used method showed only poor regioselectivity and required long reaction times (Scheme 3).

As a consequence, a considerable amount of the $3^{\prime}, 5^{\prime}$ bis dimethoxytritylated product was detected while there was still starting material present. This problem was reduced by the addition of one equivalent each of silver nitrate and sym collidine to accelerate the reaction, which led to a con siderable improvement in the yield of the $5^{\prime} \mathrm{DMTr}$ protect ed compound. ${ }^{[30]}$

To improve the yield of the cross coupling, several com monly used ligands were studied. Thus, Buchwald's ligand ${ }^{[31]}$ PEPPSI $i$ Pr,${ }^{[32]}$ benzyldi 1 adamantylphosphine ${ }^{[33]}$ and Xantphos ${ }^{[34]}$ were used, as well as rac BINAP (Figure 2).

The Buchwald ligand generated the desired product only in moderate yield and with low purity. Use of the PEPPSI $i$ Pr ligand resulted in an undefined product, while the ben zyldi 1 adamantylphosphine showed no reaction at all. Xantphos and rac BINAP proved to be the most appropri ate ligands for the cross coupling with aromatic amines. To obtain very good to excellent yields with these two ligands, it is necessary to pre react the catalyst and ligand for $1 \mathrm{~h}$ prior to addition of the nucleoside, amine, and base. This pre reaction procedure increased the yield from about $70 \%$ to over $90 \%$ (Table 1 ).
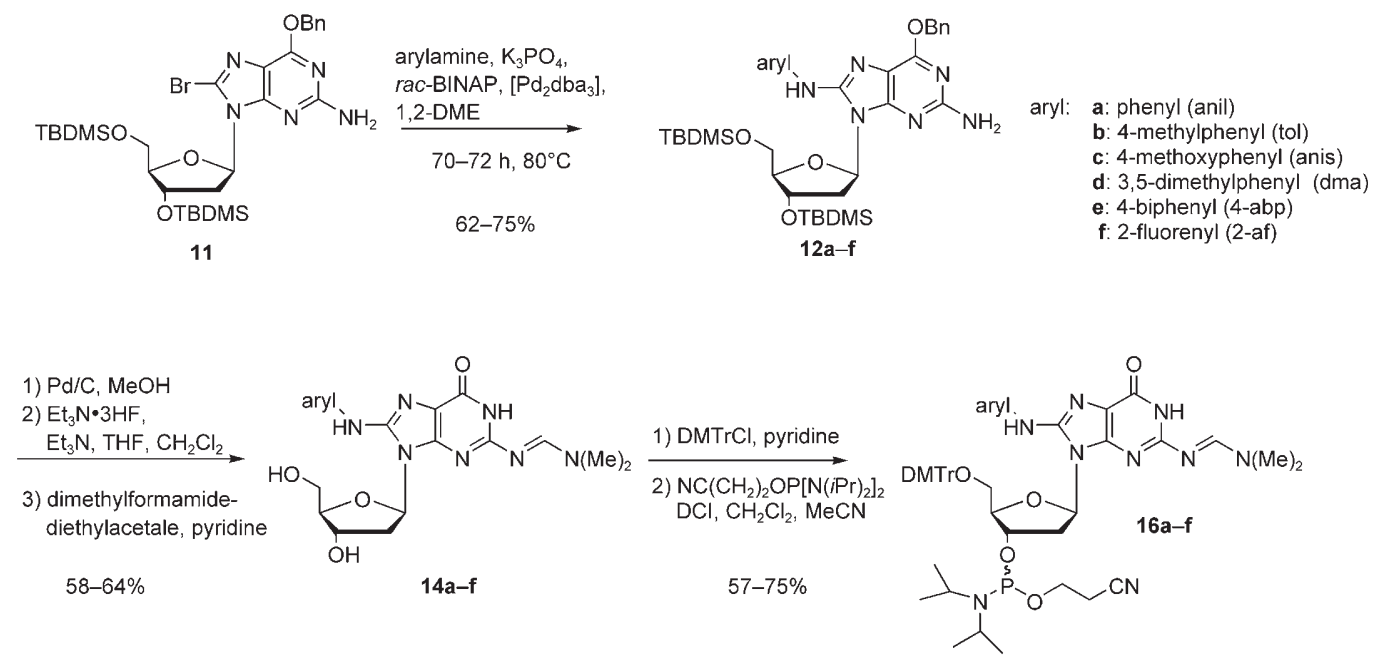

Scheme 2. Synthesis of C8 arylamine modified $2^{\prime} \mathrm{dG}$ phosphoramidites. 


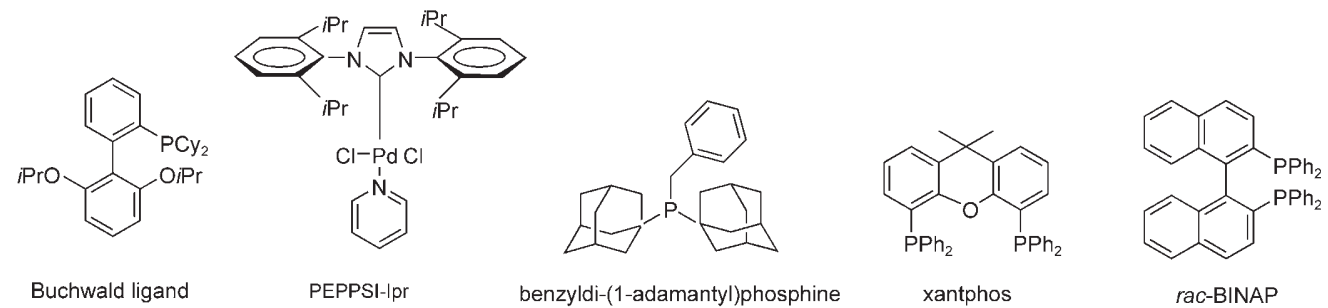

Figure 2. Ligands tested for the Buchwald Hartwig reaction.
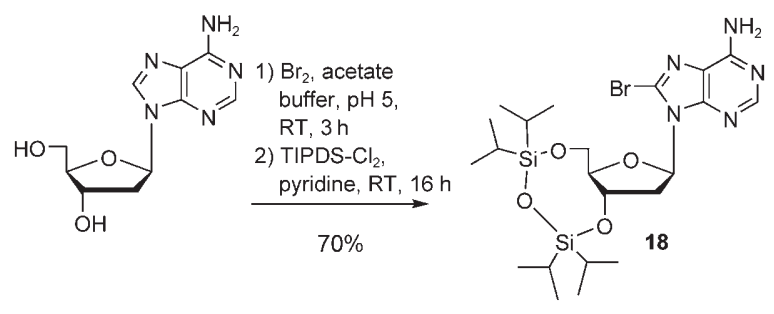

arylamine rac-BINAP $\left[\mathrm{Pd}_{2} \mathrm{dba}_{3}\right]$ $\mathrm{Cs}_{2} \mathrm{CO}_{3}$ 1,2-DME, $90^{\circ} \mathrm{C}, 36-48 \mathrm{~h}$ $65-93 \%$ aryl: 4-methoxyphenyl 19a (anis) aryl: 4-biphenyl 19b (4-abp) aryl: 3,5-dimethylphenyl 19c (dma) aryl: 2 -fluorenyl 19

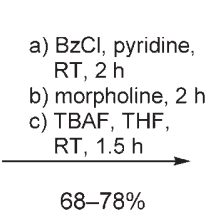

$68-78 \%$

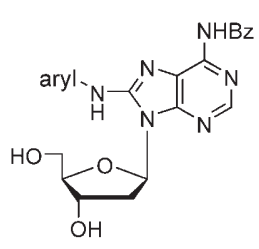

aryl: 4-methoxyphenyl 20a aryl: 4-biphenyl 20b
1) $\mathrm{DMTrCl}, \mathrm{AgNO}_{3}$, pyridine, $\mathrm{RT}, 4 \mathrm{~h}$ 2) $\mathrm{NC}\left(\mathrm{CH}_{2}\right)_{2} \mathrm{OP}\left(\mathrm{N}(\mathrm{iPr})_{2}\right)_{2}$ $\mathrm{DCl}, \mathrm{CH}_{2} \mathrm{Cl}_{2}, \mathrm{CH}_{3} \mathrm{CN}$, RT, 30 min

$40-50 \%$

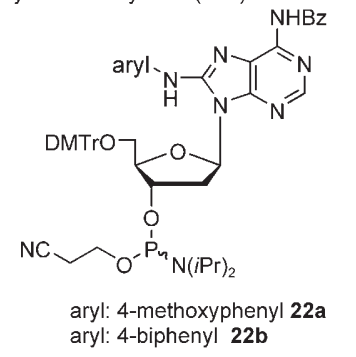

Scheme 3. Synthesis of C8 arylamine modified 2' dA phosphoramidites.

Table 1. Optimization of Buchwald Hartwig cross coupling for dA.

\begin{tabular}{ccccccc}
\hline Ligand & $\begin{array}{c}\text { Base/ } \\
\text { Solvent }\end{array}$ & $\begin{array}{c}\text { Aryl } \\
\text { amine }\end{array}$ & $t[\mathrm{~h}]$ & Yield [\%] & $\begin{array}{c}\text { Pre reaction of catalyst } \\
\text { and ligand }\end{array}$ & Product \\
\hline rac BINAP & $\mathrm{Cs}_{2} \mathrm{CO}_{3} / 1,2 \mathrm{DME}$ & 4 anisidine & 48 & 75 & no & 19a \\
rac BINAP & $\mathrm{Cs}_{2} \mathrm{CO}_{3} / 1,2 \mathrm{DME}$ & 4 aminobiphenyl & 58 & 65 & no & 19b \\
rac BINAP & $\mathrm{Cs}_{2} \mathrm{CO}_{3} / 1,2 \mathrm{DME}$ & 3,5 dimethylaniline & 48 & 73 & no & 19c \\
rac BINAP & $\mathrm{Cs}_{2} \mathrm{CO}_{3} / 1,2 \mathrm{DME}$ & 2 aminofluorene & 48 & 93 & yes & 19d \\
Xantphos & $\mathrm{Cs}_{2} \mathrm{CO}_{3} / 1,2 \mathrm{DME}$ & 3,5 dimethylaniline & 18 & 92 & yes & $\mathbf{1 9 c}$ \\
\hline
\end{tabular}

times with a total coupling ef ficiency of $6070 \%$ for the modified $\quad 2$ ' deoxyguanosine and a coupling efficiency of $>98 \%$ for the modified $2^{\prime}$ de oxyadenosine phosphorami dites. The basic deprotection step was completed within $4 \mathrm{~h}$ at $45^{\circ} \mathrm{C}$ according to Johnson et al. by adding ethane thiol. ${ }^{[35,36]}$ They observed that the $\mathrm{C} 8$ aminofluorene adduct undergoes an oxidative rear rangement in the presence of strong bases and oxygen, anal ogous to that observed for 8 oxo $2^{\prime} \mathrm{dG}$. The addition of ethanethiol to the degassed ammonium hydroxide prevents the oxidative side reaction during the final deprotection. The deprotected oligonucleo tides were purified by re versed phase HPLC and char acterized by ESI mass spec trometry.

Melting temperature $\left(T_{\mathrm{m}}\right)$ and circular dichroism studies: In the past, dG adducts were in corporated in the middle of a

Site-specific synthesis of oligonucleotides containing C8-adducts of different arylamines: Compounds 16a $\mathbf{f}$ and $22 \mathbf{a , b}$, which are readily soluble in acetonitrile, were employed in oligonucleotide synthesis using a modified coupling protocol with three coupling steps for the $\mathrm{C} 8$ adducts. In this way, we synthesized a site specifically modified 12 mer oligonucleo tide including the NarI sequence 23a f (Table 2). Addition ally, we prepared 30 mer oligonucleotides $24 \mathbf{a}$ j (Table 3) needed for DNA polymerase assays and 12 mer oligonucleo tides 25a q for an EcoRI assay (Table 4).

In the automated DNA synthesis, we used commercially available protected phosphoramidites for the regular nucleo sides. For the incorporation of the adducts, the $\mathrm{C} 8$ modified $\mathrm{dG}$ and $\mathrm{dA}$ phosphoramidites were dissolved in acetonitrile $(0.1 \mathrm{M}$ solution $)$ and the coupling step was repeated three homo $(\mathrm{T})_{14}$ sequence and hybridization experiments were conducted ${ }^{[16]}$ For comparison, the unmodified $(\mathrm{T})_{7}(\mathrm{dG})(\mathrm{T})_{7}$ was hybridized to $(\mathrm{dA})_{7}(\mathrm{X})(\mathrm{dA})_{7}(\mathrm{X}=\mathrm{dC}, \mathrm{T}, \mathrm{dA}, \mathrm{dG}) . \mathrm{A}$ mismatch within the hybrid caused a decrease of the $T_{\mathrm{m}}$ value of about $10^{\circ} \mathrm{C}\left(T_{\mathrm{m}} \approx 28.5^{\circ} \mathrm{C}\right)$. Incorporation of a $\mathrm{dG}^{*}$ adduct into the homo(T) sequence led to a reduction of $5^{\circ} \mathrm{C}$ in the case of the matched $(\mathrm{dA})_{7}(\mathrm{dC})(\mathrm{dA})_{7}$ strand, irrespec tive of the arylamine modification. Hybridization of the mis matched $(\mathrm{dA})_{7}(\mathrm{X})(\mathrm{dA})_{7}$ strand with the modified strand led to the same thermal stability as in the case of the mis matched duplex and no stabilization from a possible Hoogs teen base pairing was observed $\left(T_{\mathrm{m}} \approx 27.5^{\circ} \mathrm{C}\right) .{ }^{[16]}$

For the present investigations, all oligonucleotides were hybridized to complementary strands and the effect of the C8 arylamine adduct on the thermal stability of the DNA 
duplex was measured through UV melting temperature analysis ( $T_{\mathrm{m}}$ values). The data for the 12 mer oligonucleo tides $23 \mathbf{a} \mathbf{f}$ are given in Table 2.

Table 2. Synthesized oligonucleotides 23a f and $T_{\mathrm{m}}$ values.

\begin{tabular}{lc}
\hline Oligonucleotide & $T_{\mathrm{m}}\left[{ }^{\circ} \mathrm{C}\right]$ \\
\hline 5' CTC GGC GCC ATC 3' 23a & 58 \\
5' CTC GGC G(anis)CC ATC 3' 23 b & 51 \\
5' CTC GGC G(4-abp)CC ATC 3' 23-c & 40 \\
5' CTC GGC ACC ATC 3' 23 d & 56 \\
5' CTC GGC A(anis)CC ATC 3' 23e & 47 \\
5' CTC GGC A(4-abp)CC ATC 3' 23 f & 49 \\
\hline
\end{tabular}

For C8 anisidine damaged $\mathrm{dG}$ oligonucleotide $\mathbf{2 3} \mathbf{b}$, a de crease of $7^{\circ} \mathrm{C}$ was observed compared to the $T_{\mathrm{m}}$ value of the unmodified NarI oligonucleotide $23 \mathbf{a}\left(T_{\mathrm{m}}=58^{\circ} \mathrm{C}\right)$. Inter estingly, for the oligonucleotide bearing the abp lesion $\mathbf{2 3} \mathbf{c}$, a dramatic decrease in thermal stability was observed $\left(T_{\mathrm{m}}=\right.$ $40^{\circ} \mathrm{C}$ ). Thus, the second aromatic ring of the abp lesion has a significant effect on the duplex stability. However, the sit uation was different in the case of the mutated NarI sequen ces $23 \mathbf{e}$ and $23 \mathbf{f}$ bearing a damaged dA nucleoside. As com pared with the unmodified reference oligonucleotide $\mathbf{2 3} \mathbf{d}$, both lesions caused a similar destabilization of about $8^{\circ} \mathrm{C}$ (Table 2). Here, the strong carcinogen abp clearly did not cause a further decrease in stability as in the case of the dG adducts.

The data collected for the 30 mer oligonucleotides $\mathbf{2 4 a} \mathbf{j}$ are summarized in Table 3. For the C 8 arylamine $2^{\prime} \mathrm{dG}$ oli gonucleotides modified with borderline carcinogens $24 \mathbf{b}$ d, no effect on the $T_{\mathrm{m}}$ value was observed with respect to the unmodified oligonucleotide 24 a $\left(62^{\circ} \mathrm{C}\right)$. In contrast, the oli gonucleotides damaged by strong arylamine carcinogens $(24 \mathbf{e} \mathbf{g})$ showed a decrease in thermal stability $\left(59^{\circ} \mathrm{C}\right)$. This decrease is certainly higher than the experimental error of $\pm 0.5^{\circ} \mathrm{C}$. Astonishingly, the oligonucleotides modified with different monocyclic aromatic amines always showed the same thermal stability as compared to the non damaged ref erence strands 24 a and $24 \mathrm{~h}$.

Similar trends were observed for C8 arylamine $2^{\prime} \mathrm{dA}$ oli gonucleotides $\mathbf{2 4} \mathbf{i}, \mathbf{j}$. For the $p$ anisidine modified oligonu cleotide $24 \mathbf{i}$, an identical $T_{\mathrm{m}}$ value was measured as for the unmodified oligonucleotide $\mathbf{2 4 h}\left(59^{\circ} \mathrm{C}\right)$, whereas the oligo nucleotide modified with 4 aminobiphenyl $\mathbf{2 4 j}$ showed a de crease of the $T_{\mathrm{m}}$ value $\left(57^{\circ} \mathrm{C}\right)$.

Thus, oligonucleotides modified by strong carcinogens consistently showed a $23^{\circ} \mathrm{C}$ reduction in $T_{\mathrm{m}}$ compared to the reference. The conformational distortion as a result of C8 dG or C8 dA damage of the DNA double helix caused by a borderline or a strong carcinogen is therefore signifi cantly different and is in the range of the hybridization con tribution of one $\mathrm{G}$ C or one A $\mathrm{T}$ base pair, respectively.

For the self complementary 12 mer oligonucleotides of the EcoRI sequence, the effect on the $T_{\mathrm{m}}$ values was much more pronounced (Table 4). This was expected because in the duplexes formed in this case one adduct occurs in each strand.

Table 4. Synthesized oligonucleotides 25a $\mathbf{q}$ and corresponding $T_{\mathrm{m}}$ values.

\begin{tabular}{|c|c|}
\hline Oligonucleotide & $T_{\mathrm{m}}\left[{ }^{\circ} \mathrm{C}\right]$ \\
\hline 5' GTAGAATTCTAC 3' $25 \mathbf{a}$ & 42 \\
\hline 5' GTAG(anil)AATTCTAC 3' $25 \mathbf{b}$ & 29 \\
\hline 5' GTAG(tol)AATTCTAC 3' 25 c & 24 \\
\hline 5' GTAG(anis)AATTCTAC 3' 25 d & 25 \\
\hline 5' GTAG(dma)AATTCTAC 3' $25 \mathbf{e}$ & 24 \\
\hline 5' GTAG(4-abp)AATTCTAC 3' 25 f & 24 \\
\hline 5' GTAG(2-af)AATTCTAC 3' 25 g & 24 \\
\hline 5' G(anil)TA GAATTCTAC 3' $\mathbf{2 5} \mathbf{h}$ & 35 \\
\hline 5'-G(4-abp)TAGAATTCTAC 3' $\mathbf{2 5}$ i & 30 \\
\hline $5^{\prime}$ GTA(anis)GAATTCTAC $3^{\prime} \mathbf{2 5} \mathbf{j}$ & 29 \\
\hline 5 GTA(4-abp)GAATTCTAC 3' 25 k & 27 \\
\hline 5' GTAGA(anis)ATTCTAC 3' 251 & 35 \\
\hline 5'GTAGA(4-abp)GAATTCTAC 3' 25 m & 42 \\
\hline 5' GTAGAA(anis)TTCTAC 3' 25 n & 37 \\
\hline 5' GTAGAA(4-abp)TTCTAC 3' 25 o & 39 \\
\hline 5' GTAGAATTCTA(anis)C 3' 25p & 28 \\
\hline 5' GTAGAATTCTA(4-abp)C 3' 25 q & 33 \\
\hline
\end{tabular}

A decrease in the thermal stabilities of the $\mathrm{dG}$ adduct bearing oligonucleotides $25 \mathbf{b} \mathbf{g}$ ( $T_{\mathrm{m}}$ values decreased by 13 $\left.18^{\circ} \mathrm{C}\right)$ compared to reference oligonucleotide $25 \mathrm{a}\left(T_{\mathrm{m}}=\right.$ $42^{\circ} \mathrm{C}$ ) was observed. Here, no significant difference between the oligonucleotides damaged by monocyclic aromatic amines and those damaged by a polycyclic aromatic amine was measured. In contrast, a significant difference in the in fluences on thermal stability can be observed for the oligo nucleotides $\mathbf{2 5 h}$,i. Here, the monocyclic DNA damage leads to a decrease of $7^{\circ} \mathrm{C}$ to a $T_{\mathrm{m}}$ of $35^{\circ} \mathrm{C}$, whereas the polycyclic DNA damage has a bigger in fluence leading to a $T_{\mathrm{m}}$ of $30^{\circ} \mathrm{C}$.

In the case of the $\mathrm{dA}$ modi fied oligonucleotides, there is no such strong influence on the $T_{\mathrm{m}}$ value. The oligonucleotides modified with $p$ anisidine $\mathbf{2 5} \mathbf{j}, \mathbf{l}, \mathbf{n}, \mathbf{p}$ showed only a $514^{\circ} \mathrm{C}$ decrease in the $T_{\mathrm{m}}$ value com pared to that of the unmodi 
fied oligonucleotide 25a. Surprisingly, the influence on the thermal stabilities of the oligonucleotides modified with the strong carcinogen 4 aminobiphenyl $25 \mathbf{k}, \mathbf{m}, \mathbf{o}, \mathbf{q}$ was lower than that for the monocyclic aromatic amines. Here, a de crease of $312^{\circ} \mathrm{C}$ could be observed. For the oligonucleotide $\mathbf{2 5} \mathbf{m}$, the $T_{\mathrm{m}}$ value was found to be identical to that of the non damaged oligonucleotide $\mathbf{2 5}$ a.

In addition, the circular dichroism (CD) spectra of all of the synthesized oligonucleotides as hybrids with the comple mentary strand were measured. CD spectra were recorded to prove the overall conformation of the adduct modified DNA hybrids. For the NarI sequence 23 a f, no difference between the unmodified oligonucleotide and those bearing lesions of $\mathrm{dG}$ and $\mathrm{dA}$ could be observed and all showed typ ical spectra of a B type DNA conformation (see Supporting Information).

The same result was obtained for the $2^{\prime} \mathrm{dA}$ damaged oli gonucleotides $\mathbf{2 4} \mathbf{i}$ and $\mathbf{2 4} \mathbf{j}$ and the unmodified strand $\mathbf{2 4 h}$ (Figure 3). Again, the three oligonucleotides are predomi nantly in a B type DNA conformation. Thus, no conforma tional difference was observed between oligonucleotides modified with a borderline or a strong carcinogen.

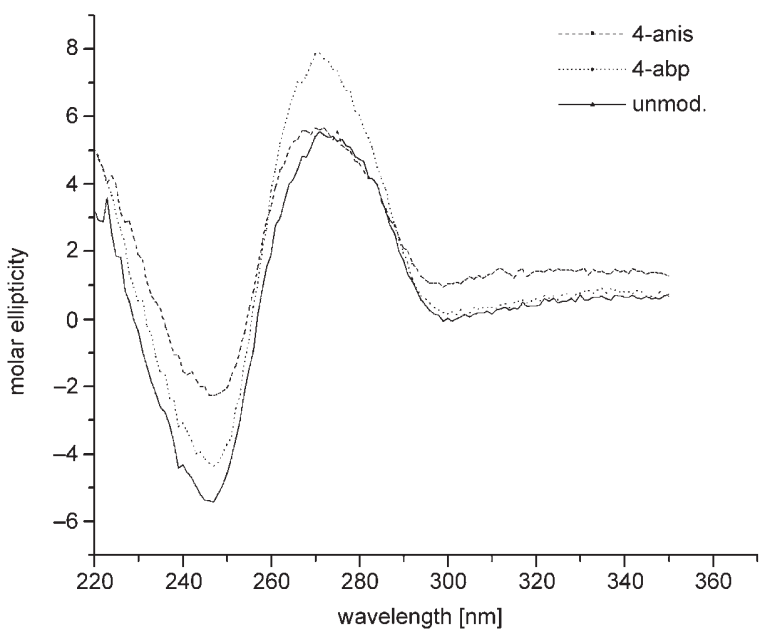

Figure 3. CD spectra of dA modified oligonucleotides $24 \mathbf{h} \mathbf{j}$.

Moreover, all of the 30 mer oligonucleotide duplexes modified at $2^{\prime} \mathrm{dG}$ show the same characteristics, a maximum at $280290 \mathrm{~nm}$ and a minimum at $240250 \mathrm{~nm}$ without signif icant changes in intensity (see the Supporting Information). These features indicate that all of the 30 mer oligonucleo tides are in a B type DNA conformation. The shifts of the maxima in the CD spectra of the modified oligonucleotides 24 e,f to higher wavelength (6 and $9 \mathrm{~nm}$, respectively) are caused by the (partly) conjugated aromatic systems.

An analogous study was performed with the EcoRI se quences. Again, all of the modified 12 mer oligonucleotides 25b q exhibited the same overall conformation (see Sup porting Information).
EcoRI restriction assay: To investigate the effect on enzy matic cleavage of arylamine modified oligonucleotides 25 by an endonuclease, the EcoRI restriction assay was chosen. EcoRI cleaved the self complementary, undamaged 12 mer oligonucleotide 25a into a 4 mer (GTAG) and an 8 mer strand (AATTCTAC). It is known that EcoRI cleaves both strands of a DNA double helix between $\mathrm{dG}^{4}$ and $\mathrm{dA}^{5}$. For the reference oligonucleotide $25 \mathrm{a}$, a half life of $2.5 \mathrm{~h}$ using 270 units of enzyme in a DTT buffer at $20^{\circ} \mathrm{C}$ was deter mined (Figure 4). The half life was calculated as described previously. ${ }^{[37]}$

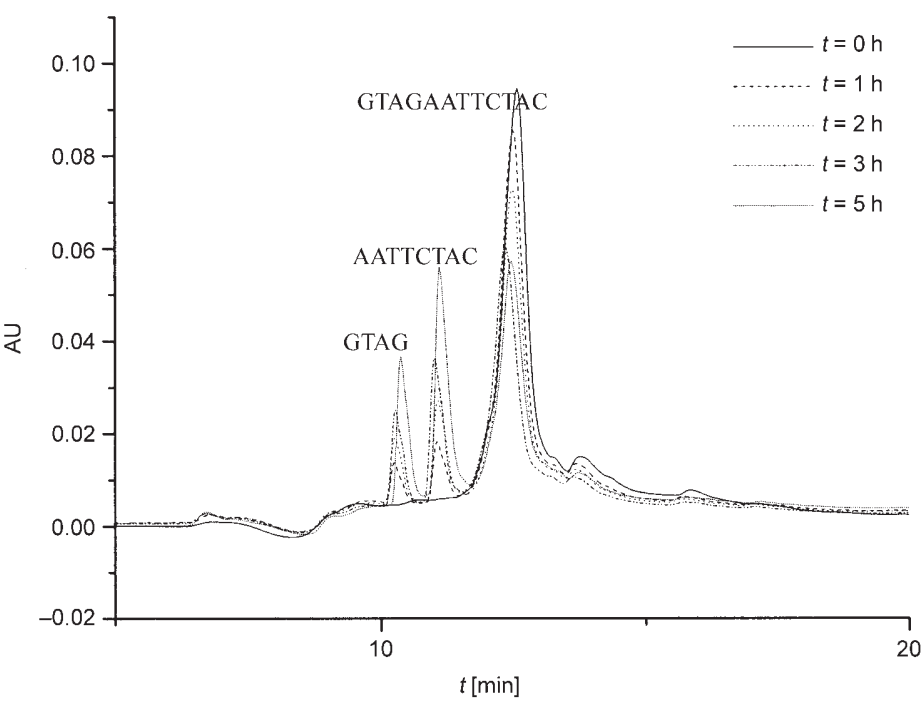

Figure 4. HPLC chromatograms of the EcoRI assay with the unmodified oligonucleotide 25 a.

Performing the cleavage assay using the arylamine modi fied oligonucleotides 25b $\mathbf{g}$ and 251 o under the same ex perimental conditions, no cleavage of any of the oligonucle otides could be detected. Even after incubation for $76 \mathrm{~h}$, the modified double strands were not digested (Figure 5). Thus, the arylamine damage of either $\mathrm{dA}$ or $\mathrm{dG}$ within the cleav age site evidently causes a conformational distortion in such a way that the enzyme is unable to bind and/or to cleave the DNA double strand.

A modification by a mono or polycyclic aromatic amine away from the recognition site generally leads to an increase in the half life for the restriction assay. For polycyclic DNA damage of $\mathrm{dG}^{1}$, a half life of $4.5 \mathrm{~h}$ was calculated. Surpris ingly, a monocyclic modification has a more pronounced effect, leading to a longer half life $(6.3 \mathrm{~h})$. A similar effect can be observed for modification at $\mathrm{dA}^{3}$ (see Table 5). Here again, the monocyclic arylamine modification clearly results in a greater structural change, which could be a reason for a weaker binding of the enzyme or inferior recognition of the acquired palindromic hexamer (see the example in Figure 6).

Primer extension assay: As investigations of other DNA ad ducts have shown, covalent DNA modifications significantly 


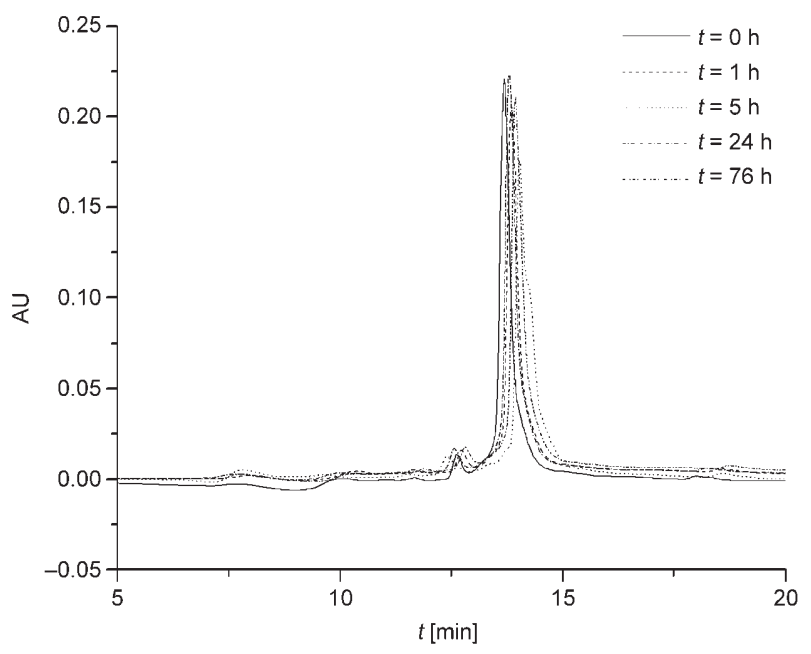

Figure 5. HPLC chromatograms of the EcoRI assay with the modified oligonucleotide $\mathbf{2 5 b}$

Table 5. Calculated half lives for the EcoR1 restriction assay for oligonu cleotides 25 a q.

\begin{tabular}{|c|c|}
\hline Oligonucleotides & $t_{1 / 2}[\mathrm{~h}]$ \\
\hline 5' GTAGAATTCTAC 3' $25 \mathbf{a}$ & 2.5 \\
\hline $5^{\prime}$ GTAG(anil)AATTCTAC $3^{\prime} \mathbf{2 5} \mathbf{b}$ & n.r. \\
\hline 5' GTAG(tol)AATTCTAC 3' 25 c & n.r. \\
\hline 5' GTAG(anis)AATTCTAC $3{ }^{\prime} \mathbf{2 5} \mathbf{d}$ & n.r. \\
\hline 5' GTAG(dma)AATTCTAC 3' $25 \mathbf{e}$ & n.r. \\
\hline 5' GTAG(4-abp)AATTCTAC 3' $25 \mathbf{f}$ & n.r. \\
\hline 5' GTAG(2-af)AATTCTAC 3' $\mathbf{2 5} \mathbf{g}$ & n.r. \\
\hline $5^{\prime} \mathbf{G}$ (anil)TA GAATTCTAC $3^{\prime} \mathbf{2 5} \mathbf{h}$ & 6.3 \\
\hline 5' G(4-abp)TAGAATTCTAC 3' $\mathbf{2 5} \mathbf{i}$ & 4.5 \\
\hline $5^{\prime}$ GTA(anis)GAATTCTAC $3^{\prime} \mathbf{2 5} \mathbf{j}$ & $>24$ \\
\hline 5' GTA(4-abp)GAATTCTAC 3' $25 \mathbf{k}$ & 3.1 \\
\hline 5' GTAGA(anis)ATTCTAC 3' 251 & n.r. \\
\hline 5' GTAGA(4-abp)ATTCTAC 3" $25 \mathrm{~m}$ & n.r. \\
\hline 5' GTAGAA(anis)TTCTAC $3^{\prime} \mathbf{2 5}$ n & n.r. \\
\hline 5' GTAGAA(4-abp)TTCTAC $3^{\prime} \mathbf{2 5}$ o & n.r. \\
\hline
\end{tabular}

n.r. $=$ no restriction.

hamper the selectivity and efficiency of lesion bypass syn thesis by replicative DNA polymerases, while other DNA polymerases are effective in performing DNA synthesis beyond the site of damage. ${ }^{[38]}$ Thus, to gain some initial in sights, we investigated several DNA polymerases from dif ferent DNA polymerase families with regard to their effec tiveness in bypassing the $\mathrm{C} 8$ arylamine adducts studied here (Figure 7).

We conducted experiments using a radioactively labeled primer template complex, which was designed in such a way that the modified nucleotide in the template strand codes for the first nucleotide after primer extension (Figure 7). Single incorporations were examined in order to gain first insights into the impact of the modification on se lectivity, in addition to experiments employing all four dNTPs to study lesion bypass. First, we investigated the high fidelity Pyrococcus furiosus (Pfu) DNA polymerase $\left(3^{\prime} \rightarrow 5^{\prime}\right.$ exonuclease deficient mutant $),{ }^{[3940]}$ a replicative

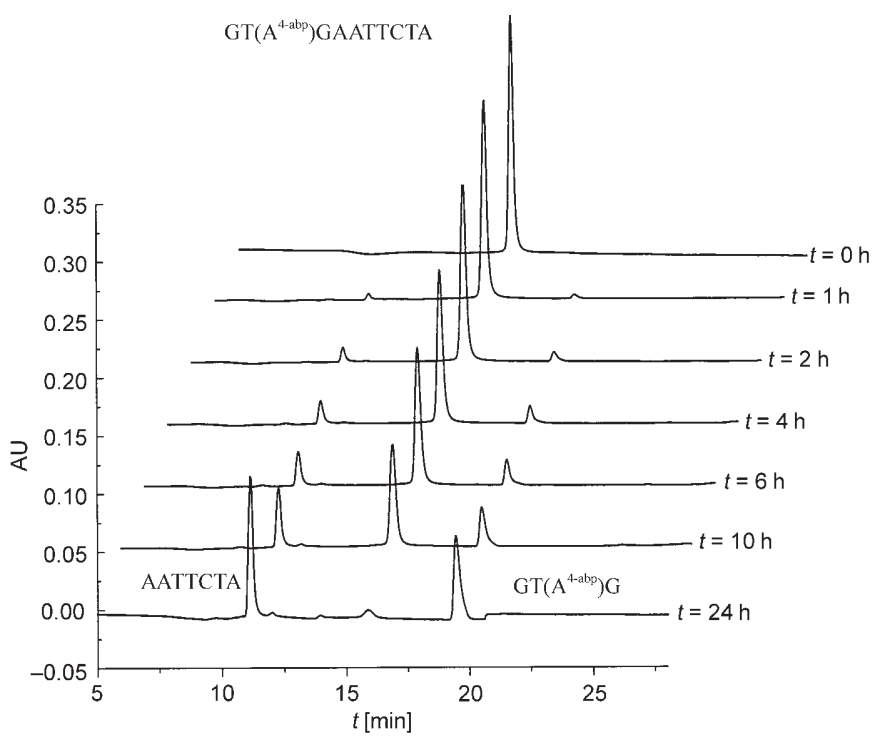

Figure 6. HPLC chromatograms of the EcoRI assay with the modified oligonucleotide $\mathbf{2 5} \mathbf{k}$.

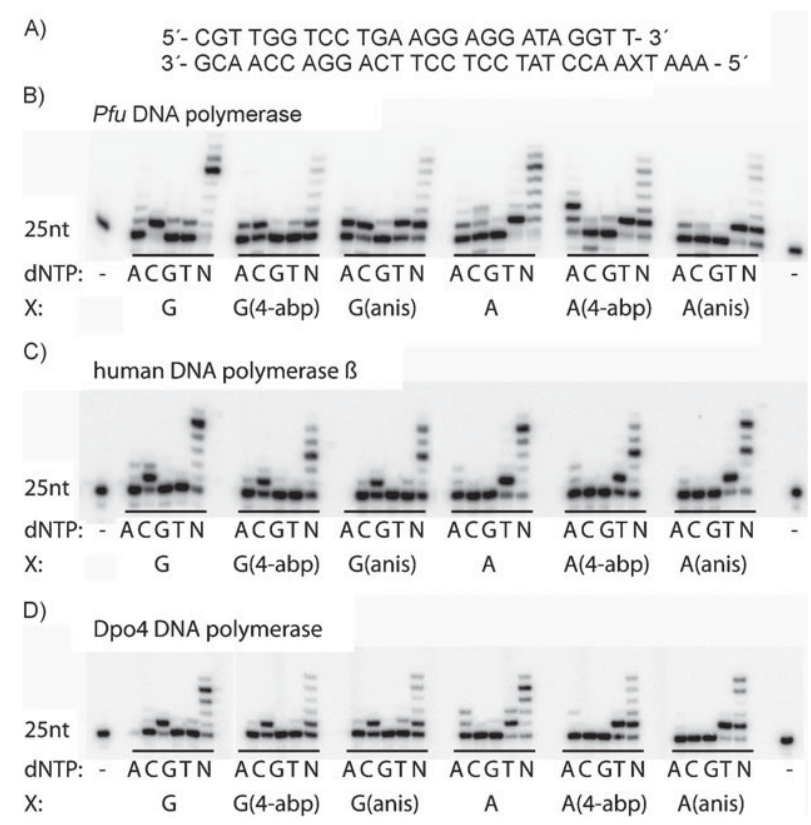

Figure 7. Effect of C8 arylamine adducts on DNA polymerases (A): DNA sequences employed. $\mathrm{X}=$ modified $\mathrm{dG}$ or $\mathrm{dA}$ residues. (B D): re actions catalyzed by the indicated DNA polymerase in the presence of one dNTP or all four dNTPs (indicated by N).

DNA polymerase belonging to sequence family $\mathrm{B}$, the same as the human replicative DNA polymerases.

The investigated lesions significantly block the progress of DNA synthesis by this enzyme, as indicated by a strong pausing band after incorporation of only one nucleotide, even when all four dNTPs are present (Figure 7B). Interest ingly, the ability to misincorporate a nucleotide significantly depends on the chemical composition of the modification as well as the modified nucleobase. While predominately the canonical dC is incorporated opposite $\mathrm{G}(4 \mathrm{abp})$ and the 
primer strand is extended by $60 \%, \mathrm{G}$ (anis) promotes misin corporation of $\mathrm{dT}$ and $\mathrm{dA}$ more efficiently, extending the primer by $60 \%$ and $54 \%$, respectively (see the Supporting Information). On the other hand, incorporation opposite $\mathrm{A}$ (anis) is more selective and the most significant primer ex tension by $90 \%$ was observed when the canonical dTTP was present. However, A(4 abp) promotes misinsertion of dA more significantly (78\%). Comparing A(anis) with G(anis), the latter seems to promote mismatch formation to a greater extent. In addition, we investigated the ability of the $3^{\prime} \rightarrow 5^{\prime}$ exonuclease proficient Pfu DNA polymerase to bypass the studied lesions (see the Supporting Information). Interest ingly, we found that this enzyme was only able to bypass the lesions in the case of $\mathrm{G}$ (anis), indicating the proofreading activity involved in the bypass process.

Next, we investigated human DNA polymerase $\beta$ (Fig ure 7C). Interestingly, this enzyme, a member of the DNA polymerase $\mathrm{X}$ family involved in DNA repair, ${ }^{[41]}$ is able to bypass the lesions and predominantly inserts the canonical nucleotide opposite the lesion (see the Supporting Informa tion). When investigating single nucleotide insertion, it was apparent that both modifications render primer extension less efficient in most cases (47 63\%), as compared to reac tions employing the unmodified templates (80 83\%). How ever, the effects of nucleobase and composition of the modi fication have a lower impact on error formation when com pared to the family B $P f u$ DNA polymerase. Next, we stud ied Sulfolobus solfataricus P2 DNA polymerase IV (Dpo4), which often serves as a functional and structural model for Y family DNA polymerases (Figure 7D).$\left.^{[42} 45\right]$ This enzyme is effective in bypassing these lesions, albeit with reduced effi ciency, as evidenced by a strong pausing band after nucleo tide insertion opposite the lesions when all four nucleotides are employed. Single nucleotide incorporation assays show that the canonical nucleotide is incorporated predominantly opposite the lesion, as has also been shown for other le sions. ${ }^{[44,45]}$ Only in the cases of the $\mathrm{G}(4 \mathrm{abp})$ and $\mathrm{G}$ (anis) modifications insertion of the non canonical dT was ob served to some extent (7 $11 \%)$.

\section{Conclusion}

We have presented detailed experimental procedures for the successful synthesis of $\mathrm{C} 8$ arylamine $\mathrm{dG}$ phosphoramidites as well as for their hitherto unknown dA counterparts. The amidites have been successfully site specifically incorporated into two different oligonucleotides. For both 30 mer oligonu cleotides and the self complementary 12 mers, the thermal stabilities of the damaged DNA strands showed a difference between the compounds modified by a monocyclic aromatic amine and those modified by 4 aminobiphenyl. Moreover, the adduct bearing oligonucleotides were found to be resist ant to digestion by EcoRI when these modifications were present within the recognition sequence of the EcoRI enzyme. An influence on the half life of this enzymatic di gestion was also found. Surprisingly, monocyclic DNA dam ages were found to have a stronger influence, leading to higher half lives in this restriction assay. We have shown that the effect of the damaged oligonucleotides on DNA polymerases very much depends on the respective DNA polymerase, the nucleobase, as well as the chemical nature of the adduct. Interestingly, the most significant potential for incorporating a non Watson Crick nucleotide was found when a high fidelity DNA polymerase promoted nucleotide insertion opposite the lesion. Investigations concerning the effect on repair enzymes of the different modified oligonu cleotides are currently in progress in our laboratories.

\section{Experimental Section}

General methods: All air or water sensitive reactions were performed in flame dried glassware under a nitrogen atmosphere. Commercial solvents and reagents were used without further purification with the following exceptions: 1,4 dioxane and 1,2 DME were distilled from potassium under nitrogen; pyridine, dichloromethane, and acetonitrile were distilled from calcium hydride under nitrogen. Water was purified on a Milli Q water system. NMR spectra are reported relative to the respective sol vent peaks ( ${ }^{1} \mathrm{H}$ NMR: $2.50 \mathrm{ppm} \quad\left(\left[\mathrm{D}_{6}\right] \mathrm{DMSO}\right), \quad 7.26 \mathrm{ppm}\left(\mathrm{CDCl}_{3}\right)$, $3.31 \mathrm{ppm} \quad\left(\mathrm{CD}_{3} \mathrm{OD}\right)$, and $7.16 \mathrm{ppm} \quad\left(\mathrm{C}_{6} \mathrm{D}_{6}\right) ;{ }^{13} \mathrm{C} \mathrm{NMR}: 39.52 \mathrm{ppm}$ ([D $\left.\left.\mathrm{D}_{6}\right] \mathrm{DMSO}\right), 77.16 \mathrm{ppm}\left(\mathrm{CDCl}_{3}\right), 49.0 \mathrm{ppm}\left(\mathrm{CD}_{3} \mathrm{OD}\right)$, and $128.06 \mathrm{ppm}$ $\left(\mathrm{C}_{6} \mathrm{D}_{6}\right)$ ). Thin layer chromatography (TLC) was performed on aluminium sheets coated with silica gel $60 \mathrm{~F}_{254}$ from Merck.

$O^{6}$-Benzyl-8-bromo-3',5'-bis(tert-butyldimethylsilyl)-2'-deoxyguanosine (11) was prepared as described previously. ${ }^{[16]}$

General procedure I for the $\mathrm{C} \mathbf{N}$ bond formation of $\boldsymbol{O}^{6}$-benzyl-8-bromo$3^{\prime}, 5^{\prime}$-bis(tert-butyldimethylsilyl)-2'-deoxyguanosine derivatives by Pd-catalyzed cross-coupling chemistry: A dried flask was purged with nitrogen and charged with bromide $\mathbf{1 1}, \mathrm{K}_{3} \mathrm{PO}_{4}$ (1.5 equiv), tris(dibenzylideneaceto ne)dipalladium $(0)\left(\left[\mathrm{Pd}_{2} \mathrm{dba}_{3}\right] ; 10 \mathrm{~mol} \%\right)$, racemic $2,2^{\prime}$ bis(diphenylphos phino) 1,1' binaphthyl (rac BINAP; $30 \mathrm{~mol} \%$ ), and the appropriate amine (2 equiv). Dry 1,2 DME $(15 \mathrm{~mL})$ was added and the mixture was stirred at $80^{\circ} \mathrm{C}$ until the reaction was complete (TLC analysis). The mix ture was allowed to cool to room temperature, whereupon saturated sodium hydrogencarbonate solution $(1 \mathrm{~mL})$ was added. After the addi tion of brine $(10 \mathrm{~mL})$, the layers were separated and the aqueous layer was extracted with ethyl acetate $(3 \times 10 \mathrm{~mL})$. The combined organic layers were washed with brine $(2 \times 10 \mathrm{~mL})$ and finally with a mixture of brine $(10 \mathrm{~mL})$ and water $(2 \mathrm{~mL})$. The organic phase was then dried over sodium sulfate and the solvent was removed in vacuo. Purification by chromatography on silica gel, eluting with $10 \rightarrow 30 \%$ ethyl acetate in hex anes, gave the desired product.

$O^{6}$-Benzyl-8N-(phenylamino)-3',5'-bis(tert-butyldimethylsilyl)-2'-deoxyguanosine (12a): GP I was conducted with $3.00 \mathrm{~g}(4.51 \mathrm{mmol})$ of bromide 11 (reaction time $72 \mathrm{~h}$ ), which afforded a yellow foam $(1.97 \mathrm{~g}, 64 \%)$. M.p. $\quad 161^{\circ} \mathrm{C} ; \quad[\alpha]_{546}^{20}=+13.8^{\circ} \quad\left(c=1.64, \quad \mathrm{CHCl}_{3}\right) ;{ }^{1} \mathrm{H} \mathrm{NMR} \quad(400 \mathrm{MHz}$, $\left.\left[\mathrm{D}_{6}\right] \mathrm{DMSO}\right): \delta=8.69(\mathrm{~s}, 1 \mathrm{H}), 7.59(\mathrm{dd}, J=7.6 \mathrm{~Hz}, 2 \mathrm{H}), 7.49(\mathrm{dd}, J=$ $6.7 \mathrm{~Hz}, 2 \mathrm{H}), 7.407 .38\left(\mathrm{~m}, 1 \mathrm{H}, \mathrm{H}_{\varepsilon}\right), 7.377 .33\left(\mathrm{~m}, 2 \mathrm{H}, \mathrm{H}_{\gamma}\right), 7.26$ (ddd, $J=$ $7.5,7.5 \mathrm{~Hz}, 2 \mathrm{H}), 6.91(\mathrm{ddd}, J=7.3,7.3 \mathrm{~Hz}, 1 \mathrm{H}), 6.31(\mathrm{dd}, J=6.9,6.9 \mathrm{~Hz}$, $1 \mathrm{H}), 6.05(\mathrm{~s}, 2 \mathrm{H}), 5.48(\mathrm{~s}, 2 \mathrm{H}), 4.64(\mathrm{ddd}, J=3.1,3.1,6.2 \mathrm{~Hz}, 1 \mathrm{H}), 3.88$ $3.80(\mathrm{~m}, 2 \mathrm{H}), 3.68(\mathrm{dd}, J=4.4,10.0 \mathrm{~Hz}, 1 \mathrm{H}), 3.473 .40(\mathrm{~m}, 1 \mathrm{H}), 2.15$ $2.10(\mathrm{~m}, 1 \mathrm{H}), 0.90(\mathrm{~s}, 9 \mathrm{H}), 0.81(\mathrm{~s}, 9 \mathrm{H}), 0.12(\mathrm{~s}, 6 \mathrm{H}), \quad 0.02(\mathrm{~s}, 3 \mathrm{H})$, $0.03 \mathrm{ppm}(\mathrm{s}, 3 \mathrm{H}) ;{ }^{13} \mathrm{C}$ NMR $\left(101 \mathrm{MHz},\left[\mathrm{D}_{6}\right] \mathrm{DMSO}\right): \delta=157.1,156.9$, $153.3,145.5,140.2,136.4,128.2,128.0,127.8,127.8,127.3,120.4,117.3$, $86.6,82.4,72.1,65.8,62.4,35.8,25.2,17.4,17.2, \quad 5.2, \quad 5.4, \quad 6.0 \mathrm{ppm}$; IR $(\mathrm{KBr}): \tilde{v}=3227,3034,1180,1005,917,895,725,669,560,505 \mathrm{~cm}^{1}$; MS (HRFAB): $m / z$ : calcd for: 676.3589 , found: $677.3616\left[M+\mathrm{H}^{+}\right]$.

$O^{6}$-Benzyl-8N-(4-methylphenylamino)-3',5'-bis(tert-butyldimethylsilyl)-2'deoxyguanosine (12 b): GP I was conducted with bromide 11 (2.50 g, $3.76 \mathrm{mmol}$; reaction time $70 \mathrm{~h})$, which afforded a yellow foam $(1.96 \mathrm{~g}$, $75 \%$ ). M.p. $86^{\circ} \mathrm{C} ;[\alpha]_{546}^{20}=+16.9^{\circ}\left(c=0.9, \mathrm{CHCl}_{3}\right) ;{ }^{1} \mathrm{H}$ NMR $(400 \mathrm{MHz}$, 
[D $\mathrm{D}_{6}$ DMSO): $\delta=8.56(\mathrm{~s}, 1 \mathrm{H}), 7.497 .47(\mathrm{~m}, 2 \mathrm{H}), 7.407 .30(\mathrm{~m}, 3 \mathrm{H}), 7.07$ $(\mathrm{d}, J=8.4 \mathrm{~Hz}, 2 \mathrm{H}), 6.80(\mathrm{~d}, J=8.0 \mathrm{~Hz}, 2 \mathrm{H}), 6.30(\mathrm{dd}, J=6.9 \mathrm{~Hz}, 1 \mathrm{H})$, $6.01(\mathrm{~s}, 2 \mathrm{H}), 5.47(\mathrm{~s}, 2 \mathrm{H}), 4.62(\mathrm{ddd}, J=6.1,3.0,3.0 \mathrm{~Hz}, 1 \mathrm{H}), 3.823 .78$ $(\mathrm{m}, 2 \mathrm{H}), 3.68(\mathrm{dd}, J=10.2,4.5 \mathrm{~Hz}, 1 \mathrm{H}), 3.423 .38(\mathrm{~m}, 1 \mathrm{H}), 2.22(\mathrm{~s}, 3 \mathrm{H})$, $2.112 .09(\mathrm{~m}, 1 \mathrm{H}), 0.89(\mathrm{~s}, 9 \mathrm{H}), 0.80(\mathrm{~s}, 9 \mathrm{H}), 0.11(\mathrm{~s}, 6 \mathrm{H}), \quad 0.02(\mathrm{~s}, 3 \mathrm{H})$, $0.03 \mathrm{ppm}(\mathrm{s}, 3 \mathrm{H}) ;{ }^{13} \mathrm{C}$ NMR (101 MHz, [D 6 DMSO): $\delta=157.6,157.4$, $146.4,138.1,137.0,129.9,129.2,128.4,128.3,127.9,123.9,117.4,111.0$, $87.1,83.0,72.7,66.4,63.0,36.5,25.7,20.3,18.0, \quad 4.6, \quad 5.2 \mathrm{ppm}$; IR $(\mathrm{KBr}): \tilde{v}=3465,3348,2953,1600,1409,1257,1105,1060,835,698 \mathrm{~cm}^{1}$; MS (HRFAB): $m / z$ : calcd for: 690.3745 , found $691.3809\left[M+\mathrm{H}^{+}\right]$.

$O^{6}$-Benzyl-8N-(4-methoxyphenylamino)-3',5'-bis(tert-butyldimethylsilyl)$\mathbf{2}^{\prime}$-deoxyguanosine (12 c): GP I was conducted with $3.02 \mathrm{~g}(4.54 \mathrm{mmol})$ of bromide 11 (reaction time $70 \mathrm{~h}$ ), which afforded a yellow foam $(2.00 \mathrm{~g}$, $62 \%)$. M.p. $117121^{\circ} \mathrm{C} ; \quad[\alpha]_{546}^{20}=+15^{\circ} \quad\left(c=0.1, \quad \mathrm{CHCl}_{3}\right) ; \quad{ }^{1} \mathrm{H}$ NMR (400 MHz, [D $\mathrm{D}_{6}$ DMSO): $\delta=8.47(\mathrm{~s}, 1 \mathrm{H}), 7.51(\mathrm{~d}, J=9.0 \mathrm{~Hz}, 2 \mathrm{H}), 7.47$ (d, $J=7.2 \mathrm{~Hz}, 2 \mathrm{H}), 7.38(\mathrm{dd}, J=7.2 \mathrm{~Hz}, 3 \mathrm{H}), 6.88(\mathrm{~d}, J=9.0 \mathrm{~Hz}, 2 \mathrm{H}), 6.29$ $(\mathrm{dd}, J=6.9 \mathrm{~Hz}, 1 \mathrm{H}), 5.97(\mathrm{~s}, 2 \mathrm{H}), 5.46(\mathrm{~s}, 2 \mathrm{H}), 4.63(\mathrm{ddd}, J=6.2,3.1$, $3.1 \mathrm{~Hz}, 1 \mathrm{H}), 3.84(\mathrm{ddd}, J=13.2,9.6,5.5 \mathrm{~Hz}, 2 \mathrm{H}), 3.70$ (s, 3H), 3.68 (dd, $J=13.2,5.5 \mathrm{~Hz}, 1 \mathrm{H}), 3.43(\mathrm{ddd}, J=13.3,6.7 \mathrm{~Hz}, 1 \mathrm{H}), 2.10$ (ddd, $J=13.3$, 6.7, $3.2 \mathrm{~Hz}, 1 \mathrm{H}), 0.90(\mathrm{~s}, 9 \mathrm{H}), 0.81(\mathrm{~s}, 9 \mathrm{H}), 0.12(\mathrm{~s}, 6 \mathrm{H}), \quad 0.02(\mathrm{~s}, 3 \mathrm{H})$, $0.03 \mathrm{ppm}(\mathrm{s}, 3 \mathrm{H}) ;{ }^{13} \mathrm{C} \mathrm{NMR}\left(101 \mathrm{MHz},\left[\mathrm{D}_{6}\right] \mathrm{DMSO}\right): \delta=157.6,157.4$, 147.2, 139.1, 137.3, 133.9, 128.6, 128.5, 128.1, 120.0, 114.0, 87.3, 83.0, 72.9, $66.6,63.2,55.3,36.6,25.9,18.0, \quad 5.2 \mathrm{ppm}$; IR (KBr): $\tilde{v}=3332,2952,2929$, 1633, 1605, 1565, 1414, 1256, $835 \mathrm{~cm}^{1}$; MS (HRFAB): $\mathrm{m} / z$ : calcd for: 706.3718, found $707.3622\left[M+\mathrm{H}^{+}\right]$.

$O^{6}$-Benzyl-8N-(3,5-dimethylphenylamino)-3',5'-bis(tert-butyldimethylsilyl)-2'-deoxyguanosine (12 d): GP I was conducted with $2.50 \mathrm{~g}(3.76 \mathrm{mmol})$ of bromide $\mathbf{1 1}$ (reaction time $72 \mathrm{~h}$ ), which afforded an orange solid $(1.74 \mathrm{~g}, 66 \%)$. M.p. $135^{\circ} \mathrm{C} ;[\alpha]_{546}^{20}=+15^{\circ}\left(c=1.64, \mathrm{CHCl}_{3}\right) ;{ }^{1} \mathrm{H}$ NMR $\left(400 \mathrm{MHz},\left[\mathrm{D}_{6}\right] \mathrm{DMSO}\right): \delta=8.38(\mathrm{~s}, 1 \mathrm{H}), 7.46(\mathrm{~d}, J=7.2 \mathrm{~Hz}, 2 \mathrm{H}), 7.36(\mathrm{t}$, $J=7.5 \mathrm{~Hz}, 2 \mathrm{H}), 7.327 .29(\mathrm{dd}, J=7.2,8.2 \mathrm{~Hz}, 2 \mathrm{H}), 7.25(\mathrm{~d}, J=7.1 \mathrm{~Hz}$, $1 \mathrm{H}), 6.55(\mathrm{~s}, 1 \mathrm{H}), 6.26(\mathrm{t}, J=6.9 \mathrm{~Hz}, 1 \mathrm{H}), 6.02(\mathrm{~s}, 2 \mathrm{H}), 5.49(\mathrm{~s}, 2 \mathrm{H})$, $4.614 .59(\mathrm{~m}, 1 \mathrm{H}), 3.853 .79(\mathrm{~m}, 2 \mathrm{H}), 3.67(\mathrm{dd}, J=4.6,5.8 \mathrm{~Hz}, 1 \mathrm{H}), 2.20$ $(\mathrm{s}, 6 \mathrm{H}), 2.112 .08(\mathrm{~m}, 2 \mathrm{H}), 0.88(\mathrm{~s}, 9 \mathrm{H}), 0.80(\mathrm{~s}, 9 \mathrm{H}), 0.10(\mathrm{~s}, 6 \mathrm{H})$, $0.00 \mathrm{ppm}(\mathrm{s}, 6 \mathrm{H}) ;{ }^{13} \mathrm{C}$ NMR $\left(101 \mathrm{MHz},\left[\mathrm{D}_{6}\right] \mathrm{DMSO}\right): \delta=157.8,154.9$, $154.1,149.3,141.0,137.7,128.7,128.5,128.4,128.3,128.0,120.8,117.9$, 87.2, 84.0, 72.8, 66.6, 63.2, 36.7, 25.9, 21.4, 17.4, 16.7, 5.2, 5.4,

$6.0 \mathrm{ppm}$; IR (KBr): $\tilde{v}=3377,3333,2950,2857,1616,1565,1464,1413$, 1253, 1108, 833, $783 \mathrm{~cm}^{1}$; MS (HRFAB): $\mathrm{m} / \mathrm{z}$ : calcd for: 704.3902 , found $705.3993\left[\mathrm{M+ \textrm {H } ^ { + }}\right]$

\section{$O^{6}$-Benzyl-8N-(4-biphenylamino)-3',5'-bis(tert-butyldimethylsilyl)-2' -de-} oxyguanosine (12 e): GP I was conducted with bromide 11 (1.40 g, $1.56 \mathrm{mmol}$, reaction time $55 \mathrm{~h}$ ), which afforded a light yellow foam $(1.03 \mathrm{~g}, 65 \%)$. M.p. $146^{\circ} \mathrm{C} ;[\alpha]_{546}^{20}=+16.3^{\circ}\left(c=0.32, \mathrm{CHCl}_{3}\right) ;{ }^{1} \mathrm{H} \mathrm{NMR}$ (400 MHz, [D $]$ DMSO): $\delta=8.05(\mathrm{~s}, 1 \mathrm{H}), 7.527 .20(\mathrm{~m}, 14 \mathrm{H}), 6.50(\mathrm{~s}$, $2 \mathrm{H}), 6.20(\mathrm{dd}, J=6.8,7.4 \mathrm{~Hz}, 1 \mathrm{H}), 5.48(\mathrm{~s}, 2 \mathrm{H}), 4.51(\mathrm{ddd}, J=6.7,4.3$, $4.3 \mathrm{~Hz}, 1 \mathrm{H}), 3.81$ (dd, $J=10.6,5.0 \mathrm{~Hz}, 1 \mathrm{H}), 3.73(\mathrm{ddd}, J=5.0,4.3,6.0 \mathrm{~Hz}$, $1 \mathrm{H}), 3.69$ (dd, $J=10.6,6.0 \mathrm{~Hz}, 1 \mathrm{H}), 3.63$ (ddd, $J=13.0,6.2,6.8 \mathrm{~Hz}, 1 \mathrm{H}$ ), 2.26 (ddd, $J=13.0,4.3,7.4 \mathrm{~Hz}, 1 \mathrm{H}), 0.89(\mathrm{~s}, 9 \mathrm{H}), 0.85(\mathrm{~s}, 9 \mathrm{H}), 0.10$ (s, $3 \mathrm{H}), \quad 0.09(\mathrm{~s}, \quad 3 \mathrm{H}), \quad 0.04(\mathrm{~s}, \quad 3 \mathrm{H}), \quad 0.05 \mathrm{ppm} \quad(\mathrm{s}, \quad 3 \mathrm{H}) ;{ }^{13} \mathrm{C} \mathrm{NMR}$ (101 MHz, [D 6 DMSO): $\delta=160.2,159.9,154.3,148.5,140.9,137.8,136.8$, $128.9,128.6,128.4,128.2,127.5,127.4,127.2,125.8,125.5,114.4,82.5$, $72.4, \quad 72.3,67.0,62.9, \quad 37.2, \quad 26.0,25.9, \quad 18.1, \quad 17.9, \quad 4.5, \quad 4.7, \quad 5.2$,

$5.3 \mathrm{ppm}$; IR (KBr): $\tilde{v}=2940,2908,2877,1607,1559,1423,1159,1005$, 938, $785 \mathrm{~cm}^{1}$; MS (HRFAB): $\mathrm{m} / \mathrm{z}$ : calcd for: 752.3902 , found 753.3992 $\left[M+\mathrm{H}^{+}\right]$

$O^{6}$-Benzyl-8N-(2-aminofluorenyl)-3',5'-bis(tert-butyldimethylsilyl)-2'-deoxyguanosine (12 e): GP I was conducted with bromide 11 (1.95 g, $2.91 \mathrm{mmol}$; reaction time $78 \mathrm{~h})$, which afforded a yellow solid $(2.05 \mathrm{~g}$, $91 \%)$. M.p. $85^{\circ} \mathrm{C} ;[\alpha]_{546}^{20}=5.2^{\circ}\left(c=0.5, \mathrm{CHCl}_{3}\right) ;{ }^{1} \mathrm{H} \mathrm{NMR}(400 \mathrm{MHz}$, [D $\mathrm{D}_{6}$ DMSO): $\delta=8.77(\mathrm{~s}, 1 \mathrm{H}), 7.917 .88(\mathrm{~m}, 1 \mathrm{H}), 7.76(\mathrm{dt}, J=7.8,5.9 \mathrm{~Hz}$, $1 \mathrm{H}), 7.59$ (dd, $J=8.3,1.9 \mathrm{~Hz}, 1 \mathrm{H}), 7.527 .46(\mathrm{~m}, 3 \mathrm{H}), 7.427 .20(\mathrm{~m}, 5 \mathrm{H})$, $7.117 .07(\mathrm{~m}, 1 \mathrm{H}), 6.34(\mathrm{dd}, J=6.9 \mathrm{~Hz}, 1 \mathrm{H}), 6.07(\mathrm{~s}, 2 \mathrm{H}), 5.50(\mathrm{~s}, 2 \mathrm{H})$, $4.63(\mathrm{ddd}, J=6.1,3.1 \mathrm{~Hz}, 1 \mathrm{H}), 3.92(\mathrm{~s}, 2 \mathrm{H}), 3.893 .86(\mathrm{~m}, 2 \mathrm{H}), 3.713 .69$ (m, $1 \mathrm{H}), 3.43$ (ddd, $J=10.1,6.5 \mathrm{~Hz}, 1 \mathrm{H}), 2.13(\mathrm{ddd}, J=10.1,7.2,3.5 \mathrm{~Hz}$, $1 \mathrm{H}), 0.90(\mathrm{~s}, 9 \mathrm{H}), 0.81(\mathrm{~s}, 9 \mathrm{H}), 0.12(\mathrm{~s}, 6 \mathrm{H}), \quad 0.00(\mathrm{~s}, 3 \mathrm{H}), \quad 0.01 \mathrm{ppm}(\mathrm{s}$, $3 \mathrm{H}) ;{ }^{13} \mathrm{C} \mathrm{NMR}\left(101 \mathrm{MHz},\left[\mathrm{D}_{6}\right] \mathrm{DMSO}\right): \delta=157.8,157.6,153.9,146.1$, $143.8,142.5,141.3,140.1,137.0,134.5,128.4,128.4,127.9,126.7,124.9$,
124.3, 120.1, 119.0, 116.8, 114.4, 111.3, 87.2, 83.0, 72.7, 66.5, 63.0, 57.9, $36.5,25.7,17.9, \quad 4.7, \quad 5.4 \mathrm{ppm}$; IR $(\mathrm{KBr}): \tilde{v}=3495,3357,2952,2927$, $1597,1560,1456,1416,1254,835,778 \mathrm{~cm}^{1}$; MS (HRFAB): $\mathrm{m} / z: \mathrm{calcd}$ for: 764.3902 , found $765.3974\left[M+\mathrm{H}^{+}\right]$

General procedure II for the debenzylation of $O^{6}$-benzyl-8 $N$-arylamino3',5'-bis(tert-butyldimethylsilyl)-2'-deoxyguanosine derivatives: A dried flask was purged with nitrogen and then charged with the $O^{6}$ benzyl $8 N$ arylamino 3',5' bis(tert butyldimethylsilyl) 2' deoxyguanosine derivative and $\mathrm{Pd} / \mathrm{C}$. Dry methanol was added and the reaction mixture was stirred under a hydrogen atmosphere at room temperature for $148 \mathrm{~h}$. The reac tion mixture was centrifuged several times with methanol, filtered, and concentrated in vacuo to give the pure product.

8N-(Phenylamino)-3',5'-bis(tert-butyldimethylsilyl)-2'-deoxyguanosine (13a): GP II was conducted with 12a $(1.90 \mathrm{~g}, 2.80 \mathrm{mmol}$; reaction time $24 \mathrm{~h})$, which afforded a white solid $(1.48 \mathrm{~g}, 90 \%)$. M.p. $155^{\circ} \mathrm{C} ;[\alpha]_{546}^{20}=$ $10.8^{\circ}\left(c=0.8, \mathrm{CHCl}_{3}\right) ;{ }^{1} \mathrm{H}$ NMR $\left(400 \mathrm{MHz},\left[\mathrm{D}_{6}\right] \mathrm{DMSO}\right): \delta=10.52(\mathrm{~s}$, $1 \mathrm{H}), 8.35(\mathrm{~s}, 1 \mathrm{H}), 7.45(\mathrm{dd}, J=7.6 \mathrm{~Hz}, 2 \mathrm{H}), 7.23(\mathrm{dd}, J=8.5 \mathrm{~Hz}, 2 \mathrm{H})$ $6.87(\mathrm{dd}, J=7.3,7.3 \mathrm{~Hz}, 1 \mathrm{H}), 6.22(\mathrm{dd}, J=7.1 \mathrm{~Hz}, 1 \mathrm{H}), 6.19(\mathrm{~s}, 2 \mathrm{H}), 4.53$ (ddd, $J=3.1,3.1,6.2 \mathrm{~Hz}, 1 \mathrm{H}), 3.843 .78(\mathrm{~m}, 2 \mathrm{H}), 3.71$ (ddd, $J=8.2,8.2$, $8.1 \mathrm{~Hz}, 1 \mathrm{H}), 3.233 .16(\mathrm{~m}, 1 \mathrm{H}), 2.182 .14(\mathrm{~m}, 1 \mathrm{H}), 0.88(\mathrm{~s}, 9 \mathrm{H}), 0.83$ (s, $9 \mathrm{H}), 0.10(\mathrm{~s}, 6 \mathrm{H}), 0.00 \mathrm{ppm}(\mathrm{s}, 6 \mathrm{H}) ;{ }^{13} \mathrm{C} \mathrm{NMR}\left(101 \mathrm{MHz},\left[\mathrm{D}_{6}\right] \mathrm{DMSO}\right)$ : $\delta=155.3,152.0,149.5,143.2,141.3,128.2,120.0,116.5,113.0,86.8,82.5$, $72.3,62.7,36.5,25.4,25.3,17.7,17.4, \quad 5.1, \quad 5.3 \mathrm{ppm}$; IR $(\mathrm{KBr}): \tilde{v}=3353$, 1179, 1006, 953, 692, 667, 576, $501 \mathrm{~cm}^{1}$; MS (HRFAB): $\mathrm{m} / \mathrm{z}$ : calcd for: 586.8736 , found $587.8705\left[M+\mathrm{H}^{+}\right]$.

$\mathbf{8} \boldsymbol{N}$-(4-Methylphenylamino)-3',5'-bis(tert-butyldimethylsilyl)-2'-deoxyguanosine (13b): GP II was conducted with $\mathbf{1 2 b}(1.90 \mathrm{~g}, 2.74 \mathrm{mmol}$; reaction time $24 \mathrm{~h}$ ), which afforded a yellow solid $(1.69 \mathrm{~g}, 85 \%)$. M.p. $119^{\circ} \mathrm{C}$; $[\alpha]_{546}^{20}=7.9^{\circ}\left(c=0.47, \mathrm{CHCl}_{3}\right) ;{ }^{1} \mathrm{H} \mathrm{NMR}\left(400 \mathrm{MHz},\left[\mathrm{D}_{6}\right] \mathrm{DMSO}\right): \delta=$ $10.55(\mathrm{~s}, 1 \mathrm{H}), 8.22(\mathrm{~s}, 1 \mathrm{H}), 7.37(\mathrm{~d}, J=8.4 \mathrm{~Hz}, 2 \mathrm{H}), 7.04(\mathrm{~d}, J=8.4 \mathrm{~Hz}$, $2 \mathrm{H}), 6.20(\mathrm{dd}, J=7.0 \mathrm{~Hz}, 1 \mathrm{H}), 6.17(\mathrm{~s}, 2 \mathrm{H}), 4.554 .52(\mathrm{~m}, 1 \mathrm{H}), 3.843 .81$ (ddd, $J=8.3,9.3 \mathrm{~Hz}, 2 \mathrm{H}), 3.733 .70(\mathrm{~m}, 1 \mathrm{H}), 3.18$ (ddd, $J=13.2,7.0$, $6.7 \mathrm{~Hz}, 1 \mathrm{H}), 2.23(\mathrm{~s}, 3 \mathrm{H}), 2.06(\mathrm{ddd}, J=13.2,6.7,3.0 \mathrm{~Hz}, 1 \mathrm{H}), 0.88$ (s, $9 \mathrm{H}), 0.83(\mathrm{~s}, 9 \mathrm{H}), 0.09(\mathrm{~s}, 6 \mathrm{H}), 0.02(\mathrm{~s}, 3 \mathrm{H}), 0.00 \mathrm{ppm}(\mathrm{s}, 3 \mathrm{H}) ;{ }^{13} \mathrm{C} \mathrm{NMR}$ (101 MHz, [D $\mathrm{D}_{6}$ DMSO): $\delta=155.7,152.3,146.0,143.9,139.0,128.3,123.9$, 114.5, 111.0, 87.1, 82.9, 72.7, 63.1, 36.9, 25.7, 20.1, 18.1, 4.6, 5.3 ppm; IR $(\mathrm{KBr}): \tilde{v}=3312,2918,1693,1603,1517,1369,1252,1083,837$, $776 \mathrm{~cm}^{1}$; MS (HRFAB): $\mathrm{m} / \mathrm{z}$ : calcd for: 600.3276, found 601.3344 $\left[\mathrm{M}+\mathrm{H}^{+}\right]$

8N-(4-Methoxyphenylamino)-3',5'-bis(tert-butyldimethylsilyl)-2'-deoxyguanosine (13c): GP II was conducted with 12 c $(1.92 \mathrm{~g}, 2.69 \mathrm{mmol}$; reac tion time $4 \mathrm{~h}$ ), which afforded a white solid $(1.58 \mathrm{~g}, 96 \%)$. M.p. $112^{\circ} \mathrm{C}$; $[\alpha]_{546}^{20}=9.9^{\circ}\left(c=0.8, \mathrm{CHCl}_{3}\right) ;{ }^{1} \mathrm{H} \mathrm{NMR}\left(400 \mathrm{MHz},\left[\mathrm{D}_{6}\right] \mathrm{DMSO}\right): \delta=$ $10.53(\mathrm{~s}, 1 \mathrm{H}), 8.14(\mathrm{~s}, 1 \mathrm{H}), 7.42(\mathrm{~d}, J=9.0 \mathrm{~Hz}, 2 \mathrm{H}), 6.84(\mathrm{~d}, J=9.0 \mathrm{~Hz}$, $2 \mathrm{H}), 6.20(\mathrm{dd}, J=7.1 \mathrm{~Hz}, 1 \mathrm{H}), 6.15(\mathrm{~s}, 2 \mathrm{H}), 4.52(\mathrm{ddd}, J=6.2,3.1,3.1 \mathrm{~Hz}$, $1 \mathrm{H}), 3.853 .83(\mathrm{~m}, J=13.2,9.6,5.5 \mathrm{~Hz}, 2 \mathrm{H}), 3.70(\mathrm{~s}, 3 \mathrm{H}), 3.68(\mathrm{dd}, J=$ $13.2,5.5 \mathrm{~Hz}, 1 \mathrm{H}), 3.20$ (ddd, $J=13.8,6.6 \mathrm{~Hz}, 1 \mathrm{H}), 2.10$ (ddd, $J=13.8,6.6$, $3.2 \mathrm{~Hz}, 1 \mathrm{H}), 0.88(\mathrm{~s}, 9 \mathrm{H}), 0.83(\mathrm{~s}, 9 \mathrm{H}), 0.10(\mathrm{~s}, 6 \mathrm{H}), 0.00(\mathrm{~s}, 3 \mathrm{H})$, $0.03 \mathrm{ppm}(\mathrm{s}, 3 \mathrm{H}) ;{ }^{13} \mathrm{C}$ NMR $\left(101 \mathrm{MHz},\left[\mathrm{D}_{6}\right] \mathrm{DMSO}\right): \delta=155.8,153.9$, $152.2,150.0,144.7,134.8,128.4,119.3,114.0,87.3,83.0,72.9,63.3,55.3$ $37.0,26.0,25.9,18.0,17.9, \quad 4.6, \quad 5.2 \mathrm{ppm}$; IR $(\mathrm{KBr}): \tilde{v}=2929,2856$, 1698, 1613, 1513, 1248, 1108, 834, $777 \mathrm{~cm}^{1}$; MS (HRFAB): $\mathrm{m} / \mathrm{z}:$ calcd 616.3222, found $617.3312\left[M+\mathrm{H}^{+}\right]$

8N-(3,5-Dimethylphenylamino)-3',5'-bis(tert-butyldimethylsilyl)-2'-deoxyguanosine (13d): GP II was conducted with of 12 d $(1.17 \mathrm{~g}, 1.54 \mathrm{mmol}$; re action time $12 \mathrm{~h}$ ), which afforded a white solid (739 mg, 78\%). M.p. $185^{\circ} \mathrm{C} ;[\alpha]_{546}^{20}=43^{\circ}\left(c=0.8, \mathrm{CHCl}_{3}\right) ;{ }^{1} \mathrm{H}$ NMR $\left(400 \mathrm{MHz},\left[\mathrm{D}_{6}\right] \mathrm{DMSO}\right)$ : $\delta=10.57(\mathrm{~s}, 1 \mathrm{H}), 8.04(\mathrm{~s}, 1 \mathrm{H}), 7.317 .28(\mathrm{~m}, 2 \mathrm{H}), 6.97(\mathrm{~s}, 1 \mathrm{H}), 6.51(\mathrm{~s}$ $2 \mathrm{H}), 6.206 .11(\mathrm{~m}, 1 \mathrm{H}), 4.49(\mathrm{t}, J=2.8 \mathrm{~Hz}, 1 \mathrm{H}), 4.02(\mathrm{q}, J=7.1 \mathrm{~Hz}, 1 \mathrm{H})$, $3.823 .57(\mathrm{~m}, 2 \mathrm{H}), 3.08(\mathrm{q}, J=6.8 \mathrm{~Hz}, 1 \mathrm{H}), 2.232 .19(\mathrm{~m}, 1 \mathrm{H}), 0.86(\mathrm{~s}$ $9 \mathrm{H}), 0.83(\mathrm{~s}, 9 \mathrm{H}), 0.7(\mathrm{~s}, 6 \mathrm{H}), 0.00 \mathrm{ppm}(\mathrm{s}, 6 \mathrm{H}) ;{ }^{13} \mathrm{C} \mathrm{NMR}(101 \mathrm{MHz}$, [D $]$ DMSO): $\delta=155.9,152.7,150.2,143.6,142.0,137.7,119.7,117.8$, $112.2,93.7,87.2,73.0,63.2,37.2,30.5,26.0,26.0,21.4,18.3,17.3,4.7$,

$6.1 \mathrm{ppm}$; IR (KBr): $\tilde{v}=3489,2928,2857,1696,1596,1497,1406,1285$, 1091, 836, $775 \mathrm{~cm}^{1}$; MS (HRFAB): $\mathrm{m} / z$ : calcd for: 614.3439 , found $615.3510\left[M+\mathrm{H}^{+}\right]$

8N-(4-Biphenylamino)-3' $\mathbf{5}^{\prime}$-bis(tert-butyldimethylsilyl)-2'-deoxyguanosine (13e): GP II was conducted with $12 \mathrm{e}(1.00 \mathrm{~g}, 1.32 \mathrm{mmol}$; reaction time 
$16 \mathrm{~h})$, which afforded a white solid $(820 \mathrm{mg}, 93 \%)$. M.p. decomposition at $200{ }^{\circ} \mathrm{C} ;[\alpha]_{546}^{20}=8^{\circ}\left(c=0.3, \mathrm{CHCl}_{3}\right) ;{ }^{1} \mathrm{H}$ NMR $\left(400 \mathrm{MHz},\left[\mathrm{D}_{6}\right] \mathrm{DMSO}\right)$ : $\delta=10.59(\mathrm{~s}, 1 \mathrm{H}), 7.87(\mathrm{~s}, 1 \mathrm{H}), 7.83(\mathrm{~d}, J=8.3 \mathrm{~Hz}, 2 \mathrm{H}), 7.60(\mathrm{dd}, J=$ $8.3 \mathrm{~Hz}, 4 \mathrm{H}), 7.42(\mathrm{dd}, J=7.6 \mathrm{~Hz}, 2 \mathrm{H}), 7.29(\mathrm{dd}, J=7.6 \mathrm{~Hz}, 1 \mathrm{H}), 6.47$ (s, $2 \mathrm{H}), 6.10(\mathrm{dd}, J=6.1,7.6 \mathrm{~Hz}, 1 \mathrm{H}), 4.48(\mathrm{ddd}, J=6.3,5.3,4.3 \mathrm{~Hz}, 1 \mathrm{H})$, $3.81(\mathrm{dd}, J=10.2,4.7 \mathrm{~Hz}, 1 \mathrm{H}), 3.73(\mathrm{ddd}, J=6.3,4.7,4.3 \mathrm{~Hz}, 1 \mathrm{H}), 3.69$ $(\mathrm{dd}, J=10.2,6.3 \mathrm{~Hz}, 1 \mathrm{H}), 3.63(\mathrm{ddd}, J=13.0,6.1,6.8 \mathrm{~Hz}, 1 \mathrm{H}), 2.22$ (ddd, $J=13.0,4.3,7.6 \mathrm{~Hz}, 1 \mathrm{H}), 0.88(\mathrm{~s}, 9 \mathrm{H}), 0.86(\mathrm{~s}, 9 \mathrm{H}), 0.09$ (s, 3H), 0.08 (s, $3 \mathrm{H}), \quad 0.03 \quad(\mathrm{~s}, \quad 3 \mathrm{H}), \quad 0.04 \mathrm{ppm} \quad(\mathrm{s}, \quad 3 \mathrm{H}) ; \quad{ }^{13} \mathrm{C} \mathrm{NMR} \quad(101 \mathrm{MHz}$, [D $]$ DMSO): $\delta=160.4,159.9,154.5,148.6,140.9,139.8,128.9,127.6$, $127.3,127.2,125.8,125.5,114.4,82.3,72.4,72.3,62.9,37.2,26.0,25.9,18.1$, $17.9, \quad 4.5, \quad 4.7, \quad 5.2, \quad 5.3 \mathrm{ppm} ; \mathrm{IR}(\mathrm{KBr}): \tilde{v}=3346,3173,2954,2928$, $1647,1603,1537,1486,1383,1169,1075,776 \mathrm{~cm}^{1}$; MS (HRFAB): $\mathrm{m} / z$ : calcd for: 662.3432 , found $663.3496\left[M+\mathrm{H}^{+}\right]$.

\section{$\mathbf{8 N}$-(2-Aminofluorenyl)-3',5'-bis(tert-butyldimethylsilyl)-2'-deoxyguano-} sine (13 f): GP II was conducted with 12 f $(1.95 \mathrm{~g}, 2.55 \mathrm{mmol}$; reaction time $48 \mathrm{~h})$, which afforded a white solid $(1.45 \mathrm{~g}, 84 \%)$. M.p. $169^{\circ} \mathrm{C}$; $[\alpha]_{546}^{20}=21^{\circ}\left(c=0.34, \mathrm{CHCl}_{3}\right) ;{ }^{1} \mathrm{H} \mathrm{NMR}\left(400 \mathrm{MHz},\left[\mathrm{D}_{6}\right] \mathrm{DMSO}\right): \delta=$ $10.61(\mathrm{~s}, 1 \mathrm{H}), 8.50(\mathrm{~s}, 1 \mathrm{H}), 7.80(\mathrm{~m}, 1 \mathrm{H}), 7.75(\mathrm{dt}, J=7.9,6.0 \mathrm{~Hz}, 1 \mathrm{H})$, $7.63(\mathrm{dd}, J=8.3,1.9 \mathrm{~Hz}, 1 \mathrm{H}), 7.527 .50(\mathrm{~m}, 1 \mathrm{H}), 7.41(\mathrm{dd}, J=8.3,2.0 \mathrm{~Hz}$, $1 \mathrm{H}), 7.32(\mathrm{dt}, J=7.6 \mathrm{~Hz}, 1 \mathrm{H}), 7.087 .06(\mathrm{~m}, 1 \mathrm{H}), 6.55(\mathrm{dd}, J=6.6 \mathrm{~Hz}$, $1 \mathrm{H}), 6.21(\mathrm{~s}, 2 \mathrm{H}), 4.554 .53(\mathrm{~m}, 1 \mathrm{H}), 3.99(\mathrm{~s}, 2 \mathrm{H}), 3.923 .65(\mathrm{~m}, 3 \mathrm{H})$, $3.21(\mathrm{dd}, J=6.8 \mathrm{~Hz}, 1 \mathrm{H}), 2.112 .09(\mathrm{~m}, 1 \mathrm{H}), 0.87(\mathrm{~s}, 9 \mathrm{H}), 0.84(\mathrm{~s}, 9 \mathrm{H})$, 0.09 (s, 6H), 0.08 (s, 3H), $0.01 \mathrm{ppm} \quad(\mathrm{s}, 3 \mathrm{H}) ;{ }^{13} \mathrm{C}$ NMR $(101 \mathrm{MHz}$, [D $]$ DMSO): $\delta=158.3,157.3,152.3,149.8,143.9,143.5,140.9,140.1$, 137.0, 126.9, 125.4, 124.8, 120.1, 118.9, 115.9, 113.4, 110.3, 87.2, 83.0, 72.6, $63.1,57.9,36.9,25.8,17.9, \quad 4.7, \quad 5.4 \mathrm{ppm}$; IR: $(\mathrm{KBr}): \tilde{v}=3357,2952$, 2928, 1684, 1591, 1562, 1456, 1359, 1256, $836 \mathrm{~cm}^{1}$; MS (HRFAB): $\mathrm{m} / \mathrm{z}$ : calcd 674.3432 , found $675.3483\left[M+\mathrm{H}^{+}\right]$

General procedure III for the desilylation and $\boldsymbol{N}^{2}$-formamidine protection of $8 \mathrm{~N}$-arylamino-3', $\mathbf{5}^{\prime}$-bis(tert-butyldimethylsilyl)-2'-deoxyguanosine derivatives: The $8 N$ arylamino $3^{\prime}, 5^{\prime}$ bis (tert butyldimethylsilyl) $2^{\prime}$ deoxy guanosine derivative was dissolved in dichloromethane/tetrahydrofuran 1:1 and triethylamine (10 equiv) and triethylamine trihydrofluoride (12.5 equiv) were added. The resulting mixture was stirred at room tem perature until the reaction was complete (TLC analysis). After the sol vent had been removed in vacuo, the residue was purified by chromatog raphy. The crude product, containing the deprotected adduct and triethyl ammonium salts, was subjected to co evaporation of the volatiles with pyridine and was then dissolved in dry pyridine. Dimethylformamide di ethyl acetal ( 2 equiv) was then added and the mixture was stirred at room temperature for $16 \mathrm{~h}$. Thereafter, the solvent was removed in vacuo and the residue was purified by chromatography eluting with methanol $(0 \rightarrow 30 \%)$ in dichloromethane.

$\boldsymbol{N}^{\mathbf{2}}$-Formamidino-8 $\boldsymbol{N}$-(phenylamino)-2'-deoxyguanosine (14a): GP III was conducted with $13 \mathrm{a}(1.41 \mathrm{~g}, 2.40 \mathrm{mmol}$; reaction time $5 \mathrm{~h}$ for the first step), which afforded a slightly yellow solid (800 mg, $81 \%$ ). M.p. $161{ }^{\circ} \mathrm{C}$; $[\alpha]_{546}^{20}=+18.8^{\circ} \quad\left(c=1.2, \quad \mathrm{CH}_{2} \mathrm{Cl}_{2} / \mathrm{MeOH}\right) ; \quad{ }^{1} \mathrm{H}$ NMR $\quad(400 \mathrm{MHz}$, $\left.\left[\mathrm{D}_{6}\right] \mathrm{DMSO}\right): \delta=11.26(\mathrm{~s}, 1 \mathrm{H}), 8.72(\mathrm{~s}, 1 \mathrm{H}), 8.53(\mathrm{~s}, 1 \mathrm{H}), 7.74(\mathrm{dd}, J=$ $7.7 \mathrm{~Hz}, 2 \mathrm{H}), 7.267 .21(\mathrm{~m}, 2 \mathrm{H}), 6.92(\mathrm{dd}, J=6.8,7.5 \mathrm{~Hz}, 1 \mathrm{H}), 6.44(\mathrm{dd}$, $J=5.6,9.3 \mathrm{~Hz}, 1 \mathrm{H}), 5.87(\mathrm{dd}, J=4.8,4.8 \mathrm{~Hz}, 1 \mathrm{H}), 5.39(\mathrm{~d}, J=3.9 \mathrm{~Hz}$, $1 \mathrm{H}), 4.464 .44(\mathrm{~m}, 1 \mathrm{H}), 3.92(\mathrm{~d}, J=2.2 \mathrm{~Hz}, 2 \mathrm{H}), 3.76(\mathrm{dd}, J=12.0$, $4.6 \mathrm{~Hz}, 1 \mathrm{H}), 3.17$ (d, J=5.6 Hz, 1H), 3.15 (s, 3 H), 3.02 (s, 3H), 2.09 $2.04 \mathrm{ppm}(\mathrm{m}, 1 \mathrm{H}) ;{ }^{13} \mathrm{C} \mathrm{NMR}\left(101 \mathrm{MHz},\left[\mathrm{D}_{6}\right] \mathrm{DMSO}\right): \delta=157.1,156.2$, 155.5, 147.7, 143.9, 140.3, 128.1, 120.4, 117.1, 115.2, 86.8, 82.3, 70.7, 60.8, 38.0, $34.2 \mathrm{ppm}$; IR (KBr): $\tilde{v}=3265,1115,991,960,915,859,504 \mathrm{~cm}^{1}$; MS (HRFAB): $m / z$ : calcd for: 414.1812, found $415.2543\left[M+\mathrm{H}^{+}\right]$.

$\boldsymbol{N}^{2}$-Formamidino-8 $\boldsymbol{N}$-(4-methylphenylamino)-2'-deoxyguanosine $\quad$ (14b): GP III was conducted with $\mathbf{1 3 b}(1.30 \mathrm{~g}, 2.16 \mathrm{mmol}$; reaction time $4 \mathrm{~h}$ for the first step), which afforded a slightly yellow solid (590 mg, 72\%). M.p. $182^{\circ} \mathrm{C} ;[\alpha]_{546}^{20}=+28.5^{\circ}\left(c=0.33, \mathrm{CH}_{2} \mathrm{Cl}_{2} / \mathrm{MeOH}\right) ;{ }^{1} \mathrm{H}$ NMR $(400 \mathrm{MHz}$, $\left.\left[\mathrm{D}_{6}\right] \mathrm{DMSO}\right): \delta=11.24(\mathrm{~s}, 1 \mathrm{H}), 8.64(\mathrm{~s}, 1 \mathrm{H}), 8.52(\mathrm{~s}, 1 \mathrm{H}), 7.63(\mathrm{~d}, J=$ $8.5 \mathrm{~Hz}, 2 \mathrm{H}), 7.06(\mathrm{~d}, J=8.4 \mathrm{~Hz}, 2 \mathrm{H}), 6.42(\mathrm{dd}, J=9.4,5.9 \mathrm{~Hz}, 1 \mathrm{H}), 5.87$ $(\mathrm{dd}, J=4.7 \mathrm{~Hz}, 1 \mathrm{H}), 5.39(\mathrm{~d}, J=3.8 \mathrm{~Hz}, 1 \mathrm{H}), 4.474 .45(\mathrm{~m}, 1 \mathrm{H}), 3.94$ $3.91(\mathrm{~m}, 1 \mathrm{H}), 3.793 .75(\mathrm{~m}, 2 \mathrm{H}), 3.01(\mathrm{~s}, 3 \mathrm{H}), 3.14(\mathrm{~s}, 3 \mathrm{H}), 2.57$ (ddd, $J=$ 13.1, 9.5, 6.4 Hz, 1 H), $2.24(\mathrm{~s}, 3 \mathrm{H}), 1.992 .01 \mathrm{ppm}(\mathrm{m}, 1 \mathrm{H}) ;{ }^{13} \mathrm{C} \mathrm{NMR}$ (101 MHz, [D 6 DMSO): $\delta=157.5,156.5,155.8,148.1,144.5,138.2,129.5$, $128.9,117.6,115.6,87.2,82.7,71.1,61.2,38.3,34.6,20.3$ ppm; IR (KBr): $\tilde{v}=3307, \quad 1667,1632,1533,1344,1114,1061,960,819 \mathrm{~cm}^{1}$; MS (HRFAB): $m / z$ : calcd for: 427.1968 , found $428.2046\left[M+\mathrm{H}^{+}\right]$.

$N^{2}$-Formamidino-8 $N$-(4-methoxyphenylamino)-2'-deoxyguanosine (14c): GP III was conducted with $\mathbf{1 3 c}(1.14 \mathrm{~g}, 1.86 \mathrm{mmol}$; reaction time $2 \mathrm{~h}$ for the first step), which afforded a white solid $(680 \mathrm{mg}, 76 \%)$. M.p. $124^{\circ} \mathrm{C}$; $[\alpha]_{546}^{20}=+8.4^{\circ}\left(c=0.8, \mathrm{CH}_{2} \mathrm{Cl}_{2} / \mathrm{MeOH}\right) ;{ }^{1} \mathrm{H}$ NMR $\left(400 \mathrm{MHz},\left[\mathrm{D}_{6}\right] \mathrm{DMSO}\right)$ : $\delta=11.21(\mathrm{~s}, 1 \mathrm{H}), 8.57(\mathrm{~s}, 1 \mathrm{H}), 8.51(\mathrm{~s}, 1 \mathrm{H}), 7.64(\mathrm{~d}, J=9.0 \mathrm{~Hz}, 2 \mathrm{H}), 6.85$ $(\mathrm{d}, J=9.0 \mathrm{~Hz}, 2 \mathrm{H}), 6.42(\mathrm{dd}, J=9.4,5.9 \mathrm{~Hz}, 1 \mathrm{H}), 5.86(\mathrm{dd}, J=4.8 \mathrm{~Hz}$, $1 \mathrm{H}), 5.37(\mathrm{~d}, J=3.8 \mathrm{~Hz}, 1 \mathrm{H}), 4.44(\mathrm{ddd}, J=5.7 \mathrm{~Hz}, 1 \mathrm{H}), 3.91(\mathrm{ddd}, J=$ $5.7 \mathrm{~Hz}, 2 \mathrm{H}), 3.73$ (dd, $J=13.2,5.5 \mathrm{~Hz}, 1 \mathrm{H}), 3.71(\mathrm{~s}, 3 \mathrm{H}), 3.40$ (ddd, $J=$ $13.8,6.6 \mathrm{~Hz}, 1 \mathrm{H}), 3.14(\mathrm{~s}, 3 \mathrm{H}), 3.01(\mathrm{~s}, 3 \mathrm{H}), 2.04 \mathrm{ppm}(\mathrm{ddd}, J=12.6$, $5.9 \mathrm{~Hz}, 1 \mathrm{H}) ;{ }^{13} \mathrm{C}$ NMR $\left(101 \mathrm{MHz},\left[\mathrm{D}_{6}\right] \mathrm{DMSO}\right): \delta=158.3,156.1,153.8$ $153.3,149.9,144.1,120.8,119.3,113.9,112.0,87.5,83.0,71.7,61.7,55.4$ 38.5, $34.7 \mathrm{ppm}$; IR (KBr): $\tilde{v}=3338,3161,2944,2910,1651,1599,1531$, 1475, 1361, 1139, 1038, $776 \mathrm{~cm}^{1}$; MS (HRFAB): $\mathrm{m} / \mathrm{z}$ : calcd for: 443.4699 , found $444.4802\left[M+\mathrm{H}^{+}\right]$.

\section{$\boldsymbol{N}^{2}$-Formamidino-8 $\boldsymbol{N}$-(3,5-dimethylphenylamino)-2'-deoxyguanosine}

(14d): GP III was conducted with $\mathbf{1 3 d}(1.17 \mathrm{~g}, 1.75 \mathrm{mmol}$; reaction time $5 \mathrm{~h}$ for the first step), which afforded a yellow solid (280 mg, 46\%). M.p. $151^{\circ} \mathrm{C} ;[\alpha]_{546}^{20}=10^{\circ}\left(c=1.0, \mathrm{CHCl}_{3}\right) ;{ }^{1} \mathrm{H} \mathrm{NMR}\left(400 \mathrm{MHz},\left[\mathrm{D}_{6}\right] \mathrm{DMSO}\right):$ $\delta=11.23(\mathrm{~s}, 1 \mathrm{H}), 8.50(\mathrm{~s}, 1 \mathrm{H}), 8.49(\mathrm{~s}, 1 \mathrm{H}), 7.30(\mathrm{~s}, 2 \mathrm{H}), 6.53(\mathrm{~s}, 1 \mathrm{H})$, $6.39(\mathrm{dd}, J=5.9,6.7 \mathrm{~Hz}, 1 \mathrm{H}), 5.81(\mathrm{dd}, J=4.6,9.2 \mathrm{~Hz}, 1 \mathrm{H}), 5.34(\mathrm{~d}, J=$ $3.9 \mathrm{~Hz}, 1 \mathrm{H}), 4.444 .42(\mathrm{~m}, 1 \mathrm{H}), 3.88(\mathrm{~d}, J=2.3 \mathrm{~Hz}, 1 \mathrm{H}), 3.733 .68(\mathrm{~m}$ $2 \mathrm{H}), 3.12(\mathrm{~s}, 3 \mathrm{H}), 2.99(\mathrm{~s}, 3 \mathrm{H}), 2.522 .39(\mathrm{~m}, 1 \mathrm{H}), 2.20(\mathrm{~s}, 6 \mathrm{H}), 2.04$ $1.99 \mathrm{ppm}(\mathrm{m}, 1 \mathrm{H}) ;{ }^{13} \mathrm{C} \mathrm{NMR}\left(101 \mathrm{MHz},\left[\mathrm{D}_{6}\right] \mathrm{DMSO}\right): \delta=158.6,157.8$, $156.8,156.6,148.5,144.5,140.8,137.6,122.3,115.6,87.3,82.1,71.2,61.3$ $38.5,34.8,21.5 \mathrm{ppm}$; IR $(\mathrm{KBr}): \tilde{v}=3302,2921,1675,1630,1560,1345$, $1113 \mathrm{~cm}^{1}$; MS (HRFAB): $\mathrm{m} / \mathrm{z}$ : calcd for: 441.2120, found 442.2221 $\left[M+\mathrm{H}^{+}\right]$.

$N^{2}$-Formamidino-8 $N$-(4-biphenylamino)-2'-deoxyguanosine (14e): GP III was conducted with $13 \mathrm{e}(600 \mathrm{mg}, 0.90 \mathrm{mmol}$; reaction time $3 \mathrm{~h}$ for the first step), which afforded a white solid $(332 \mathrm{mg}, 64 \%)$. M.p. $245^{\circ} \mathrm{C}$; $[\alpha]_{546}^{20}=+28.9^{\circ} \quad\left(c=0.5, \quad \mathrm{CH}_{2} \mathrm{Cl}_{2} / \mathrm{MeOH}\right) ; \quad{ }^{1} \mathrm{H} \mathrm{NMR} \quad(400 \mathrm{MHz}$, [D $]$ DMSO): $\delta=11.28(\mathrm{~s}, 1 \mathrm{H}), 8.68(\mathrm{~s}, 1 \mathrm{H}), 8.57(\mathrm{~s}, 1 \mathrm{H}), 7.85(\mathrm{~d}, J=$ $8.3 \mathrm{~Hz}, 2 \mathrm{H}), 7.63(\mathrm{dd}, J=8.3 \mathrm{~Hz}, 4 \mathrm{H}), 7.42(\mathrm{dd}, J=7.6 \mathrm{~Hz}, 2 \mathrm{H}), 7.29$ (dd, $J=7.6 \mathrm{~Hz}, 1 \mathrm{H}), 6.46(\mathrm{dd}, J=9.3,5.9 \mathrm{~Hz}, 1 \mathrm{H}), 5.93(\mathrm{~s}, 1 \mathrm{H}), 5.40(\mathrm{~s}, 1 \mathrm{H})$ $4.494 .47(\mathrm{~m}, 1 \mathrm{H}), 3.94(\mathrm{dd}, J=12.1 \mathrm{~Hz}, 1 \mathrm{H}), 3.793 .77(\mathrm{~m}, 3 \mathrm{H}), 3.07$ (s, $3 \mathrm{H}), 3.06(\mathrm{~s}, 3 \mathrm{H}), 2.08 \mathrm{ppm}(\mathrm{ddd}, J=13.0,5.9 \mathrm{~Hz}, 1 \mathrm{H}) ;{ }^{13} \mathrm{C}$ NMR (101 MHz, [D 6 DMSO): $\delta=157.7,156.7,156.0,149.7,148.3,140.4,140.1$, $132.7,129.0,126.9,126.8,126.2,115.8,87.4,83.0,71.3,61.4,38.6$, 34.8 ppm; IR (KBr): $\tilde{v}=3346,3173,2954,2928,1647,1603,1537,1486$, 1383, 1169, 1075, $776 \mathrm{~cm}^{1}$; MS (HRFAB): $\mathrm{m} / \mathrm{z}$ : calcd for: 489.2125 , found $490.2229\left[M+\mathrm{H}^{+}\right]$

$N^{2}$-Formamidino-8 $N$-(2-aminofluorenyl)-2'-deoxyguanosine (14 f): GP III was conducted with $\mathbf{1 3}$ f $(1.35 \mathrm{~g}, 2.00 \mathrm{mmol}$; reaction time $5 \mathrm{~h}$ for the first step), which afforded a slightly red solid $(237 \mathrm{mg}, 31 \%)$. M.p. $209^{\circ} \mathrm{C}$; $[\alpha]_{546}^{20}=+5^{\circ}\left(c=0.1, \mathrm{CH}_{2} \mathrm{Cl}_{2} / \mathrm{MeOH}\right) ;{ }^{1} \mathrm{H} \mathrm{NMR}\left(400 \mathrm{MHz},\left[\mathrm{D}_{6}\right] \mathrm{DMSO}\right):$ $\delta=11.30(\mathrm{~s}, 1 \mathrm{H}), 8.83(\mathrm{~s}, 1 \mathrm{H}), 8.53(\mathrm{~s}, 1 \mathrm{H}), 8.11(\mathrm{~d}, J=1.3 \mathrm{~Hz}, 1 \mathrm{H}), 7.79$ $7.77(\mathrm{~m}, 2 \mathrm{H}), 7.68(\mathrm{dd}, J=8.4,1.8 \mathrm{~Hz}, 1 \mathrm{H}), 7.53(\mathrm{~d}, J=7.4 \mathrm{~Hz}, 1 \mathrm{H}), 7.33$ $(\mathrm{t}, J=7.4 \mathrm{~Hz}, 1 \mathrm{H}), 7.22(\mathrm{dt}, J=7.4,7.4,1.0 \mathrm{~Hz}, 1 \mathrm{H}), 6.34(\mathrm{dd}, J=6.0$, $9.3 \mathrm{~Hz}, 1 \mathrm{H}), 5.96(\mathrm{t}, J=4.7 \mathrm{~Hz}, 1 \mathrm{H}), 5.41(\mathrm{~d}, J=3.7 \mathrm{~Hz}, 1 \mathrm{H}), 4.504 .48$ $(\mathrm{m}, 1 \mathrm{H}), 3.993 .94(\mathrm{~m}, 1 \mathrm{H}), 3.90(\mathrm{~s}, 2 \mathrm{H}), 3.833 .79(\mathrm{~m}, 2 \mathrm{H}), 3.15(\mathrm{~s}, 3 \mathrm{H})$, $3.02(\mathrm{~s}, 3 \mathrm{H}), 2.652 .61(\mathrm{~m}, 1 \mathrm{H}), 2.152 .08 \mathrm{ppm}(\mathrm{m}, 1 \mathrm{H}) ;{ }^{13} \mathrm{C} \mathrm{NMR}$ (101 MHz, [D 6 DMSO): $\delta=157.5,156.6,155.9,152.8,148.1,144.2,143.8$, $142.4,141.4,139.9,134.1,126.7,125.4,124.9,120.0,119.0,116.5,115.6$ $114.0,87.2,82.8,71.1,61.3,48.6,36.5,34.6 \mathrm{ppm}$; IR (KBr): $\tilde{v}=3283,2923$, $1673,1630,1343,1113,1058,946,731 \mathrm{~cm}^{1}$; MS (HRFAB): $\mathrm{m} / \mathrm{z}:$ calcd 501.2203, found $502.2237\left[M+\mathrm{H}^{+}\right]$

General procedure IV for the $\mathbf{5}^{\prime}$ - $\boldsymbol{O}$-dimethoxytritylation of $\boldsymbol{N}^{2}$-formamidino-8 $N$-arylamino-2'-deoxyguanosine derivatives: The $N^{2}$ formamidino $8 \mathrm{~N}$ arylamino $2^{\prime}$ deoxyguanosine derivative was twice subjected to co evaporation of the volatiles with pyridine and then dissolved in dry pyri dine. Dimethoxytrityl chloride ( 2 equiv) was then added and the resulting mixture was stirred at room temperature until the reaction was complete (TLC analysis). The reaction was stopped by adding saturated aqueous $\mathrm{NaHCO}_{3}$ solution. The layers were separated and the aqueous layer was extracted three times with $\mathrm{CH}_{2} \mathrm{Cl}_{2}$. The combined organic layers were dried over sodium sulfate and the solvent was removed in vacuo. Purifi 
cation of the residue by chromatography on silica gel eluting with metha nol $(0 \rightarrow 10 \%)$ in dichloromethane furnished the desired product.

$\boldsymbol{N}^{\mathbf{2}}$-Formamidino-8 $\boldsymbol{N}$-(phenylamino)-5' $\boldsymbol{O}$-dimethoxytrityl-2' -deoxyguanosine (15a): GP IV was conducted with 14 a $(542 \mathrm{mg}, 1.31 \mathrm{mmol}$; reaction time $3.5 \mathrm{~h})$, which afforded a slightly yellow solid $(737 \mathrm{mg}, 79 \%)$. M.p. $168^{\circ} \mathrm{C} ;[\alpha]_{546}^{20}=2.9^{\circ}\left(c=1.0, \mathrm{CHCl}_{3}\right) ;{ }^{1} \mathrm{H} \mathrm{NMR}\left(400 \mathrm{MHz},\left[\mathrm{D}_{6}\right] \mathrm{DMSO}\right)$ : $\delta=11.30(\mathrm{~s}, 1 \mathrm{H}), 8.69(\mathrm{~s}, 1 \mathrm{H}), 8.23(\mathrm{~s}, 1 \mathrm{H}), 7.66(\mathrm{dd}, J=7.7 \mathrm{~Hz}, 2 \mathrm{H})$, $7.60(\mathrm{dd}, J=7.7 \mathrm{~Hz}, 1 \mathrm{H}), 7.337 .30(\mathrm{~m}, 2 \mathrm{H}), 7.207 .13(\mathrm{~m}, 13 \mathrm{H}), 6.37$ $(\mathrm{dd}, J=5.0,7.7 \mathrm{~Hz}, 1 \mathrm{H}), 5.365 .35(\mathrm{~m}, 1 \mathrm{H}), 4.59(\mathrm{ddd}, J=5.5 \mathrm{~Hz}, 1 \mathrm{H})$, 3.90 (ddd, $J=3.1,6.8,6.9 \mathrm{~Hz}, 2 \mathrm{H}), 3.703 .68$ (m, 7H), 3.17 (d, $J=4.6 \mathrm{~Hz}$, $1 \mathrm{H}), 2.99(\mathrm{~s}, 3 \mathrm{H}), 2.97(\mathrm{~s}, 3 \mathrm{H}), 2.242 .20 \mathrm{ppm}(\mathrm{m}, 1 \mathrm{H}) ;{ }^{13} \mathrm{C} \mathrm{NMR}$ (101 MHz, [D $\mathrm{D}_{6}$ DMSO): $\delta=157.2,156.7,156.5,156.4,155.6,155.2,155.0$, $154.7,153.7,153.4,146.7,146.3,143.6,128.4,128.3,128.2,128.1,128.0$, $127.8,127.1,126.5,126.4,126.2,126.1,125.1,119.1,115.7,115.4,111.8$, 111.5, 84.0, 83.9, 81.0, 62.6, 36.1, $33.1 \mathrm{ppm}$; IR (KBr): $\tilde{v}=2931,2835,914$, 790, 777, 727, 583, 555, $503 \mathrm{~cm}^{1}$; MS (HRFAB): $\mathrm{m} / \mathrm{z}$ : calcd for: 715.3118 , found $716.3202\left[M+\mathrm{H}^{+}\right]$.

$\boldsymbol{N}^{2}$-Formamidino-8 $\boldsymbol{N}$-(4-methylphenylamino)-5' $-O$-dimethoxytrityl-2'-deoxyguanosine (15b): GP IV was conducted with 14b $(500 \mathrm{mg}, 1.16 \mathrm{mmol}$; reaction time $5 \mathrm{~h})$, which afforded a white solid $(675 \mathrm{mg}, 81 \%)$. M.p. $165^{\circ} \mathrm{C} ;[\alpha]_{546}^{20}=9.7^{\circ}\left(c=0.69, \mathrm{CHCl}_{3}\right) ;{ }^{1} \mathrm{H}$ NMR $\left(400 \mathrm{MHz},\left[\mathrm{D}_{6}\right] \mathrm{DMSO}\right)$ : $\delta=11.27(\mathrm{~s}, 1 \mathrm{H}), 8.56(\mathrm{~s}, 1 \mathrm{H}), 8.23(\mathrm{~s}, 1 \mathrm{H}), 7.56(\mathrm{~d}, J=8.5 \mathrm{~Hz}, 2 \mathrm{H}), 7.28$ $7.13(\mathrm{~m}, 8 \mathrm{H}), 7.06(\mathrm{~d}, J=8.4 \mathrm{~Hz}, 2 \mathrm{H}), 6.776 .68(\mathrm{~m}, 5 \mathrm{H}), 6.42(\mathrm{dd}, J=$ 7.7, $5.1 \mathrm{~Hz}, 1 \mathrm{H}), 5.34(\mathrm{~d}, J=3.8 \mathrm{~Hz}, 1 \mathrm{H}), 4.504 .48(\mathrm{~m}, 1 \mathrm{H}), 3.933 .90$ $(\mathrm{m}, 1 \mathrm{H}), 3.773 .72(\mathrm{~m}, 2 \mathrm{H}), 3.67(\mathrm{~s}, 6 \mathrm{H}), 3.213 .19(\mathrm{~m}, 1 \mathrm{H}), 2.99(\mathrm{~s}, 3 \mathrm{H})$, $2.96(\mathrm{~s}, 3 \mathrm{H}), 2.24(\mathrm{~s}, 3 \mathrm{H}), 2.19 \mathrm{ppm}(\mathrm{ddd}, J=12.3,6.7 \mathrm{~Hz}, 1 \mathrm{H}) ;{ }^{13} \mathrm{C}$ NMR (101 MHz, [D $\mathrm{D}_{6}$ DMSO): $\delta=157.9,157.8,157.0,156.6,155.1,148.1,144.9$, $138.7,135.5,129.6,129.5,129.3,128.9,127.6,126.5,117.4,116.8,112.9$, 85.4, 82.3, 70.6, 64.0, 54.9, 37.5, 34.5, $20.3 \mathrm{ppm}$; IR (KBr): $\tilde{v}=3361,2927$, 1674, 1628, 1527, 1342, 1247, $827 \mathrm{~cm}^{1}$; MS (HRFAB): $\mathrm{m} / z$ : calcd for: 729.3275 , found $730.3353\left[M+\mathrm{H}^{+}\right]$.

$\boldsymbol{N}^{2}$-Formamidino-8 $\boldsymbol{N}$-(4-methoxyphenylamino)-5'-O-dimethoxytrityl-2'deoxyguanosine (15c): GP IV was conducted with $\mathbf{1 4 c}(650 \mathrm{mg}$, $1.46 \mathrm{mmol}$; reaction time $3.5 \mathrm{~h})$, which afforded a white solid $(850 \mathrm{mg}$, $79 \%$ ). M.p. $131^{\circ} \mathrm{C} ;[\alpha]_{546}^{20}=10.6^{\circ}\left(c=0.76, \mathrm{CHCl}_{3}\right) ;{ }^{1} \mathrm{H}$ NMR $(400 \mathrm{MHz}$, [D $\mathrm{D}_{6}$ DMSO): $\delta=11.24(\mathrm{~s}, 1 \mathrm{H}), 8.47(\mathrm{~s}, 1 \mathrm{H}), 8.22(\mathrm{~s}, 1 \mathrm{H}), 7.60(\mathrm{~d}, J=$ $9.0 \mathrm{~Hz}, 2 \mathrm{H}), 7.267 .13(\mathrm{~m}, 10 \mathrm{H}), 6.86(\mathrm{~d}, J=9.0 \mathrm{~Hz}, 2 \mathrm{H}), 6.756 .70(\mathrm{~m}$, $5 \mathrm{H}), 6.42(\mathrm{dd}, J=7.5,5.1 \mathrm{~Hz}, 1 \mathrm{H}), 5.34(\mathrm{~d}, J=5.4 \mathrm{~Hz}, 1 \mathrm{H}), 4.58(\mathrm{ddd}, J=$ $5.4 \mathrm{~Hz}, 1 \mathrm{H}), 4.09$ (ddd, $J=5.2,5.4 \mathrm{~Hz}, 2 \mathrm{H}), 3.73(\mathrm{dd}, J=13.2,5.5 \mathrm{~Hz}$, $1 \mathrm{H}), 3.71(\mathrm{~s}, 3 \mathrm{H}), 3.68$ (s, 6 H), 3.40 (ddd, $J=13.8,6.6 \mathrm{~Hz}, 1 \mathrm{H}), 3.17$ (s, $3 \mathrm{H}), 3.16(\mathrm{~s}, 3 \mathrm{H}), 2.32 \mathrm{ppm}$ (ddd, $J=12.6,5.4 \mathrm{~Hz}, 1 \mathrm{H}) ;{ }^{13} \mathrm{C} \mathrm{NMR}$ (101 MHz, [D $\mathrm{D}_{6}$ DMSO): $\delta=158.3,156.1,153.8,153.3,149.9,144.1,140.6$, $139.9,135.8,135.7,132.6,129.7,129.6,128.9,127.8,127.4,126.8,126.6$, $126.4,126.0,120.8,119.2,113.9,113.1,87.5,83.0,71.7,61.7,55.4,38.5$, $34.7 \mathrm{ppm}$; IR (KBr): $\tilde{v}=3423,3041,2982,1638,1476,1037 \mathrm{~cm}^{1}$; MS (HRFAB): $m / z$ : calcd for: 745.3224 , found $746.3215\left[M+\mathrm{H}^{+}\right]$.

$\boldsymbol{N}^{2}$-Formamidino-8 $\boldsymbol{N}$-(3,5-dimethylphenylamino)-5' $-O$-dimethoxytrityl-2' deoxyguanosine (15d): GP IV was conducted with 14d (280 mg, $0.64 \mathrm{mmol}$; reaction time $12 \mathrm{~h}$ ), which afforded a white solid (383 mg, $82 \%)$. M.p. $164^{\circ} \mathrm{C} ;[\alpha]_{546}^{20}=+10^{\circ}\left(c=1.0, \mathrm{CHCl}_{3}\right) ;{ }^{1} \mathrm{H} \mathrm{NMR}(400 \mathrm{MHz}$, [D $\left.\mathrm{D}_{6} \mathrm{DMSO}\right): \delta=11.25(\mathrm{~s}, 1 \mathrm{H}), 8.41(\mathrm{~s}, 1 \mathrm{H}), 8.20(\mathrm{~s}, 1 \mathrm{H}), 8.05(\mathrm{~s}, 1 \mathrm{H})$, $7.247 .10(\mathrm{~m}, 11 \mathrm{H}), 6.68(\mathrm{dd}, J=8.9,4.6 \mathrm{~Hz}, 4 \mathrm{H}), 6.29(\mathrm{dd}, J=5.1$, $2.6 \mathrm{~Hz}, 1 \mathrm{H}), 5.28(\mathrm{~d}, J=4.8 \mathrm{~Hz}, 1 \mathrm{H}), 4.52(\mathrm{dd}, J=5.7,6.2 \mathrm{~Hz}, 1 \mathrm{H}), 3.86$ $3.82(\mathrm{~m}, 2 \mathrm{H}), 3.64(\mathrm{~d}, J=1.1 \mathrm{~Hz}, 6 \mathrm{H}), 3.12(\mathrm{~d}, J=5.2 \mathrm{~Hz}, 1 \mathrm{H}), 2.94(\mathrm{~d}$, $J=8.9 \mathrm{~Hz}, 6 \mathrm{H}), 2.18(\mathrm{~s}, 7 \mathrm{H}), 1.991 .86(\mathrm{~m}, 1 \mathrm{H}) ;{ }^{13} \mathrm{C} \mathrm{NMR}(101 \mathrm{MHz}$, $\left.\left[\mathrm{D}_{6}\right] \mathrm{DMSO}\right): \delta=159.3,159.2,159.1,158.6,158.4,156.3,152.3,149.5$, $148.0,146.6,146.3,136.1,130.6,129.8,128.8,118.9,117.8,113.7,113.6$, 85.9, 85.3, 80.0, 64.4, 54.9, 34.9, 24.7, 20.0 ppm; IR (KBr): $\tilde{v}=3366,2921$, $1675,1629,1560,1342,1249,1113,1032,830 \mathrm{~cm}^{1}$; MS (HRFAB): $\mathrm{m} / \mathrm{z}$ : calcd for: 743.3430 , found $744.3407\left[M+\mathrm{H}^{+}\right]$.

$\boldsymbol{N}^{\mathbf{2}}$-Formamidino-8 $\boldsymbol{N}$-(4-biphenylamino)-5' $\boldsymbol{O} \boldsymbol{O}$-dimethoxytrityl-2'-deoxyguanosine (15e): GP IV was conducted with 14e $(182 \mathrm{mg}, 0.37 \mathrm{mmol}$; re action time $3.5 \mathrm{~h})$, which afforded a white solid $(247 \mathrm{mg}, 84 \%)$. M.p. $120^{\circ} \mathrm{C} ;[\alpha]_{546}^{20}=15.4^{\circ}\left(c=0.5, \mathrm{CHCl}_{3}\right) ;{ }^{1} \mathrm{H}$ NMR $\left(400 \mathrm{MHz},\left[\mathrm{D}_{6}\right] \mathrm{DMSO}\right)$ : $\delta=11.29(\mathrm{~s}, 1 \mathrm{H}), 8.81(\mathrm{~s}, 1 \mathrm{H}), 8.24(\mathrm{~s}, 1 \mathrm{H}), 7.656 .70(\mathrm{~m}, 22 \mathrm{H}), 6.39(\mathrm{dd}$, $J=7.6,5.1 \mathrm{~Hz}, 1 \mathrm{H}), 5.375 .34(\mathrm{~m}, 1 \mathrm{H}), 4.60(\mathrm{ddd}, 1 \mathrm{H}), 3.91(\mathrm{dd}, J=$ $2.1 \mathrm{~Hz}, 1 \mathrm{H}), 3.753 .71(\mathrm{~m}, 3 \mathrm{H}), 3.67(\mathrm{~s}, 6 \mathrm{H}), 3.00(\mathrm{~s}, 3 \mathrm{H}), 2.98(\mathrm{~s}, 4 \mathrm{H})$, $2.22 \mathrm{ppm}(\mathrm{ddd}, J=5.1 \mathrm{~Hz}, 1 \mathrm{H}) ;{ }^{13} \mathrm{C}$ NMR $\left(101 \mathrm{MHz},\left[\mathrm{D}_{6}\right] \mathrm{DMSO}\right): \delta=$
$157.7,156.7,156.0,149.7,148.3,140.4,140.1,139.9,135.8,135.7,132.7$, $132.6,129.7,129.6,129.0,128.9,127.8,127.4,126.9,126.8,126.2,115.8$, 87.4, 83.0, 71.3, 61.4, 55.4, 38.6, 34.8 ppm; IR (KBr): $\tilde{v}=3380,2931,1672$, 1628, 1527, 1343, $1249 \mathrm{~cm}^{1}$; MS (HRFAB): $\mathrm{m} / \mathrm{z}$ : calcd for: 791.3431, found $792.3535\left[M+\mathrm{H}^{+}\right]$

$\boldsymbol{N}^{2}$-Formamidino-8 $\boldsymbol{N}$-(2-aminofluorenyl)-5' - $O$-dimethoxytrityl-2' -deoxyguanosine (15 f): GP IV was conducted with $14 \mathbf{f}(200 \mathrm{mg}, 0.39 \mathrm{mmol}$; re action time $3.5 \mathrm{~h}$ ), which afforded a slightly reddish solid $(247 \mathrm{mg}, 78 \%)$. M.p. $\quad 180^{\circ} \mathrm{C} ; \quad[\alpha]_{546}^{20}=11^{\circ} \quad\left(c=0.3, \quad \mathrm{CHCl}_{3}\right) ; \quad{ }^{1} \mathrm{H} \mathrm{NMR} \quad(400 \mathrm{MHz}$ [D $\mathrm{D}_{6}$ DMSO): $\delta=11.32(\mathrm{~s}, 1 \mathrm{H}), 8.79(\mathrm{~s}, 1 \mathrm{H}), 8.25(\mathrm{~s}, 1 \mathrm{H}), 8.03(\mathrm{~d}, J=$ $1.3 \mathrm{~Hz}, 1 \mathrm{H}), 7.787 .76(\mathrm{~m}, 2 \mathrm{H}), 7.56(\mathrm{dd}, J=8.4,2.0 \mathrm{~Hz}, 1 \mathrm{H}), 7.536 .65$ $(\mathrm{m}, 16 \mathrm{H}), 6.40(\mathrm{dd}, J=5.1,7.7 \mathrm{~Hz}, 1 \mathrm{H}), 5.35(\mathrm{~d}, J=3.6 \mathrm{~Hz}, 1 \mathrm{H}), 4.61$ $4.59(\mathrm{~m}, 1 \mathrm{H}), 3.963 .91(\mathrm{~m}, 1 \mathrm{H}), 3.88(\mathrm{~s}, 2 \mathrm{H}), 3.693 .67(\mathrm{~m}, 8 \mathrm{H}), 3.22$ $3.18(\mathrm{~m}, 1 \mathrm{H}), 3.00(\mathrm{~s}, 3 \mathrm{H}), 2.98(\mathrm{~s}, 3 \mathrm{H}), 2.272 .22 \mathrm{ppm}(\mathrm{m}, 1 \mathrm{H})$; ${ }^{13} \mathrm{C}$ NMR (101 MHz, [D $]$ DMSO): $\delta=157.9,157.8,157.0,156.7,155.9$, $152.8,148.2,145.0,143.8,142.4,141.4,140.0,135.6,134.9,133.9,129.6$, $129.5,126.7,126.5,125.5,124.9,120.1,119.0,116.9,116.2,113.6,112.9$, 85.5, 82.5, 70.6, 64.1, 54.9, 36.5, 34.5 ppm; IR (KBr): $\tilde{v}=3354,2928,1674$, 1628, 1455, 1424, 1342, 1175, 1031, 827, 765, $701 \mathrm{~cm}^{1}$; MS (HRFAB): $\mathrm{m} / \mathrm{z}$ : calcd 803.3431, found $804.3483\left[\mathrm{M}+\mathrm{H}^{+}\right]$.

General procedure $V$ for the phosphitylation of $N^{2}$-formamidino- $8 N$-arylamino-5'-O-dimethoxytrityl-2'-deoxyguanosine derivatives: The $N^{2}$ form amidino $8 N$ arylamino $2^{\prime}$ deoxyguanosine derivative was twice subjected to co evaporation of the volatiles with dry acetonitrile and then dissolved in a mixture of anhydrous acetonitrile and dry dichloromethane (1:1). A $0.25 \mathrm{~m}$ solution of dicyanoimidazole in anhydrous acetonitrile (1 equiv) and bis $N, N^{\prime}$ diisopropylamino ( 2 cyanoethyl)phosphite (1.5 equiv) were added. The resulting mixture was stirred at room temperature until the starting material could no longer be detected (TLC analysis). The reac tion was then stopped by adding saturated aqueous $\mathrm{NaHCO}_{3}$ solution. The layers were separated and the aqueous layer was extracted three times with $\mathrm{CH}_{2} \mathrm{Cl}_{2}$. The combined organic layers were dried over sodium sulfate and the solvent was removed in vacuo. Purification of the residue by chromatography on alumina furnished the desired product, which was obtained as a fine powder after lyophilization from benzene.

$N^{2}$-Formamidino-8N-(phenylamino)-5'-O-dimethoxytrityl-2'-deoxyguanosin-3'-yl- $\boldsymbol{\beta}$-cyanoethyl- $\boldsymbol{N}, \boldsymbol{N}^{\prime}$-diisopropylphosphoramidite (16a): GP V was conducted with $\mathbf{1 5} \mathbf{a}(200 \mathrm{mg}, 0.21 \mathrm{mmol}$; reaction time $1 \mathrm{~h})$, which afford ed a white solid $(140 \mathrm{mg}, 61 \%)$. M.p. $136^{\circ} \mathrm{C} ;[\alpha]_{546}^{20}=+7^{\circ} \quad(c=0.1$, $\left.\mathrm{CHCl}_{3}\right) ;{ }^{1} \mathrm{H}$ NMR: $\left(400 \mathrm{MHz}, \mathrm{C}_{6} \mathrm{D}_{6}\right): \delta=11.29(\mathrm{~s}, 2 \mathrm{H}), 8.36(\mathrm{~s}, 1 \mathrm{H}), 8.23$ $(\mathrm{s}, 1 \mathrm{H}), 7.626 .62(\mathrm{~m}, 38 \mathrm{H}), 6.41(\mathrm{dd}, J=6.1,6.1 \mathrm{~Hz}, 1 \mathrm{H}), 6.31(\mathrm{dd}, J=$ 6.3, $6.3 \mathrm{~Hz}, 1 \mathrm{H}), 4.894 .86(\mathrm{~m}, 1 \mathrm{H}), 4.854 .81(\mathrm{~m}, 1 \mathrm{H}), 4.414 .37(\mathrm{~m}$, $2 \mathrm{H}), 3.563 .30(\mathrm{~m}, 38 \mathrm{H}), 2.812 .77(\mathrm{~m}, 1 \mathrm{H}), 2.612 .58(\mathrm{~m}, 2 \mathrm{H}), 2.23$ (ddd, $1 \mathrm{H}), 1.85(\mathrm{dd}, J=6.1,6.1 \mathrm{~Hz}, 2 \mathrm{H}), 1.150 .96 \mathrm{ppm}(\mathrm{m}, 24 \mathrm{H})$; ${ }^{13} \mathrm{C}$ NMR $\left(101 \mathrm{MHz}, \mathrm{C}_{6} \mathrm{D}_{6}\right): \delta=178.7,159.3,159.2,158.2,147.6,147.5$, $145.3,145.3,136.3,133.2,130.9,130.8,130.7,130.6,130.5,129.3,128.8$, 128.7, 128.6, 128.4, 118.4, 118.2, 114.6, 113.7, 113.6, 87.1, 86.6, 85.6, 75.0, $74.8,74.0,73.8,64.1,64.0,58.7,58.6,58.5,58.5,55.1,54.9,54.8,43.6,43.6$, 43.5, 43.5, 38.6, 38.4, 37.7, 30.2, 24.8, 24.7, 24.6, 20.6, 20.5, $20.3 \mathrm{ppm;}$ ${ }^{31} \mathrm{P}$ NMR $\left(161 \mathrm{MHz}, \mathrm{C}_{6} \mathrm{D}_{6}\right): \delta=148.03,148.21 \mathrm{ppm}$; IR $(\mathrm{KBr}): \tilde{v}=3385$, 2964, 2930, 1628, 1527, 1509, 1344, 1250, 1032, $978 \mathrm{~cm}^{1}$; UV (MeCN): $\lambda_{\max }=345,256 \mathrm{~nm}$; MS (ESI): $\mathrm{m} / z$ : calcd for: 915.4197 , found 938.4091 $\left[M+\mathrm{Na}^{+}\right]$

$N^{2}$-Formamidino-8N-(4-methylphenylamino)-5'-O-dimethoxytrityl-2'-deoxyguanosin-3'-yl- $\beta$-cyanoethyl- $N, N^{\prime}$-diisopropylphosphoramidite $\quad(16 \mathbf{b})$ : GP V was conducted with $\mathbf{1 5 b}(50 \mathrm{mg}, 0.05 \mathrm{mmol}$; reaction time $1 \mathrm{~h})$, which afforded a white solid $(43 \mathrm{mg}, 68 \%)$. M.p. $111^{\circ} \mathrm{C} ;[\alpha]_{546}^{20}=21^{\circ}$ $\left(c=0.07, \mathrm{CHCl}_{3}\right) ;{ }^{1} \mathrm{H}$ NMR $\left(400 \mathrm{MHz}, \mathrm{C}_{6} \mathrm{D}_{6}\right): \delta=12.04(\mathrm{~s}, 2 \mathrm{H}), 8.47(\mathrm{~s}$ $1 \mathrm{H}), 8.42(\mathrm{~s}, 1 \mathrm{H}), 8.006 .66(\mathrm{~m}, 36 \mathrm{H}), 6.43(\mathrm{dd}, J=6.1,6.1 \mathrm{~Hz}, 1 \mathrm{H}), 6.39$ $(\mathrm{dd}, J=6.3,6.3 \mathrm{~Hz}, 1 \mathrm{H}), 5.045 .00(\mathrm{~m}, 1 \mathrm{H}), 4.944 .91(\mathrm{~m}, 1 \mathrm{H}), 4.374 .33$ $(\mathrm{m}, 2 \mathrm{H}), 3.513 .32(\mathrm{~m}, 38 \mathrm{H}), 2.892 .85(\mathrm{~m}, 1 \mathrm{H}), 2.622 .54(\mathrm{~m}, 8 \mathrm{H}), 2.05$ $(\mathrm{ddd}, 1 \mathrm{H}), 1.81(\mathrm{dd}, J=6.2,6.2 \mathrm{~Hz}, 1 \mathrm{H}), 1.761 .72(\mathrm{~m}, 1 \mathrm{H}), 1.15$ $1.10 \mathrm{ppm}(\mathrm{m}, 24 \mathrm{H}) ;{ }^{13} \mathrm{C}$ NMR $\left(101 \mathrm{MHz}, \mathrm{C}_{6} \mathrm{D}_{6}\right): \delta=159.2,158.3,155.5$, $155.4,148.1,147.1,145.3,145.3,136.1,135.9,133.9,133.8,130.6,130.5$, $129.7,128.8,127.2,127.2,120.4,120.3,118.9,118.8,117.3,116.1,114.6$, 113.6, 113.6, 87.1, 86.9, 85.6, 75.0, 74.8, 74.0, 73.8, 64.1, 64.0, 54.9, 43.6, 43.6, 43.5, 43.5, 40.7, 38.6, 38.4, 36.3, 30.2, 24.6, 20.8, 19.6 ppm; ${ }^{31} \mathrm{P}$ NMR $\left(161 \mathrm{MHz}, \mathrm{C}_{6} \mathrm{D}_{6}\right): \delta=148.93,148.87 \mathrm{ppm}$; IR $(\mathrm{KBr}): \tilde{v}=3853,3744,3675$, 
2927, 2219, 1669, 1628, 1528, 1249, $1115 \mathrm{~cm}^{1}$; UV (MeCN): $\lambda_{\max }=330$, $297 \mathrm{~nm}$; MS (ESI): $m / z$ : calcd for: 929.4353 , found $952.4256\left[\mathrm{M}^{\left.-\mathrm{Na}^{+}\right]}\right.$. $\boldsymbol{N}^{2}$-Formamidino-8 $\boldsymbol{N}$-(4-methoxyphenylamino)-5' $-O$-dimethoxytrityl-2' deoxyguanosin-3'-yl- $\beta$-cyanoethyl- $N, N^{\prime}$-diisopropylphosphoramidite (16c): GP V was conducted with 15 c $(200 \mathrm{mg}, 0.21 \mathrm{mmol}$; reaction time $1 \mathrm{~h})$, which afforded a white solid $(140 \mathrm{mg}, 61 \%)$. M.p. $122^{\circ} \mathrm{C} ;[\alpha]_{546}^{20}=$ $+15^{\circ}\left(c=0.1, \mathrm{CHCl}_{3}\right) ;{ }^{1} \mathrm{H}$ NMR $\left(400 \mathrm{MHz}, \mathrm{C}_{6} \mathrm{D}_{6}\right): \delta=10.99(\mathrm{~s}, 2 \mathrm{H}), 8.35$ $(\mathrm{s}, 1 \mathrm{H}), 8.31(\mathrm{~s}, 1 \mathrm{H}), 7.68(\mathrm{~s}, 1 \mathrm{H}), 7.66(\mathrm{~s}, 1 \mathrm{H}), 7.596 .71(\mathrm{~m}, 34 \mathrm{H}), 6.44$ (dd, $J=6.3,6.3 \mathrm{~Hz}, 1 \mathrm{H}), 6.37$ (dd, $J=6.6,6.6 \mathrm{~Hz}, 1 \mathrm{H}), 4.954 .92$ (m, $1 \mathrm{H}), 4.874 .85(\mathrm{~m}, 1 \mathrm{H}), 4.414 .36(\mathrm{~m}, 2 \mathrm{H}), 3.643 .16(\mathrm{~m}, 44 \mathrm{H}), 2.83$ $2.80(\mathrm{~m}, 1 \mathrm{H}), 2.602 .54(\mathrm{~m}, 2 \mathrm{H}), 2.20(\mathrm{ddd}, 1 \mathrm{H}), 1.89(\mathrm{dd}, J=6.2,6.2 \mathrm{~Hz}$, $1 \mathrm{H}), 1.861 .83(\mathrm{~m}, 1 \mathrm{H}), 1.241 .10 \mathrm{ppm}(\mathrm{m}, 24 \mathrm{H}) ;{ }^{13} \mathrm{C} \mathrm{NMR}(101 \mathrm{MHz}$, $\left.\mathrm{C}_{6} \mathrm{D}_{6}\right): \delta=178.7,159.3,159.2,158.3,155.5,155.4,147.6,147.5,145.3$, $145.3,136.1,136.0,136.0,135.9,133.9,133.8,130.7,130.6,130.6,130.5$, $128.8,128.7,128.6,128.3,128.2,128.0,127.2,127.2,120.4,120.3,118.9$, $118.8,118.2,114.6,113.6,113.6,87.1,86.6,86.5,86.4,86.3,86.2,85.6,75.0$, $74.8,74.0,73.8,64.1,64.0,58.8,58.6,58.6,58.5,55.2,54.9,54.9,43.6,43.6$, 43.5, 43.5, 38.6, 38.4, 37.7, 30.2, 24.8, 24.7, 24.6, 20.6, 20.5, 20.3 ppm; ${ }^{31} \mathrm{P}$ NMR (161 MHz, $\left.\mathrm{C}_{6} \mathrm{D}_{6}\right): \delta=147.34,148.63 \mathrm{ppm}$; IR $(\mathrm{KBr}): \tilde{v}=3411$, $2965,2360,1628,1527,1510,1344,1247,1114 \mathrm{~cm}^{1}$; UV $(\mathrm{MeCN}): \lambda_{\max }=$ 331, 258, $224 \mathrm{~nm}$; MS (ESI): $m / z$ : calcd for: 945.4302 , found 968.4191 $\left[M+\mathrm{Na}^{+}\right]$

\section{$N^{2}$-Formamidino-8 $N$-(3,5-dimethylphenylamino)-5'-O-dimethoxytrityl-2'} deoxyguanosin-3'-yl- $\beta$-cyanoethyl- $N, N^{\prime}$-diisopropylphosphoramidite (16d): GP V was conducted 15d with $(100 \mathrm{mg}, 0.22 \mathrm{mmol}$; reaction time $1 \mathrm{~h})$, which afforded a white solid $(122 \mathrm{mg}, 57 \%)$. M.p. $124^{\circ} \mathrm{C} ;[\alpha]_{546}^{20}=$ $28^{\circ}\left(c=0.1, \mathrm{CHCl}_{3}\right) ;{ }^{1} \mathrm{H} \mathrm{NMR}\left(400 \mathrm{MHz}, \mathrm{C}_{6} \mathrm{D}_{6}\right): \delta=11.61(\mathrm{~s}, 1 \mathrm{H})$, $11.43(\mathrm{~s}, 1 \mathrm{H}), 8.51(\mathrm{~s}, 1 \mathrm{H}), 8.43(\mathrm{~s}, 1 \mathrm{H}), 7.656 .54(\mathrm{~m}, 36 \mathrm{H}), 6.46(\mathrm{dd}, J=$ $5.5,5.5 \mathrm{~Hz}, 1 \mathrm{H}), 6.36(\mathrm{dd}, J=6.2,6.2 \mathrm{~Hz}, 1 \mathrm{H}), 5.024 .96(\mathrm{~m}, 1 \mathrm{H}), 4.85$ $4.79(\mathrm{~m}, 1 \mathrm{H}), 4.374 .33(\mathrm{~m}, 2 \mathrm{H}), 3.743 .33(\mathrm{~m}, 26 \mathrm{H}), 2.792 .59(\mathrm{~m}$, $13 \mathrm{H}), 2.462 .29(\mathrm{~m}, 3 \mathrm{H}), 2.16(\mathrm{~s}, 6 \mathrm{H}), 2.18(\mathrm{~s}, 6 \mathrm{H}), 1.941 .89(\mathrm{~m}, 2 \mathrm{H})$, $1.160 .91 \mathrm{ppm}(\mathrm{m}, 24 \mathrm{H}) ;{ }^{13} \mathrm{C}$ NMR $\left(101 \mathrm{MHz}, \mathrm{C}_{6} \mathrm{D}_{6}\right): \delta=159.3,159.2$, 158.4, 158.0, 156.2, 146.1, 145.4, 145.3, 140.9, 140.7, 138.7, 138.6, 136.1, $116.5,116.4,113.7,87.1,86.8,85.0,84.8,78.6,78.7,73.9,73.1,63.6,62.9$, 59.1, 57.2, 56.8, 54.9, 43.7, 43.6, 43.5, 41.1, 39.8, 34.8, 34.7, 24.7, 24.6, 24.5, 21.6, 21.5, 21.4, 20.6, 20.2, 20.1, 16.0 ppm; ${ }^{31} \mathrm{P} \mathrm{NMR}\left(161 \mathrm{MHz}, \mathrm{C}_{6} \mathrm{D}_{6}\right): \delta=$ 149.3, $148.7 \mathrm{ppm}$; IR (KBr): $\tilde{v}=3411,2965,1686,1629,1528,1341,1250$, $1103 \mathrm{~cm}^{1}$; MS (ESI): $\mathrm{m} / z$ : calcd for: 943.4510 , found $965.7158\left[M+\mathrm{Na}^{+}\right]$.

\section{$\boldsymbol{N}^{2}$-Formamidino-8 $\boldsymbol{N}$-(4-biphenylamino)-5' $\boldsymbol{O} \boldsymbol{O}$-dimethoxytrityl-2' -deoxy-} guanosin-3'-yl- $\beta$-cyanoethyl- $N, N^{\prime}$-diisopropylphosphoramidite $\quad(16 \mathrm{e})$ : GP V was conducted with 15 e $(45 \mathrm{mg}, 0.05 \mathrm{mmol}$; reaction time $1 \mathrm{~h})$, which afforded a yellow solid $(30 \mathrm{mg}, 60 \%)$. M.p. $64^{\circ} \mathrm{C} ;[\alpha]_{546}^{20}=+13^{\circ}$ $\left(c=0.1, \mathrm{CHCl}_{3}\right) ;{ }^{1} \mathrm{H}$ NMR $\left(400 \mathrm{MHz}, \mathrm{C}_{6} \mathrm{D}_{6}\right): \delta=12.23(\mathrm{~s}, 2 \mathrm{H}), 8.36(\mathrm{~s}$, $1 \mathrm{H}), 8.34(\mathrm{~s}, 1 \mathrm{H}), 7.96(\mathrm{~s}, 2 \mathrm{H}), 7.526 .67(\mathrm{~m}, 44 \mathrm{H}), 6.34(\mathrm{dd}, J=6.6$, $6.6 \mathrm{~Hz}, 1 \mathrm{H}), 6.29(\mathrm{dd}, J=6.3,6.3 \mathrm{~Hz}, 1 \mathrm{H}), 5.045 .00(\mathrm{~m}, 2 \mathrm{H}), 4.354 .29$ $(\mathrm{m}, 2 \mathrm{H}), 3.643 .29(\mathrm{~m}, 38 \mathrm{H}), 2.842 .80(\mathrm{~m}, 1 \mathrm{H}), 2.372 .31(\mathrm{~m}, 3 \mathrm{H})$, $1.851 .81(\mathrm{~m}, 2 \mathrm{H}), 0.990 .96 \mathrm{ppm}(\mathrm{m}, 24 \mathrm{H}) ;{ }^{13} \mathrm{C} \mathrm{NMR}\left(101 \mathrm{MHz}, \mathrm{C}_{6} \mathrm{D}_{6}\right)$ : $\delta=177.3,158.2,158.1,157.3,154.6,154.2,146.6,146.5,144.3,144.2,136.1$, $136.0,136.0,135.9,133.9,133.8,130.7,130.6,130.6,130.5,128.8,128.7$, $128.6,128.3,128.2,128.0,127.2,127.2,120.4,120.3,118.9,118.8,118.2$, 114.6, 113.6, 113.6, 87.1, 86.6, 86.5, 86.4, 86.3, 86.2, 85.6, 75.0, 74.8, 74.0, $73.8,64.1,64.0,58.8,58.6,58.6,58.5,55.2,46.6,46.6,46.5,46.5,38.6,38.4$, 37.7, 30.2, 24.8, 24.7, 24.6, 19.6, 19.5, $19.3 \mathrm{ppm} ;{ }^{31} \mathrm{P}$ NMR (161 MHz, $\left.\mathrm{C}_{6} \mathrm{D}_{6}\right): \delta=149.04,149.01 \mathrm{ppm} ;$ IR $(\mathrm{KBr}): \tilde{v}=3422,2926,1629,1529,1384$, 1249, $1103 \mathrm{~cm}^{1}$; UV (MeCN): $\lambda_{\max }=330,296,251,226 \mathrm{~nm}$; MS (ESI): $\mathrm{m} / \mathrm{z}$ : calcd for: 991.4510 , found $1014.4410\left[\mathrm{M}+\mathrm{Na}^{+}\right]$.

\section{$\boldsymbol{N}^{2}$-Formamidino-8 $\boldsymbol{N}$-(2-aminofluorenyl)-5' $-O$-dimethoxytrityl-2'-deoxy-} guanosin-3'-yl- $\beta$-cyanoethyl- $N, N^{\prime}$-diisopropylphosphoramidite $\quad(16 \mathrm{f})$ : GP V was conducted $15 \mathbf{f}$ with $(50 \mathrm{mg}, 0.06 \mathrm{mmol}$; reaction time $1 \mathrm{~h})$, which afforded a white solid $(60 \mathrm{mg}, 88 \%)$. M.p. $112^{\circ} \mathrm{C} ;[\alpha]_{578}^{20}=+3^{\circ}(c=$ $\left.0.21, \mathrm{CHCl}_{3}\right) ;{ }^{1} \mathrm{H}$ NMR (400 MHz, $\left.\mathrm{C}_{6} \mathrm{D}_{6}\right): \delta=11.05(\mathrm{~s}, 2 \mathrm{H}), 8.39(\mathrm{~s}, 2 \mathrm{H})$, $8.10(\mathrm{~s}, 1 \mathrm{H}), 8.08(\mathrm{~s}, 1 \mathrm{H}), 8.058 .02(\mathrm{~m}, 2 \mathrm{H}), 7.817 .76(\mathrm{~m}, 4 \mathrm{H}), 7.62$ $7.36(\mathrm{~m}, 26 \mathrm{H}), 7.28(\mathrm{~d}, J=7.3 \mathrm{~Hz}, 2 \mathrm{H}), 7.237 .21(\mathrm{~m}, 2 \mathrm{H}), 7.097 .03(\mathrm{~m}$, $4 \mathrm{H}), 6.59(\mathrm{dd}, J=6.7 \mathrm{~Hz}, 1 \mathrm{H}), 6.53(\mathrm{dd}, J=6.1 \mathrm{~Hz}, 1 \mathrm{H}), 5.055 .01(\mathrm{~m}$, $1 \mathrm{H}), 4.944 .91(\mathrm{~m}, 1 \mathrm{H}), 4.444 .39(\mathrm{~m}, 2 \mathrm{H}), 3.743 .70(\mathrm{~m}, 10 \mathrm{H}), 3.39$ $3.33(\mathrm{~m}, 12 \mathrm{H}), 2.692 .63(\mathrm{~m}, 14 \mathrm{H}), 1.89(\mathrm{ddd}, J=5.6,11.5 \mathrm{~Hz}, 2 \mathrm{H}), 1.12$ $(\mathrm{dd}, J=6.1 \mathrm{~Hz}, 12 \mathrm{H}), 1.06(\mathrm{~d}, J=6.7 \mathrm{~Hz}, 6 \mathrm{H}), 0.93 \mathrm{ppm}(\mathrm{d}, J=6.7 \mathrm{~Hz}$, $6 \mathrm{H}) ;{ }^{13} \mathrm{C}$ NMR $\left(101 \mathrm{MHz}, \mathrm{C}_{6} \mathrm{D}_{6}\right): \delta=160.7,159.2,158.2,157.9,156.1$,
$155.7,149.3,143.4,136.1,135.8,130.6,128.8,128.6,128.5,128.3,128.0$, 127.8, 113.6, 54.9, 43.6, 34.7, 24.7, 24.6, 21.2, 20.5, 20.1, 8.4 ppm; ${ }^{31} \mathrm{P}$ NMR $\left(202 \mathrm{MHz}, \mathrm{C}_{6} \mathrm{D}_{6}\right): \delta=162.0,161.78 \mathrm{ppm}$; IR (KBr): $\tilde{v}=3377,2966,2930$, 2836, 2760, 2722, 1681, 1607, 1575, 1457, 1427, 1344, 1301, 1251, 1178, 1154, 1115, 1076, 1033, 978, 829, 767, 732, $703 \mathrm{~cm}^{1}$; UV (MeCN): $\lambda_{\max }=$ $336 \mathrm{~nm}$; MS (ESI): $m / z$ : calcd for: 1003.4823 , found $1026.4440\left[M+\mathrm{Na}^{+}\right]$.

8-Bromo-2'-deoxyadenosine (17) was prepared as described previously. ${ }^{[46]}$

8-Bromo-3', $\mathbf{5}^{\prime}$-O $\mathrm{O}$-tetrakisisopropyldisiloxanediyl-2'-deoxyadenosine (18): 8 Bromo $2^{\prime}$ deoxyadenosine $(\mathbf{1 7} ; 515 \mathrm{mg}, 1.56 \mathrm{mmol})$ was subjected to co evaporation of the volatiles with anhydrous pyridine three times, and then suspended in anhydrous pyridine $(10 \mathrm{~mL})$ under a nitrogen atmos phere. 1,3 Dichloro 1,1,3,3 tetraisopropyldisiloxane (TIPDS $\left.\mathrm{Cl}_{2}\right)(530 \mu \mathrm{L}$, $526 \mathrm{mg}, 1.67 \mathrm{mmol}$ ) was then added and the reaction mixture was stirred for $16 \mathrm{~h}$ at room temperature. The reaction was stopped by the addition of methanol $(1 \mathrm{~mL})$. The mixture was diluted with dichloromethane and washed once with water and once with brine. The solvent was removed in vacuo, and the residue was purified by flash chromatography on silica gel $\left(5 \% \mathrm{MeOH}\right.$ in $\left.\mathrm{CH}_{2} \mathrm{Cl}_{2}\right)$ and recrystallized from hexane to give $\mathbf{1 8}$ as a colourless solid $(880 \mathrm{mg}, 1.54 \mathrm{mmol}, 98 \%)$. M.p. $158^{\circ} \mathrm{C} ;[\alpha]_{546}^{20}=53.9^{\circ}$ $\left(c=0.750, \mathrm{CHCl}_{3}\right) ;{ }^{1} \mathrm{H} \mathrm{NMR}\left(400 \mathrm{MHz},\left[\mathrm{D}_{6}\right] \mathrm{DMSO}\right): \delta=8.22(\mathrm{~s}, 1 \mathrm{H})$, $6.29(\mathrm{dd}, J=9.0,2.9 \mathrm{~Hz}, 1 \mathrm{H}), 5.76(\mathrm{~s}, 2 \mathrm{H}), 5.47(\mathrm{dd}, J=14.9,8.0 \mathrm{~Hz}, 1 \mathrm{H})$, $4.013 .93(\mathrm{~m}, 2 \mathrm{H}), 3.89$ (ddd, $J=6.4,4.4 \mathrm{~Hz}, 1 \mathrm{H}), 3.22$ (ddd, $J=13.5,8.9$, $2.9 \mathrm{~Hz}, 1 \mathrm{H}), 2.60(\mathrm{ddd}, J=13.4,8.5,4.2 \mathrm{~Hz}, 1 \mathrm{H}), 1.261 .05 \mathrm{ppm}(\mathrm{m}$, $28 \mathrm{H}) ;{ }^{13} \mathrm{C}$ NMR $\left(100 \mathrm{MHz},\left[\mathrm{D}_{6}\right] \mathrm{DMSO}\right): \delta=159.8,152.5,150.4,122.2$, 85.6, 84.5, 72.2, 63.1, 38.6, $17.717 .1,13.412 .7 \mathrm{ppm}$; IR (KBr): $\tilde{v}=3329$, 3174, 2945, 2893, 1662, 1602, 1574, 1461, 1388, 1351, 1321, 1299, 1280, 1252, 1178, 1139, 1097, 1035, 885, $693 \mathrm{~cm}^{1}$; MS (HRFAB): $\mathrm{m} / \mathrm{z}:$ calcd for: 571.1646 , found $572.1723\left[M+\mathrm{H}^{+}\right]$

General procedure VIa for the amination of $3^{\prime}, 5^{\prime}-O$-silyl-protected 8-BrdA derivatives (19a,b): Racemic 2,2' bis(diphenylphosphino) 1,1' bi naphthyl (rac BINAP; $30 \mathrm{~mol} \%$ ), tris(benzylideneacetone)dipalladi um(0) $\left(\left[\mathrm{Pd}_{2} \mathrm{dba}_{3}\right] ; 10 \mathrm{~mol} \%\right), \mathbf{1 8}$, the amine (2 equiv), and $\mathrm{Cs}_{2} \mathrm{CO}_{3}$ ( 1.5 equiv) were dissolved in anhydrous 1,2 dimethoxyethane $(50 \mathrm{~mL})$ and the mixture was stirred under reflux until the reaction was complete (30 $48 \mathrm{~h}$ ). The reaction mixture was allowed to cool to room tempera ture, whereupon saturated sodium hydrogencarbonate solution $(1 \mathrm{~mL})$ was added. After the addition of brine $(10 \mathrm{~mL})$, the layers were separat ed and the aqueous layer was extracted with ethyl acetate $(3 \times 10 \mathrm{~mL})$. The combined organic layers were washed with brine $(2 \times 10 \mathrm{~mL})$ and with a mixture of brine $(10 \mathrm{~mL})$ and water $(2 \mathrm{~mL})$. The organic layer was dried over sodium sulfate and the solvent was removed in vacuo. Purifi cation of the residue by flash chromatography on silica gel, eluting with $0 \rightarrow 50 \%$ ethyl acetate in hexane, gave the desired product.

8N-(4-Methoxyphenylamino)-3',5'-O-(1,1,3,3-tetrakis(isopropyl)-1,3-disiloxanediyl)-2'-deoxyadenosine (19a): GP VIa was conducted with 18 $(2.34 \mathrm{~g}, 4.09 \mathrm{mmol})$, which afforded the desired product as a pale yellow foam $(1.85 \mathrm{~g}, 3.01 \mathrm{mmol}, 74 \%)$. M.p. $5961^{\circ} \mathrm{C} ;[\alpha]_{546}^{20}=29.0^{\circ}(c=0.400$, $\left.\mathrm{CHCl}_{3}\right) ;{ }^{1} \mathrm{H}$ NMR $\left(400 \mathrm{MHz}, \mathrm{CDCl}_{3}\right): \delta=8.16(\mathrm{~s}, 1 \mathrm{H}), 7.48(\mathrm{~m}, 2 \mathrm{H}), 7.41$ (brs, $1 \mathrm{H}), 6.88(\mathrm{~m}, 2 \mathrm{H}), 6.31(\mathrm{dd}, J=7.8,3.8 \mathrm{~Hz}, 1 \mathrm{H}), 5.34(\mathrm{brs}, 2 \mathrm{H})$, $4.90(\mathrm{dd}, J=15.2,7.9 \mathrm{~Hz}, 1 \mathrm{H}), 4.16(\mathrm{dd}, J=9.2,3.4 \mathrm{~Hz}, 1 \mathrm{H}), 3.98(\mathrm{dd}, J=$ 12.5, $5.0 \mathrm{~Hz}, 1 \mathrm{H}), 3.90$ (ddd, $J=7.0,4.9,3.4 \mathrm{~Hz}, 1 \mathrm{H}), 3.79$ (s, $3 \mathrm{H}), 3.06$ $(\mathrm{ddd}, J=13.4,8.1,3.6 \mathrm{~Hz}, 1 \mathrm{H}), 2.59(\mathrm{ddd}, J=13.4,7.9 \mathrm{~Hz}, 1 \mathrm{H}), 1.13$ $0.89 \mathrm{ppm}(\mathrm{m}, 28 \mathrm{H}) ;{ }^{13} \mathrm{C} \mathrm{NMR}\left(100 \mathrm{MHz}, \mathrm{CDCl}_{3}\right): \delta=155.8,152.5,149.4$, $132.5,121.5,117.4,114.5,85.3,83.8,70.5,61.9,55.7,38.8,17.617 .0,13.5$ $12.6 \mathrm{ppm}$; IR (KBr): $\tilde{v}=3378,2945,2867,1638,1607,1561,1511,1465$, $1420,1342,1286,1246,1180,1114,1037,886,827,780,697,598,460 \mathrm{~cm}^{1}$; MS (HRFAB): $m / z$ : calcd for: 614.3068 , found $615.3149\left[M+\mathrm{H}^{+}\right]$.

8N-(4-Aminobiphenyl)-3',5'-O-(1,1,3,3-tetrakis(isopropyl)-1,3-disiloxanediyl)-2'-deoxyadenosine (19b): GP VIa was conducted with 18 (2.35 g, $4.10 \mathrm{mmol}$ ), which afforded the desired product as a pale yellow foam $(1.76 \mathrm{~g}, 2.67 \mathrm{mmol}, 65 \%)$. M.p. $102^{\circ} \mathrm{C} ;[\alpha]_{546}^{20}=58.4^{\circ}\left(c=0.125, \mathrm{CHCl}_{3}\right)$; ${ }^{1} \mathrm{H}$ NMR $\left(400 \mathrm{MHz}, \mathrm{CDCl}_{3}\right): \delta=8.19(\mathrm{~s}, 1 \mathrm{H}), 7.78(\mathrm{brs}, 1 \mathrm{H}), 7.69(\mathrm{~m}$, $2 \mathrm{H}), 7.58(\mathrm{~m}, 4 \mathrm{H}), 7.44(\mathrm{~m}, 2 \mathrm{H}), 7.33(\mathrm{~m}, 1 \mathrm{H}), 6.35(\mathrm{dd}, J=7.5,3.8 \mathrm{~Hz}$, $1 \mathrm{H}), 5.59(\mathrm{~s}, 2 \mathrm{H}), 4.88(\mathrm{dd}, J=15.2,7.9 \mathrm{~Hz}, 1 \mathrm{H}), 4.16(\mathrm{dd}, J=12.6$, $3.6 \mathrm{~Hz}, 1 \mathrm{H}), 4.04$ (dd, $J=12.5,4.8 \mathrm{~Hz}, 1 \mathrm{H}), 3.95$ (ddd, $J=7.3,4.4,3.0 \mathrm{~Hz}$, $1 \mathrm{H}), 3.07$ (ddd, $J=13.4,8.0,3.6 \mathrm{~Hz}, 1 \mathrm{H}), 2.59$ (ddd, $J=13.4,7.8 \mathrm{~Hz}, 1 \mathrm{H})$, $1.120 .91 \mathrm{ppm}(\mathrm{m}, 28 \mathrm{H}) ;{ }^{13} \mathrm{C} \mathrm{NMR}\left(100 \mathrm{MHz}, \mathrm{CDCl}_{3}\right): \delta=156.7,152.4$, $149.7,148.3,140.9,132.5,121.5,117.4,114.5,85.3,83.8,70.5,61.9,55.7$, 
38.8, 17.6 17.0, $13.512 .6 \mathrm{ppm}$; IR $(\mathrm{KBr}): \tilde{v}=3367,2364,1972,1954$, 1908, 1892, 1811, 1659, 1624, 1577, 1495, 1474, 1449, 1179, 1123, 1073, 1001, 918, 847, 771, 703, 685, 650, 635, 614, 530, $414 \mathrm{~cm}^{1}$; MS (HRFAB): $\mathrm{m} / \mathrm{z}$ : calcd for: 660.3276 , found $661.3377\left[\mathrm{M}+\mathrm{H}^{+}\right]$.

General procedure VIb for the amination of $3^{\prime}, 5^{\prime}-O$-silyl-protected 8-BrdA derivatives $(\mathbf{1 9 c}, \mathbf{d})$ : This procedure was the same as VIa, but with a pre incubation of $\mathrm{Pd}_{2} \mathrm{dba}_{3}$ and rac BINAP for $1 \mathrm{~h}$

\section{N-(3,5-Dimethylphenylamino)-3',5'-O-(1,1,3,3-tetrakis(isopropyl)-1,3-}

disiloxanediyl)-2'-deoxyadenosine (19c): GP VIb was conducted with 18 $(829 \mathrm{mg}, 1.45 \mathrm{mmol})$, which afforded the desired product as a pale yellow foam $(818 \mathrm{mg}, 1.33 \mathrm{mmol}, 92 \%)$. M.p. $184^{\circ} \mathrm{C} ;[\alpha]_{546}^{20}=37^{\circ} \quad(c=1$, $\mathrm{CHCl}_{3}$ ); ${ }^{1} \mathrm{H} \mathrm{NMR}\left(400 \mathrm{MHz}, \mathrm{CDCl}_{3}\right): \delta=8.18(\mathrm{~s}, 1 \mathrm{H}), 7.99(\mathrm{~s}, 1 \mathrm{H}), 7.41$ $(\mathrm{s}, 1 \mathrm{H}), 7.18(\mathrm{~s}, 2 \mathrm{H}), 6.29(\mathrm{dd}, J=7.5,4.0 \mathrm{~Hz}, 1 \mathrm{H}), 5.30(\mathrm{~s}, 2 \mathrm{H}), 4.88(\mathrm{dd}$, $J=14.3,7.5 \mathrm{~Hz}, 1 \mathrm{H}), 3.933 .91(\mathrm{~m}, 2 \mathrm{H}), 3.893 .84(\mathrm{~m}, 1 \mathrm{H}), 3.11$ (ddd, $J=13.4,8.0,3.9 \mathrm{~Hz}, 1 \mathrm{H}), 2.602 .52(\mathrm{~m}, 1 \mathrm{H}), 2.31(\mathrm{~s}, 6 \mathrm{H}), 1.111 .03(\mathrm{~m}$, $24 \mathrm{H}), 0.93 \mathrm{ppm}(\mathrm{s}, 4 \mathrm{H}) ;{ }^{13} \mathrm{C} \mathrm{NMR}\left(100 \mathrm{MHz}, \mathrm{CDCl}_{3}\right): \delta=152.5,150.4$, 146.9, 142.8, 139.1, 138.9, 124.8, 119.4, 116.8, 85.3, 84.0, 70.9, 62.3, 38.9, $21.6,17.9,17.8,17.7,17.6,17.5,17.5,17.4,17.4,17.3,13.9,13.5,13.1$ $12.9 \mathrm{ppm}$; IR $(\mathrm{KBr}): \tilde{v}=3370,3178,3055,2944,2866,1637,1567,1465$, 1437, 1387, 1336, 1289, 1251, 1186, 1116, 1035, 947, 920, 885, 836, 776, $746,699,560,575,541,524,458 \mathrm{~cm}^{1}$; MS (HRFAB): $\mathrm{m} / \mathrm{z}$ : calcd for: 612.3276, found $613.3339\left[M+\mathrm{H}^{+}\right]$.

$8 \mathrm{~N}$-(2-Aminofluorenyl)-3',5'-O-(1,1,3,3-tetrakis(isopropyl)-1,3-disiloxanediyl)-2'-deoxyadenosine (19 d): GP VIb was conducted with 18 (331 mg, $0.579 \mathrm{mmol}$ ), which afforded the desired product as a pale yellow foam (362 mg, $0.538 \mathrm{mmol}, 93 \%)$. M.p. $99^{\circ} \mathrm{C} ;[\alpha]_{546}^{20}=27^{\circ}\left(c=0.1, \mathrm{CHCl}_{3}\right)$; ${ }^{1} \mathrm{H}$ NMR $\left(400 \mathrm{MHz}, \mathrm{CDCl}_{3}\right): \delta=8.21(\mathrm{~s}, 1 \mathrm{H}), 7.91$ (brs, $\left.1 \mathrm{H}\right), 7.70(\mathrm{~d}, J=$ $8.0 \mathrm{~Hz}, 1 \mathrm{H}), 7.63(\mathrm{~d}, J=7.8 \mathrm{~Hz}, 2 \mathrm{H}), 7.56(\mathrm{~d}, J=8.0 \mathrm{~Hz}, 1 \mathrm{H}), 7.31$ (s, $1 \mathrm{H}), 7.18(\mathrm{dd}, J=7.4,7.4 \mathrm{~Hz}, 2 \mathrm{H}), 6.35(\mathrm{dd}, J=7.5,3.8 \mathrm{~Hz}, 1 \mathrm{H}), 5.22$ (s, $2 \mathrm{H}), 4.89$ (dd, $J=15.0,7.9 \mathrm{~Hz}, 1 \mathrm{H}), 4.12(\mathrm{dd}, J=14.3,7.0 \mathrm{~Hz}, 2 \mathrm{H}), 4.07$ $4.02(\mathrm{~m}, 1 \mathrm{H}), 3.973 .94(\mathrm{~m}, 2 \mathrm{H}), 3.133 .07(\mathrm{~m}, 1 \mathrm{H}), 2.612 .54(\mathrm{~m}, 1 \mathrm{H})$, $1.111 .04(\mathrm{~m}, 18 \mathrm{H}), 0.960 .91 \mathrm{ppm}(\mathrm{m}, 10 \mathrm{H}) ;{ }^{13} \mathrm{C} \mathrm{NMR} \quad(100 \mathrm{MHz}$, $\left.\mathrm{CDCl}_{3}\right): \delta=152.3,149.7,149.3,148.8,144.8,143.3,141.9,138.3,137.2$, $128.5,127.2,126.4,125.3,120.6,119.7,118.6,117.6,85.6,84.4,70.4,62.0$, $45.8,39.8,17.9,17.8,17.7,17.6,17.5,17.5,17.4,17.4,17.3,13.9,13.5,13.1$, $12.9 \mathrm{ppm}$; IR $(\mathrm{KBr}): \tilde{v}=3365,3189,3060,2945,2866,1708,1637,1600$, 1560, 1493, 1459, 1430, 1404, 1331, 1288, 1251, 1184, 1117, 1038, 946, 919, $885,826,765,731,698,580,422 \mathrm{~cm}^{1}$; MS (HRFAB): $\mathrm{m} / \mathrm{z}$ : calcd for: 672.3276 , found $673.3370\left[M+\mathrm{H}^{+}\right]$.

General procedure VII for the $N^{6}$-benzoylation and $3^{\prime}, 5^{\prime}$-desilylation of C8-arylamine-dA adducts $(\mathbf{2 0} \mathbf{a}, \mathbf{b})$ : The $3^{\prime}, 5^{\prime} O$ silyl protected $\mathrm{C} 8$ aryl amine modified dA derivative $\mathbf{1 9} \mathbf{a}, \mathbf{b}$ was dissolved in anhydrous pyridine $(30 \mathrm{~mL})$ under an atmosphere of nitrogen and distilled benzoyl chloride (1.5 equiv) was added. The reaction mixture was stirred for $2 \mathrm{~h}$ at room temperature. It was then diluted with dichloromethane $(200 \mathrm{~mL})$ and washed with saturated sodium hydrogencarbonate solution, and the aque ous layer was extracted twice with dichloromethane. After removal of the dichloromethane in vacuo, morpholine ( 2.5 equiv) was added and the resulting mixture was stirred at room temperature for a further $2 \mathrm{~h}$. The reaction mixture was again diluted with dichloromethane $(200 \mathrm{~mL})$ and then washed twice with $0.5 \mathrm{~m}$ sodium dihydrogenphosphate solution. The aqueous layer was extracted three times with dichloromethane. After complete removal of the dichloromethane in vacuo, the residue was dis solved in tetrahydrofuran and tetrabutylammonium fluoride (2.5 equiv) was added. After complete desilylation, the solvent was removed in vacuo and the residue was purified by flash chromatography on silica gel, eluting with dichloromethane containing $10 \%$ methanol, to yield the product.

$\boldsymbol{N}^{\mathbf{6}}$-Benzoyl-8N-(4-aminobiphenyl)-2'-deoxyadenosine (20a): GP VII was conducted with 19a $(2.30 \mathrm{~g}, 3.74 \mathrm{mmol})$, which gave the desired product as a pale yellow solid $(1.28 \mathrm{~g}, 2.69 \mathrm{mmol}, 72 \%)$. M.p. $161^{\circ} \mathrm{C} ;[\alpha]_{546}^{20}=27^{\circ}$ $(c=1, \mathrm{MeOH}) ;{ }^{1} \mathrm{H}$ NMR $\left(400 \mathrm{MHz}, \mathrm{CD}_{3} \mathrm{OD}\right): \delta=8.44(\mathrm{~s}, 1 \mathrm{H}), 7.97(\mathrm{~m}$, 2H), 7.59 (tt, $J=7.4,1.3 \mathrm{~Hz}, 1 \mathrm{H}), 7.497 .43(\mathrm{~m}, 4 \mathrm{H}), 6.84(\mathrm{~d}, J=8.9 \mathrm{~Hz}$, $2 \mathrm{H}), 6.73(\mathrm{dd}, J=9.0,5.7 \mathrm{~Hz}, 1 \mathrm{H}), 4.644 .58(\mathrm{~m}, 1 \mathrm{H}), 4.144 .10(\mathrm{~m}, 1 \mathrm{H})$, $3.94(\mathrm{dd}, J=11.7,2.5 \mathrm{~Hz}, 1 \mathrm{H}), 3.88(\mathrm{dd}, J=11.7,1.7 \mathrm{~Hz}, 1 \mathrm{H}), 3.73$ (s, $3 \mathrm{H}$; OMe), 2.81 (ddd, $J=13.5,9.4,6.1 \mathrm{~Hz}, 1 \mathrm{H}), 2.27 \mathrm{ppm}(\mathrm{ddd}, J=13.4$, $5.9,1.7 \mathrm{~Hz}, 1 \mathrm{H}) ;{ }^{13} \mathrm{C}$ NMR $\left(100 \mathrm{MHz}, \mathrm{CD}_{3} \mathrm{OD}\right): \delta=156.2,152.2,150.1$, 135.0, 132.6, 131.8, 129.5, 129.0, 128.8, 128.0, 123.1, 114.4, 87.9, 84.5, 72.4,
63.3, 55.7, $39.5 \mathrm{ppm}$; IR (KBr): $\tilde{v}=3353,3060,2932,2835,2550,2348$, 2254, 2125, 2048, 1911, 1692, 1654, 1611, 1565, 1444, 1248, 1176, 1028 $828,703,582 \mathrm{~cm}^{1}$; MS (HRESI): $\mathrm{m} / \mathrm{z}$ : calcd for: 476.1808, found $499.1706\left[M+\mathrm{Na}^{+}\right]$.

$N^{6}$-Benzoyl-8 $N$-(4-aminobiphenyl)-2'-deoxyadenosine (20b): GP VII was conducted with $19 \mathrm{~b}(1.60 \mathrm{~g}, 2.42 \mathrm{mmol})$, which gave the desired product as a pale yellow solid $\left(906 \mathrm{mg}, 1.89 \mathrm{mmol}, 78 \%\right.$ ). M.p. $151^{\circ} \mathrm{C} ;[\alpha]_{546}^{20}=$ $+4.3^{\circ}\left(c=0.5, \mathrm{CH}_{3} \mathrm{OH}\right) ;{ }^{1} \mathrm{H}$ NMR $\left(400 \mathrm{MHz}, \mathrm{CD}_{3} \mathrm{OD}\right): \delta=8.41(\mathrm{~s}, 1 \mathrm{H})$, $7.917 .85(\mathrm{~m}, 2 \mathrm{H}), 7.697 .64(\mathrm{~m}, 2 \mathrm{H}), 7.49(\mathrm{tt}, J=7.4,1.2 \mathrm{~Hz}, 1 \mathrm{H}), 7.47$ $7.43(\mathrm{~m}, 4 \mathrm{H}), 7.427 .39(\mathrm{~m}, 2 \mathrm{H}), 7.367 .30(\mathrm{~m}, 2 \mathrm{H}), 7.24(\mathrm{tt}, J=7.4$, $1.2 \mathrm{~Hz}, 1 \mathrm{H}), 6.71(\mathrm{dd}, J=9.4,5.8 \mathrm{~Hz}, 1 \mathrm{H}), 4.624 .55(\mathrm{~m}, 1 \mathrm{H}), 4.134 .08$ $(\mathrm{m}, 1 \mathrm{H}), 3.94(\mathrm{dd}, J=11.6,2.4 \mathrm{~Hz}, 1 \mathrm{H}), 3.87(\mathrm{dd}, J=11.7,2.5 \mathrm{~Hz}, 1 \mathrm{H})$, $2.74(\mathrm{ddd}, J=13.5,9.4,6.2 \mathrm{~Hz}, 1 \mathrm{H}), 2.24 \mathrm{ppm}(\mathrm{ddd}, J=13.4,5.9, J=$ $1.6 \mathrm{~Hz}, 1 \mathrm{H}) ;{ }^{13} \mathrm{C}$ NMR $\left(100 \mathrm{MHz}, \mathrm{CD}_{3} \mathrm{OD}\right): \delta=168.3,154.0,150.0,141.7$, 138.0, 135.4, 133.5, 129.8, 129.6, 129.2, 128.5, 128.1, 127.6, 122.7, 120.1 89.3, 85.4, 73.4, 62.8, $39.9 \mathrm{ppm}$; IR $(\mathrm{KBr}): \tilde{v}=3447,3277,3050,3031$, 2927, 2874, 2362, 2344, 1719, 1709, 1696, 1685, 1624, 1555, 1486, 1448, 1271, 1174, 1088, 836, 763, $697 \mathrm{~cm}^{1}$; MS (HRFAB): $\mathrm{m} / \mathrm{z}$ : calcd for: 522.2016, found $523.2094\left[M+\mathrm{H}^{+}\right]$.

General procedure VIII for the $5^{\prime}$ - $\boldsymbol{O}$-dimethoxytritylation of $\boldsymbol{N}^{6}$-benzoylated C8-arylamine-dA adducts $(\mathbf{2 1} \mathbf{a}, \mathbf{b})$ : The $N^{6}$ benzoylated $\mathrm{C} 8$ aryl amine dA adduct $(\mathbf{2 0} \mathbf{a}, \mathbf{b})$ was dissolved in anhydrous pyridine $(30 \mathrm{~mL})$ under a nitrogen atmosphere and 4,4' dimethoxytrityl chloride (1.2 equiv) and silver nitrate (1.2 equiv) were added. The mixture was stirred at room temperature until the reaction was complete $(\approx 3 \mathrm{~h})$. It was then diluted with dichloromethane $(200 \mathrm{~mL})$ and washed with satu rated sodium hydrogencarbonate solution and brine. The aqueous layer was extracted twice with dichloromethane. The organic layers were com bined, dried over sodium sulfate, and filtered, and the solvent was re moved in vacuo. The residue was purified by flash chromatography on silica gel eluting with $0 \rightarrow 10 \%$ methanol in dichloromethane to afford the desired product.

$N^{6}$-Benzoyl-8N-(4-methoxyphenylamino)-5' $-O$-dimethoxytrityl-2'-deoxyadenosine (21a): GP VIII was conducted with 20 a $(1.10 \mathrm{~g}, 2.31 \mathrm{mmol})$, which gave the desired product as a pale yellow foam $(1.32 \mathrm{~g}, 1.69 \mathrm{mmol}$ $73 \%$ ). M.p. $93^{\circ} \mathrm{C} ;[\alpha]_{546}^{20}=37.2^{\circ}\left(c=0.5, \mathrm{CH}_{3} \mathrm{OH}\right) ;{ }^{1} \mathrm{H}$ NMR $(400 \mathrm{MHz}$, [D $\mathrm{D}_{6}$ DMSO): $\delta=10.78(\mathrm{~s}, 1 \mathrm{H}), 9.32(\mathrm{~s}, 1 \mathrm{H}), 8.27(\mathrm{~s}, 1 \mathrm{H}), 8.047 .99(\mathrm{~m}$ $2 \mathrm{H}), 7.78(\mathrm{~d}, J=9.2 \mathrm{~Hz}, 2 \mathrm{H}), 7.647 .58(\mathrm{~m}, 1 \mathrm{H}), 7.567 .50(\mathrm{~m}, 2 \mathrm{H})$, $7.337 .27(\mathrm{~m}, 2 \mathrm{H}), 7.227 .14(\mathrm{~m}, 7 \mathrm{H}), 6.86(\mathrm{~d}, J=9.2 \mathrm{~Hz}, 2 \mathrm{H}), 6.816 .74$ $(\mathrm{m}, 4 \mathrm{H}), 6.53(\mathrm{dd}, J=9.0,2.9 \mathrm{~Hz}, 1 \mathrm{H}), 5.41(\mathrm{~d}, J=4.3 \mathrm{~Hz}, 1 \mathrm{H}), 4.744 .67$ $(\mathrm{m}, 1 \mathrm{H}), 4.01(\mathrm{dd}, J=9.8,4.7 \mathrm{~Hz}, 1 \mathrm{H}), 3.70(\mathrm{~s}, 3 \mathrm{H}), 3.69(\mathrm{~s}, 6 \mathrm{H}), 3.59$ $3.49(\mathrm{~m}, 1 \mathrm{H}), 3.25(\mathrm{dd}, J=10.0,4.2 \mathrm{~Hz}, 1 \mathrm{H}), 3.15(\mathrm{dd}, J=10.0,6.0 \mathrm{~Hz}$ $1 \mathrm{H}), 2.312 .22 \mathrm{ppm}(\mathrm{m}, 1 \mathrm{H}) ;{ }^{13} \mathrm{C} \mathrm{NMR}\left(100 \mathrm{MHz},\left[\mathrm{D}_{6}\right] \mathrm{DMSO}\right): \delta=$ $165.3,158.0,154.7,152.8,150.4,147.9,145.0,144.6,135.8,135.6,134.0$ $132.8,129.7,129.6,128.4,128.3,127.6,126.5,126.2,120.8,113.8,113.0$ $85.6,85.3,82.9,70.8,63.7,55.2,55.0,36.4$ ppm; IR (KBr): $\tilde{v}=3356,3057$ $2999,2932,2835,2361,1735,1670,1609,1563,1462,1444,1372,1301$, 1177, 1034, 910, 828, 791, 754, 726, 617, $584 \mathrm{~cm}^{1}$; MS (HRFAB): $\mathrm{m} / z$ calcd for: 778.3115 , found $779.3193\left[M+\mathrm{H}^{+}\right]$

$N^{6}$-Benzoyl-8N-(4-aminobiphenyl)-5'-O -dimethoxytrityl-2' -deoxyadenosine (21b): GP VIII was conducted with 20 b $(880 \mathrm{mg}, 1.684 \mathrm{mmol})$, which gave the desired product as a pale yellow foam $(1.056 \mathrm{~g}$, $1.280 \mathrm{mmol}, 76 \%)$. M.p. decomposition at $132^{\circ} \mathrm{C} ;[\alpha]_{546}^{20}=+14^{\circ}(c=0.5$, $\mathrm{CHCl}_{3}$ ); ${ }^{1} \mathrm{H}$ NMR (400 MHz, [D 6 DMSO): $\delta=10.86$ (brs, $1 \mathrm{H}$ ), 9.60 (brs, $1 \mathrm{H}), 8.32(\mathrm{~s}, 1 \mathrm{H}), 8.077 .93(\mathrm{~m}, 4 \mathrm{H}), 7.677 .59(\mathrm{~m}, 5 \mathrm{H}), 7.577 .51(\mathrm{~m}$, 2H), $7.457 .38(\mathrm{~m}, 2 \mathrm{H}), 7.337 .27(\mathrm{~m}, 3 \mathrm{H}), 7.227 .14(\mathrm{~m}, 7 \mathrm{H}), 6.816 .74$ $(\mathrm{m}, 4 \mathrm{H}), 6.626 .56(\mathrm{~m}, 1 \mathrm{H}), 5.43(\mathrm{dd}, J=4.3 \mathrm{~Hz}), 4.764 .69(\mathrm{~m}, 1 \mathrm{H})$ $4.064 .00(\mathrm{~m}, 1 \mathrm{H}), 3.69(\mathrm{~s}, 3 \mathrm{H}), 3.68(\mathrm{~s}, 3 \mathrm{H}), 3.603 .51(\mathrm{~m}, 1 \mathrm{H}), 3.29$ $3.23(\mathrm{~m}, 1 \mathrm{H}), 3.203 .13(\mathrm{~m}, 1 \mathrm{H}), 2.342 .25 \mathrm{ppm}(\mathrm{m}, 1 \mathrm{H}) ;{ }^{13} \mathrm{C}$ NMR (100 MHz, [D $]$ DMSO): $\delta=165.3,158.0,149.7,148.3,145.2,145.0,139.8$ $139.3,135.8,135.6,133.9,133.8,132.1,129.7,129.6,128.9,128.5,128.3$, $127.7,126.8,126.2,125.8,119.3,113.1,85.7,83.1,70.7,63.7,55.0$, 36.4 ppm; IR (KBr): $\tilde{v}=3416,3056,2931,2834,2348,2282,1701,1607$ 1577, 1557, 1508, 1487, 1445, 1339, 1299, 1250, 1176, 1047, 1033, 828, 700 $583 \mathrm{~cm}^{1}$; MS (HRFAB): $m / z$ : calcd 824.3322, found $825.3424\left[M+\mathrm{H}^{+}\right]$

General procedure IX for phosphitylation of $\boldsymbol{N}^{6}$-benzoyl-( $\boldsymbol{N} \boldsymbol{N}$-arylamino)5'-O-dimethoxytrityl-2'-deoxyadenosine (22a,b): The $N^{6} \mathrm{Bz} 8 N$ (aryl amino) 5' $O$ DMTr $2^{\prime} \mathrm{dA}(\mathbf{2 1} \mathbf{a}, \mathbf{b})$ was dissolved in anhydrous $\mathrm{CH}_{2} \mathrm{Cl}_{2}$ 
(4 mL) and anhydrous $\mathrm{CH}_{3} \mathrm{CN}(3 \mathrm{~mL})$ under an atmosphere of nitrogen and treated with a $0.25 \mathrm{M}$ solution of 4,5 dicyanoimidazole in $\mathrm{CH}_{3} \mathrm{CN}$ (2 equiv) and 2 cyanoethyl $N, N, N^{\prime}, N^{\prime}$ tetraisopropylphosphordiamidite (1.5 equiv). After stirring the mixture for $30 \mathrm{~min}$ at room temperature, the reaction was stopped by adding $\mathrm{CH}_{3} \mathrm{OH}(0.5 \mathrm{~mL})$. The solution was diluted with $\mathrm{CH}_{2} \mathrm{Cl}_{2}(50 \mathrm{~mL})$ and washed sequentially with $5 \%$ aqueous $\mathrm{NaHCO}_{3}$ solution and brine. The organic layer was dried and concentrat ed to dryness. The residue was purified by chromatography on silica gel, eluting with $\mathrm{CH}_{2} \mathrm{Cl}_{2}$ containing $2 \% \mathrm{NEt}_{3}$. The product was redissolved in $\mathrm{CH}_{2} \mathrm{Cl}_{2}$ and further washed with $\mathrm{H}_{2} \mathrm{O}$ to give the product as a solid after freeze drying from benzene.

$N^{6}$-Benzoyl-8N-(4-methoxyphenylamino)-5'-O-dimethoxytrityl-2' -deoxyadenosin-3'-yl- $\beta$-cyanoethyl- $N, N^{\prime}$-diisopropylphosphoramidite $\quad$ (22 a): GP IX was conducted with 21 a $(200 \mathrm{mg}, 0.257 \mathrm{mmol})$, which gave the de sired product as a pale yellow solid (189 mg, $0.193 \mathrm{mmol}, 75 \%$ ). M.p. de composition at $82{ }^{\circ} \mathrm{C} ;{ }^{1} \mathrm{H}$ NMR $\left(400 \mathrm{MHz}, \mathrm{C}_{6} \mathrm{D}_{6}\right): 2$ diastereomers +2 rotamers: $\delta=9.55(\mathrm{~m}, 2 \mathrm{H}), 9.18(\mathrm{~s}, 1 \mathrm{H}), 9.16(\mathrm{~s}, 1 \mathrm{H}), 8.90(\mathrm{~m}, 2 \mathrm{H}), 8.67$ $(\mathrm{s}, 1 \mathrm{H}), 8.66(\mathrm{~s}, 1 \mathrm{H}), 8.29(\mathrm{~s}, 1 \mathrm{H}), 8.27(\mathrm{~s}, 1 \mathrm{H}), 7.91(\mathrm{~m}, 2 \mathrm{H}), 7.82(\mathrm{~m}$, $5 \mathrm{H}), 7.75(\mathrm{~m}, 3 \mathrm{H}), 7.707 .64(\mathrm{~m}, 4 \mathrm{H}), 7.627 .54(\mathrm{~m}, 6 \mathrm{H}), 7.537 .43(\mathrm{~m}$, $8 \mathrm{H}), 7.32(\mathrm{~m}, 12 \mathrm{H}), 7.32(\mathrm{~m}, 5 \mathrm{H}), 7.167 .08(\mathrm{~m}, 8 \mathrm{H}), 7.066 .87(\mathrm{~m}$, $22 \mathrm{H}), 6.806 .64(\mathrm{~m}, 24 \mathrm{H}), 6.135 .99(\mathrm{~m}, 2 \mathrm{H}), 5.91(\mathrm{~m}, 2 \mathrm{H}), 5.25(\mathrm{~m}$, $2 \mathrm{H}), 5.07(\mathrm{~m}, 4 \mathrm{H}), 4.644 .50(\mathrm{~m}, 2 \mathrm{H}), 4.41(\mathrm{~m}, 2 \mathrm{H}), 3.933 .81(\mathrm{~m}, 4 \mathrm{H})$, $3.753 .61(\mathrm{~m}, 4 \mathrm{H}), 3.623 .44(\mathrm{~m}, 16 \mathrm{H}), 3.433 .22(\mathrm{~m}, 36 \mathrm{H}), 2.532 .28(\mathrm{~m}$, $4 \mathrm{H}), 2.001 .68(\mathrm{~m}, 12 \mathrm{H}), 1.231 .11 \mathrm{ppm}(\mathrm{m}, 48 \mathrm{H}) ;{ }^{13} \mathrm{C} \mathrm{NMR}(100 \mathrm{MHz}$, $\left.\mathrm{C}_{6} \mathrm{D}_{6}\right): \delta=165.9,165.1,159.2,159.2,159.9,154.1,152.6,151.1,150.1$, $149.4,146.1,145.9,145.3,144.2,142.0,136.9,136.8,136.0,135.8,135.0$, $132.7,132.6,130.9,130.8,130.5,128.6,127.1,127.0,124.0,123.4,121.6$, $121.5,117.8,117.6,115.4,114.6,113.6,113.5,111.7,86.9,86.8,86.0,85.4$, $82.5,82.3,64.9,63.4,63.2,59.2,59.1,59.0,58.8,58.6,55.0,54.9,54.9,43.6$, 43.6, 37.5, 37.2, 30.5, 30.2, 24.8, 24.8, 24.7, 20.2, 20.1, $20.1 \mathrm{ppm} ;{ }^{31} \mathrm{P}$ NMR $\left(161 \mathrm{MHz}, \mathrm{C}_{6} \mathrm{D}_{6}\right): \delta=149.20,148.95,148.84,148.20 \mathrm{ppm}$; IR $(\mathrm{KBr}): \tilde{v}=$ 3426, 3061, 2964, 2930, 2362, 2344, 2253, 1701, 1686, 1676, 1670, 1664, $1655,1618,1612,1569,1511,1491,1483,1250,1178,1034,829,704$, $582 \mathrm{~cm}^{1}$; MS (HRESI): $\mathrm{m} / \mathrm{z}$ : calcd for: 978.4193, found 1001.4120 $\left[M+\mathrm{Na}^{+}\right]$

\section{$\boldsymbol{N}^{6}$-Benzoyl-8 $\boldsymbol{N}$-(4-aminobiphenyl)-5' $\boldsymbol{O} \boldsymbol{O}$-dimethoxytrityl-2' -deoxyadeno-} sin-3'-yl- $\beta$-cyanoethyl- $N, N^{\prime}$-diisopropylphosphoramidite $\quad(22$ b): GP IX was conducted with $21 \mathbf{b}(200 \mathrm{mg}, 0.242 \mathrm{mmol})$, which gave the desired product as a pale yellow solid $(171 \mathrm{~g}, 0.167 \mathrm{mmol}, 69 \%)$. M.p. $7779^{\circ} \mathrm{C}$; ${ }^{1} \mathrm{H}$ NMR $\left(400 \mathrm{MHz}, \mathrm{C}_{6} \mathrm{D}_{6}\right): 2$ diastereomers +2 rotamers: $\delta=9.87(\mathrm{~m}$, $2 \mathrm{H}), 8.94(\mathrm{~s}, 1 \mathrm{H}), 8.92(\mathrm{~s}, 1 \mathrm{H}), 8.85(\mathrm{~s}, 1 \mathrm{H}), 8.84(\mathrm{~s}, 1 \mathrm{H}), 8.60(\mathrm{~m}, 2 \mathrm{H})$, $8.44(\mathrm{~s}, 1 \mathrm{H}), 8.42(\mathrm{~s}, 1 \mathrm{H}), 8.24(\mathrm{~s}, 1 \mathrm{H}), 8.21(\mathrm{~s}, 1 \mathrm{H}), 8.03(\mathrm{~m}, 4 \mathrm{H}), 7.92$ $(\mathrm{m}, 4 \mathrm{H}), 7.86(\mathrm{~m}, 4 \mathrm{H}), 7.69(\mathrm{~m}, 12 \mathrm{H}), 7.637 .49(\mathrm{~m}, 20 \mathrm{H}), 7.40(\mathrm{~m}$, $12 \mathrm{H}), 7.32(\mathrm{~m}, 12 \mathrm{H}), 7.22(\mathrm{~m}, 10 \mathrm{H}), 7.187 .04(\mathrm{~m}, 12 \mathrm{H}), 6.97(\mathrm{~m}, 2 \mathrm{H})$, $6.85(\mathrm{~m}, 8 \mathrm{H}), 6.77(\mathrm{~m}, 10 \mathrm{H}), 6.035 .87(\mathrm{~m}, 2 \mathrm{H}), 5.345 .17(\mathrm{~m}, 2 \mathrm{H}), 5.15$ $4.99(\mathrm{~m}, 2 \mathrm{H}), 4.664 .54(\mathrm{~m}, 2 \mathrm{H}), 4.41(\mathrm{~m}, 2 \mathrm{H}), 3.88(\mathrm{~m}, 4 \mathrm{H}), 3.74(\mathrm{~m}$, $2 \mathrm{H}), 3.663 .57(\mathrm{~m}, 10 \mathrm{H}), 3.31(\mathrm{~m}, 12 \mathrm{H}), 3.30(\mathrm{~m}, 12 \mathrm{H}), 3.163 .00(\mathrm{~m}$, $8 \mathrm{H}), 2.622 .28(\mathrm{~m}, 4 \mathrm{H}), 1.971 .70(\mathrm{~m}, 10 \mathrm{H}), 1.101 .01 \mathrm{ppm}(\mathrm{m}, 48 \mathrm{H})$; ${ }^{13} \mathrm{C}$ NMR $\left(100 \mathrm{MHz}, \mathrm{C}_{6} \mathrm{D}_{6}\right): \delta=159.2,149.7,141.1,136.0,135.9,134.9$, $132.6,131.9,130.8,130.6,129.0,129.0,128.7,128.6,127.9,127.1,127.0$, $119.7,117.6,117.0,116.3,113.6,113.5,87.0,86.8,85.8,59.2,59.0,58.0$, 58.0, 54.8, 45.4, 45.3, 43.7, 43.6, 24.8, 24.8, 24.7, 24.6, 23.7, 22.9, 22.8, 22.8, $22.8,20.6,20.1,20.1,19.5,19.4 \mathrm{ppm} ;{ }^{31} \mathrm{P}$ NMR $\left(161 \mathrm{MHz}, \mathrm{C}_{6} \mathrm{D}_{6}\right): \delta=$ 149.37, 149.11, 148.69, 148.38 ppm; IR (KBr): $\tilde{v}=3377,3057,3032,2966$, 2931, 2872, 2836, 2362, 2344, 2252, 1734, 1700, 1607, 1508, 1250, 1179, 1034, 978, 829, 700, 526, 419, $406 \mathrm{~cm}^{1}$; MS (HRFAB): $\mathrm{m} / \mathrm{z}$ : calcd for: 1024.4401, found $1025.4433\left[M+\mathrm{H}^{+}\right]$.

Synthesis of the oligonucleotides: Oligonucleotides were synthesized on a $1 \mu \mathrm{mol}$ scale using benzoyl protected $\mathrm{dA}, \mathrm{dmf}$ protected $\mathrm{dG}$, acetyl pro tected $\mathrm{dC}$, and $\mathrm{T}$ phosphoramidites on a 394 DNA synthesizer (Applied Biosystems) using phosphoramidites and solid supports purchased from ChemGenes. The manufacturer's standard synthesis protocol was used, except that at the incorporation position of the modified phosphorami dites the coupling was repeated three times, each for a duration of $500 \mathrm{~s}$. The oligonucleotides were purified by HPLC using triethylammonium acetate buffer ( $\mathrm{pH}$ 6.9) (solvent 1) and acetonitrile (solvent 2) on a $\mathrm{C} 18$ reversed phase column with UV detection. The solvent gradient was as follows: initially $99 \%$ solvent 1 , then a 50 min linear gradient to $23 \%$ sol vent $2 ; 10$ min with $100 \%$ solvent $2 ; 10$ min with $100 \%$ solvent 1 .

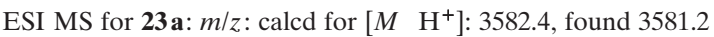

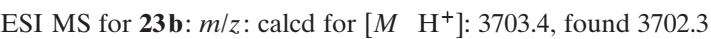

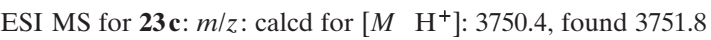

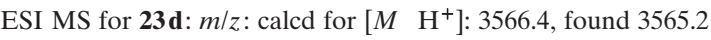
ESI MS for $23 \mathrm{e}: \mathrm{m} / \mathrm{z}$ : calcd for [M $\left.\mathrm{H}^{+}\right]$: 3688.6 , found 3687.3 ESI MS for $\mathbf{2 3} \mathbf{f}: \mathrm{m} / z$ : calcd for [M $\left.\mathrm{H}^{+}\right]$: 3734.6 , found 3733.2

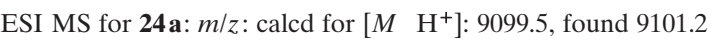

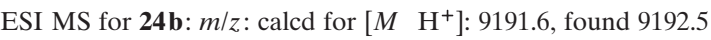
ESI MS for 24c: $m / z$ : calcd for [M $\mathrm{H}^{+}$]: 9205.6 , found 9206.5 ESI MS for 24 d: $m / z$ : calcd for [M $\mathrm{H}^{+}$]: 9221.6 , found 9220.0 ESI MS for 24e: $\mathrm{m} / z$ : calcd for [M $\left.\mathrm{H}^{+}\right]$: 9219.7 , found 9220.1

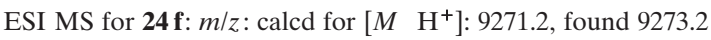
ESI MS for $\mathbf{2 4} \mathbf{g}: \mathrm{m} / z$ : calcd for $\left[\begin{array}{ll}M \mathrm{H}^{+} & \text {]: } 9283.2 \text {, found } 9284.5\end{array}\right.$

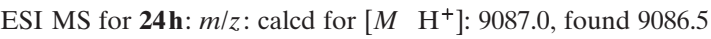
ESI MS for 24i: $m / z$ : calcd for [M $\mathrm{H}^{+}$]: 9209.2 , found 9208.6

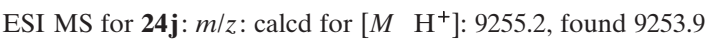
ESI MS for 25a: $m / z$ : calcd for [M $\left.\mathrm{H}^{+}\right]$: 3643.4 , found 3644

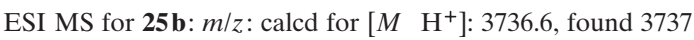

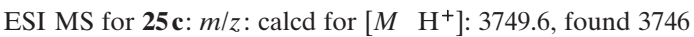
ESI MS for $\mathbf{2 5} \mathbf{d}: m / z$ : calcd for [M $\mathrm{H}^{+}$]: 3765.6 , found 3766

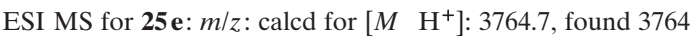

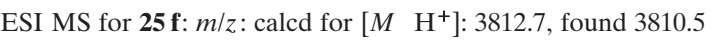
ESI MS for $\mathbf{2 5} \mathbf{g}: \mathrm{m} / \mathrm{z}$ : calcd for [M $\mathrm{H}^{+}$]: 3822.7 , found 3820.5 ESI MS for $\mathbf{2 5} \mathbf{h}: m / z$ : calcd for $\left[M \mathrm{H}^{+}\right]$: 3736.6 , found 3737

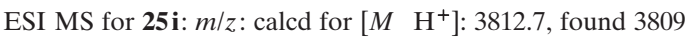

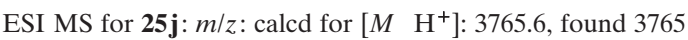
ESI MS for $25 \mathbf{k}: m / z$ : calcd for [M $\left.\mathrm{H}^{+}\right]$: 3812.7 , found 3811 ESI MS for 25I: $\mathrm{m} / \mathrm{z}$ : calcd for [M $\left.\mathrm{H}^{+}\right]$: 3765.6, found 3764 ESI MS for $\mathbf{2 5} \mathbf{m}: \mathrm{m} / z$ : calcd for [ $M \mathrm{H}^{+}$]: 3812.7 , found 3812 ESI MS for 25n: $m / z$ : calcd for $\left[M \mathrm{H}^{+}\right]$: 3765.6 , found 3760

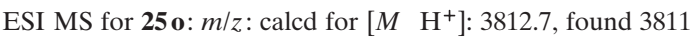

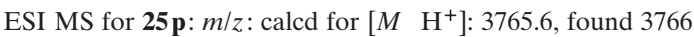
ESI MS for $25 \mathbf{q}: \mathrm{m} / \mathrm{z}$ : calcd for $\left[\begin{array}{ll}M & \mathrm{H}^{+}\end{array}\right]$: 3812.7 , found 3811 .

Thermal melting studies: Equal amounts of the two complementary strands $(2 \mathrm{nmol})$ were dissolved in $1 \mathrm{~mL}$ of buffer $(10 \mathrm{~mm}$ phosphate buffer, $140 \mathrm{~mm} \mathrm{NaCl}, 1 \mathrm{~mm}$ EDTA, $\mathrm{pH}$ 6.8). The UV absorption at $260 \mathrm{~nm}$ was monitored as a function of temperature. The temperature was increased at a rate of $0.5^{\circ} \mathrm{Cmin}{ }^{1}$ over the range $580^{\circ} \mathrm{C}$

Circular dichroism measurements: $\mathrm{CD}$ measurements were carried out at $25^{\circ} \mathrm{C}$ with the same solutions as used for the $T_{\mathrm{m}}$ studies. Samples were scanned from 350 to $220 \mathrm{~nm}$ at $0.5 \mathrm{~nm}$ intervals averaged over $1 \mathrm{~s}$.

EcoRI cleavage assay: An amount of $0.4 \mathrm{OD}$ oligonucleotide was dis solved in $100 \mu \mathrm{L}$ DTT buffer [pH 7.5; $\mathrm{MgCl}_{2}$ (190.4 mg), $\mathrm{NaCl}(1.17 \mathrm{~g})$, Tris $(1.21 \mathrm{~g})$, and DTT $(15.4 \mathrm{mg})$ in water $(200 \mathrm{~mL})]$. The solution was heated at $70^{\circ} \mathrm{C}$ for $2 \mathrm{~min}$ and then cooled in an ice bath. After the addi tion of 270 units of EcoRI, the solution was incubated at $23^{\circ} \mathrm{C}$. Aliquots of $20 \mu \mathrm{L}$ were withdrawn, which were analyzed by HPLC using triethyl ammonium acetate buffer ( $\mathrm{pH} 8.0$ ) containing $5 \%$ acetonitrile (solvent 1 ) and acetonitrile (solvent 2) on a C 18 reversed phase column with UV detection. The solvent gradient was as follows: initially $99 \%$ solvent 1 , then a 20 min linear gradient to $25 \%$ solvent $2 ; 5$ min with $100 \%$ sol vent $2 ; 5$ min with $100 \%$ solvent 1 .

Primer extension reactions: The recombinant enzymes were purified as described in the literature ( $P f u$ DNA polymerase, see ref. [40]; human DNA polymerase $\beta$ : adapted from ref. [47]; Dpo4 DNA polymerase: adapted from ref. [48]). $20 \mu \mathrm{L}$ of the reaction mixture contained $150 \mathrm{nM}$ ${ }^{32} \mathrm{P}$ labeled primer F25 (5' (CGT TGG TCC TGA AGG AGG ATA GGT) 3', $225 \mathrm{~nm}$ of the different templates, $200 \mu \mathrm{m}$ dNTPs in $1 \mathrm{x}$ reaction buffer [for Pfu DNA polymerase: $20 \mathrm{~mm}$ TrisHCl (pH 8.8), $10 \mathrm{~mm}$ 
$\left(\mathrm{NH}_{4}\right)_{2} \mathrm{SO}_{4}, 10 \mathrm{~mm} \mathrm{KCl}, 2 \mathrm{~mm} \mathrm{MgSO}$, $0.1 \%$ (v/v) Triton X 100, $0.2 \%$ $(\mathrm{w} / \mathrm{v}) \mathrm{BSA}$; for human DNA polymerase $\beta$ : $50 \mathrm{~mm}$ TrisHCl $(\mathrm{pH} 8.0)$, $10 \mathrm{~mm} \mathrm{MgCl}_{2}, 2 \mathrm{~mm}$ DTT, $20 \mathrm{~mm} \mathrm{NaCl}, 20 \mathrm{~mm} \mathrm{KCl}, 1 \%$ (v/v) glycerol; for Dpo4 DNA polymerase: $50 \mathrm{~mm}$ TrisHCl (pH 7.8), 5 mм DTT, $50 \mathrm{~mm}$ $\mathrm{NaCl}, 5 \mathrm{~mm} \mathrm{MgCl}_{2}, 5 \%$ (v/v) glycerol]. The final enzyme concentration in the reaction mixture was $10 \mathrm{~nm}$ for Pfu DNA polymerase, $300 \mathrm{~nm}$ for human DNA polymerase $\beta$, and $50 \mathrm{~nm}$ for Dpo4 DNA polymerase. The template sequences used are depicted in Figure 7. F25 was labeled using $\left[\gamma^{32} \mathrm{P}\right]$ ATP according to standard techniques. Annealing of the primer to the template strand was conducted in $20 \mathrm{~mm}$ Tris $\mathrm{HCl}(\mathrm{pH} 7.5)$ and $50 \mathrm{~mm}$ $\mathrm{NaCl}$ from $95^{\circ} \mathrm{C}$ to $25^{\circ} \mathrm{C}$ over at least $1 \mathrm{~h}$ (. Mixtures were incubated for $30 \mathrm{~min}$ at different temperatures $\left(68^{\circ} \mathrm{C}\right.$ for $P f u$ DNA polymerase; $37^{\circ} \mathrm{C}$ for human DNA polymerase $\beta$ and Dpo4 DNA polymerase) and the re actions were stopped by the addition of $45 \mu \mathrm{L}$ stop solution [80\% (v/v) formamide, $20 \mathrm{~mm}$ EDTA, $0.025 \%$ (w/v) bromophenol blue, $0.025 \%$ $(\mathrm{w} / \mathrm{v})$ xylene cyanol]. The mixtures were separated using a $12 \%$ denatur ing PAGE with visualization by phosphoimaging.

Efficiencies of primer extension reactions: The primer extension reac tions were quantified by phosphoimaging (BioRad FX) of the dried poly acrylamide gels. The ratio of primer extension was determined by sub tracting the intensity of the band corresponding to the remaining primer from the total intensity in the lane. The results presented below are aver ages from repeated experiments.

Primer extension reactions employing $\boldsymbol{P} \boldsymbol{f} \boldsymbol{u}(\mathbf{e x o}+)$ DNA polymerase: The reaction mixtures $(20 \mu \mathrm{L})$ contained $150 \mathrm{~nm}$ of ${ }^{32} \mathrm{P}$ labeled primer F25 (5' (CGT TGG TCC TGA AGG AGG ATA GGT) 3', $225 \mathrm{~nm}$ of the differ ent templates, $200 \mu \mathrm{m}$ each of dATP, dGTP, dTTP, and dCTP in $1 \mathrm{x}$ reac tion buffer [ $20 \mathrm{~mm}$ TrisHCl ( $\mathrm{pH} 8.8), 10 \mathrm{~mm}\left(\mathrm{NH}_{4}\right)_{2} \mathrm{SO}_{4}, 10 \mathrm{~mm} \mathrm{KCl}$, $2 \mathrm{~mm} \mathrm{MgSO}_{4}, 0.1 \%(\mathrm{v} / \mathrm{v})$ Triton X 100, 0.2\% (w/v) BSA]. The final enzyme concentration in the mixture was $10 \mathrm{~nm}$. The template sequences used are depicted in Figure 7. F25 was labeled using $\left[\gamma^{32} \mathrm{P}\right]$ ATP accord ing to standard techniques. Annealing of the primer to the template strand was conducted in $20 \mathrm{~mm}$ Tris $\mathrm{HCl}(\mathrm{pH} 7.5)$ and $50 \mathrm{~mm} \mathrm{NaCl}$ from $95^{\circ} \mathrm{C}$ to $25^{\circ} \mathrm{C}$ over at least $1 \mathrm{~h}$ (see Supporting Information). Mixtures were incubated for $30 \mathrm{~min}$ at different temperatures $\left(68^{\circ} \mathrm{C}\right.$ for $\mathrm{Pfu}$ DNA polymerase) and the reactions were stopped by the addition of $45 \mu \mathrm{L}$ stop solution [80\% (v/v) formamide, $20 \mathrm{~mm}$ EDTA, $0.025 \%(\mathrm{w} / \mathrm{v})$ bro mophenol blue, $0.025 \%(\mathrm{w} / \mathrm{v})$ xylene cyanol]. The mixtures were separat ed using a $12 \%$ denaturing PAGE with visualization by phosphoimaging.

\section{Acknowledgement}

The authors are grateful to the Deutsche Forschungsgemeinschaft (DFG, Bonn) for financial support (ME 1161/5 3 and MA 2288/8 1).

[1] R. C. Garner, Mutat. Res. 1998, 402, 6775

[2] H. G. Neumann, J. Cancer Res. Clin. Oncol. 1986, 112, 100106

[3] F. A. Beland, F. F. Kadlubar, Environ. Health Perspect. 1985, 62, 19 30.

[4] F. P. Gruengerich, Drug Metab. Rev. 2002, 34, 607640.

[5] R. J. Turesky, S. C. Rossi, D. H. Welti, J. O. Lay, F. F. Kadlubar, Chem. Res. Toxicol. 1992, 5, 479490.

[6] R. J. Turesky, J. Markovic, Chem. Res. Toxicol. 1994, 7, 752761.

[7] R. H. Heflich, R. E. Neft, Mutat. Res. 1994, 318, 73114.

[8] Y. Zhou, L. J. Romano, Biochemistry 1993, 32, 1404314052.

[9] Y. Zhou, S. Chladek, L. J. Romano, J. Org. Chem. 1994, 59, 556 563.

[10] L. C. J. Gillet, O. D. Schärer, Org. Lett. 2002, 4, 42054208.

[11] L. C. J. Gillet, J. Alzeer, O. D. Schärer, Nucl. Acids Res. 2005, 33, 19611969.
[12] C. E. Elmquist, J. S. Stover, Z. Wang, C. J. Rizzo, J. Am. Chem. Soc. 2004, 126, 1118911201.

[13] C. Meier, G. Boche, Carcinogenesis 1991, 12, 16331640.

[14] C. Meier, G. Boche, Tetrahedron Lett. 1990, 31, 16931696.

[15] C. Meier, S. Gräsl, Synlett 2002, 802.

[16] N. Böge, S. Gräsl, C. Meier, J. Org. Chem. 2006, 71, 97289738.

[17] M. I. Jacobsen, C. Meier, Synlett 2006, 2411.

[18] N. Böge, S. Krüger, M. Schröder, C. Meier, Synthesis 2007, 3907.

[19] N. Böge, M. Schröder, C. Meier, Synlett 2008, 10661077.

[20] C. Meier, G. Boche, Tetrahedron Lett. 1990, 31, 16851688.

[21] M. Famulok, G. Boche, Angew. Chem. 1989, 101, 470 471; Angew. Chem. Int. Ed. Engl. 1989, 28, 468469.

[22] H. Riehl, C. Meier, 2000, unpublished results.

[23] M. K. Lakshman, J. H. Hilmer, J. Q. Martin, J. C. Keeler, Y. Q. V. Dinh, F. N. Ngassa, L. M. Russon, J. Am. Chem. Soc. 2001, 123, 77797787.

[24] F. De Riccardis, F. Johnson, Org. Lett. 2000, 2, 293295.

[25] a) J. P. Wolfe, S. Wagaw, J. F. Marcoux, S. L. Buchwald, Acc. Chem. Res. 1998, 31, 805 809; b) J. F. Hartwig, Acc. Chem. Res. 1998, 31, 852855 .

[26] E. Schoffers, P. D. Olsen, J. C. Means, Org. Lett. 2001, 3, 42214223.

[27] C. Meier, S. Gräsl, I. Detmer, A. Marx, Nucleosides Nucleotides Nu cleic Acids 2005, 24, 691694.

[28] N. Böge, Z. Szombti, C. Meier, Nucleosides Nucleotides Nucleic Acids 2007, 26, 705708.

[29] R. Kierzek, Nucleosides Nucleotides 1985, 4, 641649.

[30] M. P. Reddy, J. B. Rampal, S. L. Beaucage, Tetrahedron Lett. 1987, 28, 2326.

[31] M. D. Charles, P. Schultz, S. L. Buchwald, Org. Lett. 2005, 7, 3965 3968.

[32] M. G. Organ, M. Abdel Hadi, S. Avola, N. Hadei, J. Nasielski, C. J. O'Brien, C. Velente, Chem. Eur. J. 2007, 13, 150157.

[33] T. Takamura Enya, S. Enomoto, K. Wakabayashi, J. Org. Chem. 2006, 71, 55995606.

[34] F. N. Ngassa, K. A. DeKorver, T. S. Melistas, E. A. H. Yeh, M. K. Lakshman, Org. Lett. 2006, 8, 46134616.

[35] F. Johnson, C. Y. Huang, P. L. Yu, Environ. Health Perspect. 1994, 102, 143149.

[36] S. Shibutani, R. Gentles, F. Johnson, A. P. Grollmann, Carcinogene sis 1991, 12, 813818.

[37] D. Dwyer Halliquist, K. Kezdy, S. Agarwal, Biochemistry 1982, 21, 46934697.

[38] F. P. Guengerich, Chem. Rev. 2006, 106, 420452.

[39] J. Cline, J. C. Braman, H. H. Hogrefe, Nucleic Acids Res. 1996, 24, 35463551.

[40] N. Z. Rudinger, R. Kranaster, A. Marx, Chem. Biol. 2007, 14, 185 194.

[41] W. A. Beard, S. H. Wilson, Chem. Rev. 2006, 106, 361382.

[42] F. Boudsocq, S. Iwai, F. Hanaoka, R. Woodgate, Nucleic Acids Res. 2001, 29, 46074616.

[43] H. Ling, F. Boudsocq, R. Woodgate, W. Yang, Cell 2001, 107, 91 102.

[44] R. L. Eoff, A. Irimia, M. Egli, F. P. Guengerich, J. Biol. Chem. 2007, 282, 14561467.

[45] R. L. Eoff, K. C. Angel, M. Egli, F. P. Guengerich, J. Biol. Chem. 2007, 282, 13573135584.

[46] A. Guy, A. M. Duplaa, P. Harel, R. Teoule, Helv. Chim. Acta 1988 $71,15661572$.

[47] J. L. Kosa, J. B. Sweasy, J. Biol. Chem. 1999, 274, 38513858.

[48] K. A. Fiala, Z. Suo, Biochemistry 2004, 43, 21162125. 